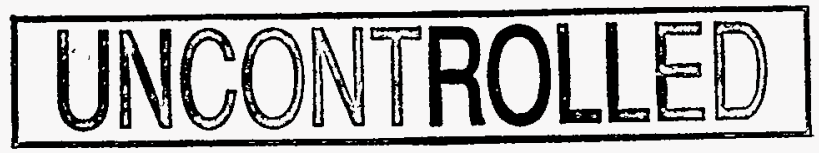

\title{
STREAMLINED APPROACH FOR ENVIRONMENTAL RESTORATION PLAN, CAU NO. 400: BOMBLET PIT AND FIVE POINTS LANDFILL, TONOPAH TEST RANGE
}

Controlled Copy No.: 25

Revision: 0

April 1996 


\section{DISCLAIMER}

Portions of this document may be illegible in electronic image products. Images are produced from the best available original document. 


\section{STREAMLINED APPROACH FOR \\ ENVIRONMENTAL RESTORATION PLAN, CAU NO. 400: \\ BOMBLET PIT AND FIVE POINTS LANDFILL, TONOPAH TEST RANGE}

Submitted by:

\section{DISCLAIMER}

This report was prepared as an account of work sponsored by an agency of the United States Government. Neither the United States Government nor any agency thereof, nor any of their employees, makes any warranty, express or implied, or assumes any legal liability or responsibility for the accuracy, completeness, or usefulness of any information, apparatus, product, or process disclosed, or represents that its use would not infringe privately owned rights. Reference herein to any specific commercial product, process, or service by trade name, trademark, manufacturer, or otherwise does not necessarily constitute or imply its endorsement, recommendation, or favoring by the United States Government or any agency thereof. The views and opinions of authors expressed herein do not necessarily state or reflect those of the United States Government or any agency thereof.

Kevin Cabble, Subproject Manager

Date:

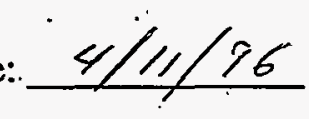

Environmental Restoration Division

Approved by:<smiles></smiles><smiles></smiles><smiles></smiles>

David Shafer, Acting Director per L. Environmental Restoration Division

Date: $4 / 11 / 96$ 


\section{Table of Contents}

List of Figures iii

List of Tables iv

List of Acronyms and Abbreviations v

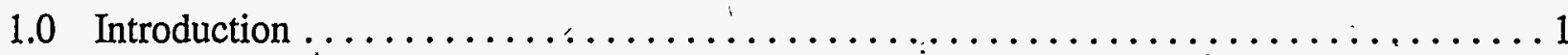

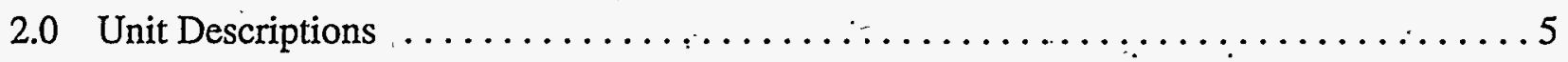

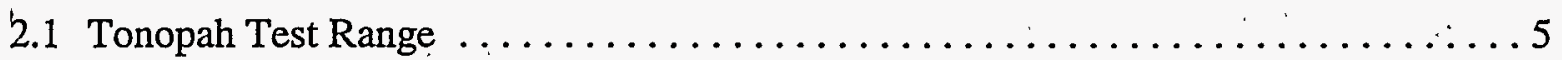

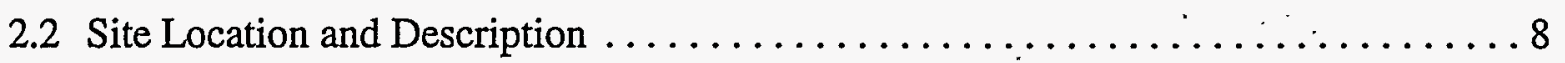

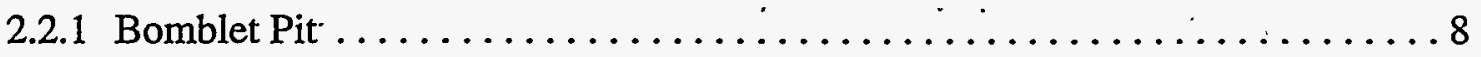

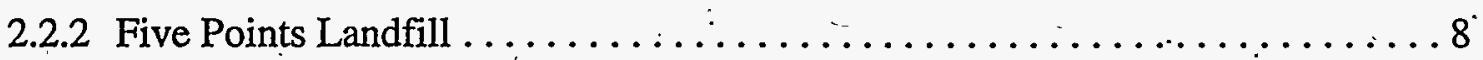

: $\quad 2.3$ Process Knowledge .................................... 11

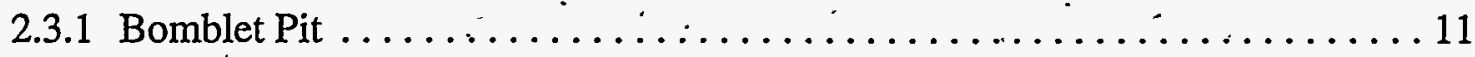

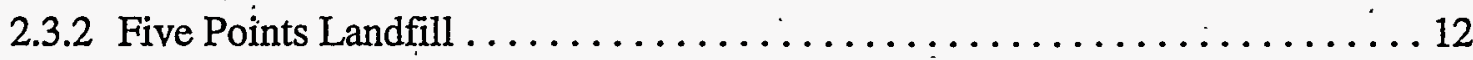

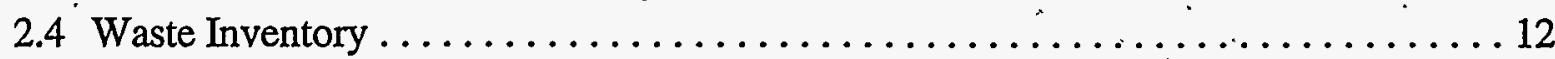

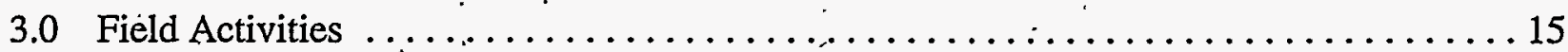

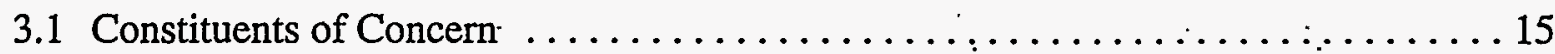

3.2 Closure Standards ....................................... 19

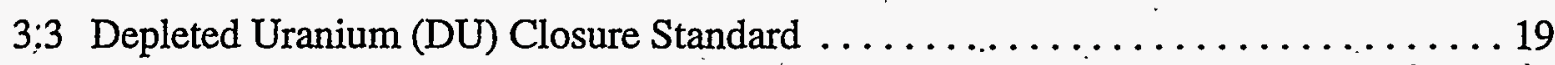

3.3.1 RESRAD Risk Assessment Calculations . . . . . . . . . . . . . . . 19

3.3.2 RESRAD Risk Assessment Methodology $\ldots \ldots \ldots \ldots \ldots \ldots \ldots \ldots \ldots$

3.3.3 Summary and Recommendations for Depleted Uranium Closure

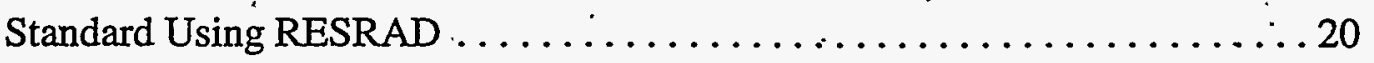

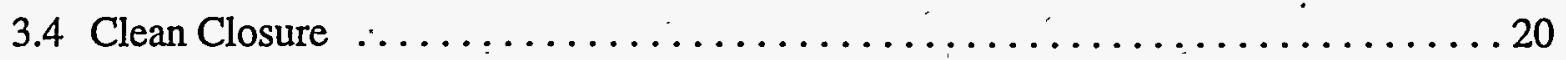

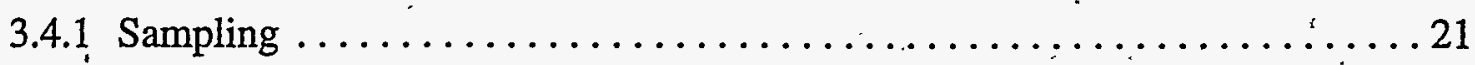

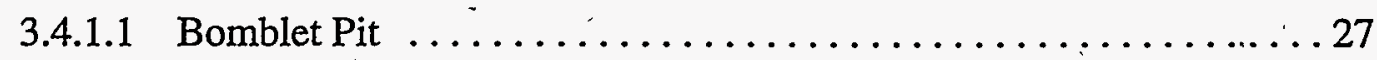

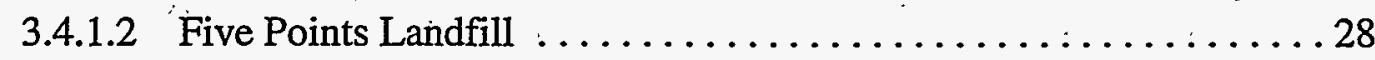

3.4.1.3 Local Background Sampling .................... 30

3.4.2 Alpha, Beta; and Gamma Radiation Field Surveys . . . . . . . . . . . 33 


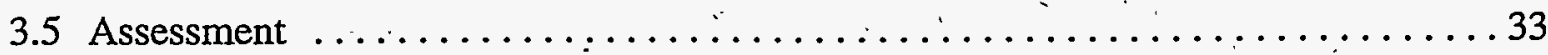

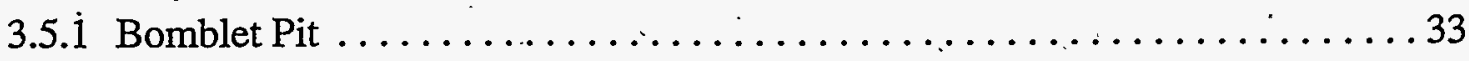

3.5 .2 Five Points Landfill . . . . . . . . . . . . . . . . . . . 33

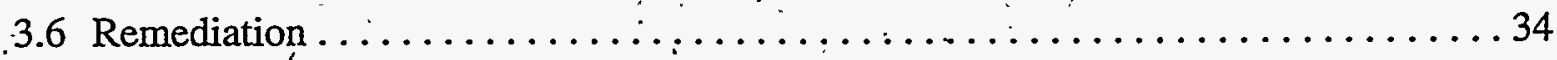

3.7 Site Restoration . . . . . . . . . . . . . . . . . . . . . . . . 34

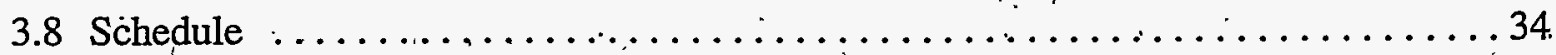

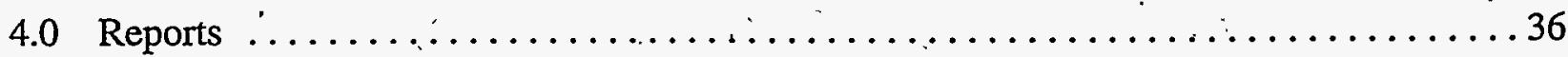

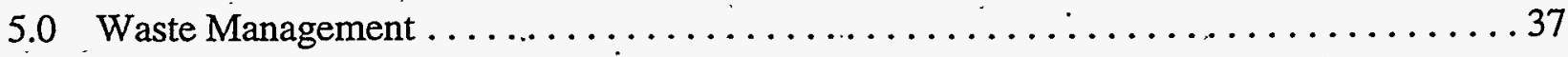

6.0. Site-Specific Health and Safety Plans $\ldots \ldots \ldots \ldots \ldots \ldots \ldots \ldots \ldots \ldots \ldots \ldots$

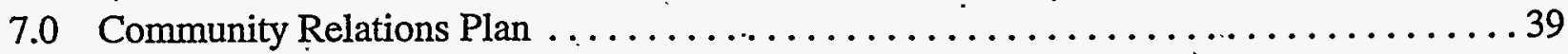

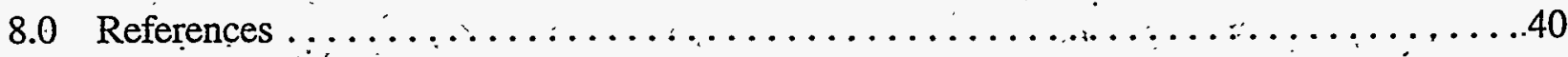

Appendix A - Quality Assurance Project Plan $\ldots \ldots \ldots \ldots \ldots \ldots \ldots \ldots \ldots \ldots \ldots \ldots \ldots$ A-1 


\section{List of Figures}

Number

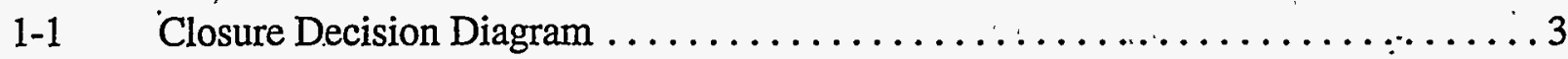

2-1 Location Map, Tonopah Test Range $\ldots \ldots \ldots \ldots \ldots \ldots \ldots \ldots \ldots \ldots$

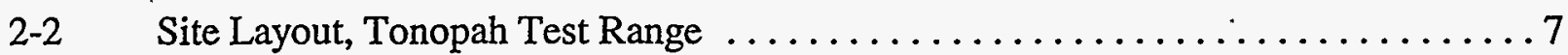

2-3 Site Location Map, Bomblet Pit, Tonopah Test Range $\ldots \ldots \ldots \ldots \ldots \ldots \ldots 9$

2-4 Site Location Map, Five Points Landfill, Tonopah Test Range .............. 10

3-i Sample Location Map, Bomblet Pit, Tonopah Test Range $\ldots \ldots \ldots \ldots \ldots \ldots 22$

3-2 Sample Location Map, Bomblet Pit, Processing Areas 1 and 2,

Tonopah Test Ránge .................................

3-3 Sample Location Map, Large UXX Processing Area, , , Bomblet Pit, Tonopah Test Range $. . . . \ldots \ldots \ldots \ldots \ldots \ldots \ldots \ldots . \ldots 24$

3-4 Sàmple Location Map, Planned Background Surface-Soil Collection Area Bomblet Pit, Tonopảh Test Range .........................25

3-5 Sample Location Map, Five Points Landfill and Background Collection Area, Tonopah Test Range $\ldots \ldots \ldots \ldots \ldots \ldots \ldots . \ldots . \ldots$

3-6 Decrease of SEM as a Function of Number of Samples $\ldots \ldots \ldots \ldots \ldots \ldots \ldots \ldots$ 


\section{List of Tables}

Number Title

Page

2-1 Amount and Type of Explosive Used during UXO Detonation at the Bomblet Pit and Associated Processing Areas

3-1 Suspected Constituents of Concern and Closure Standards 16

3-2 . Site Characterization and Closure Verification Analytical Chemical Requirements

3-3 Number and Location of Samples for the Bomblet Pit and

Processing Areas

3-4 Analytical Requirements for the Bomblet Pit and Processing Areas

3-5 Number and Location of Samples for the Five Points Landfill

3-6 Analytical Requirements for the Five Points Landfill 30

3-7 Analytical Requirements for Background Sampling Locations 


\section{List of Acronyms and Abbreviations}

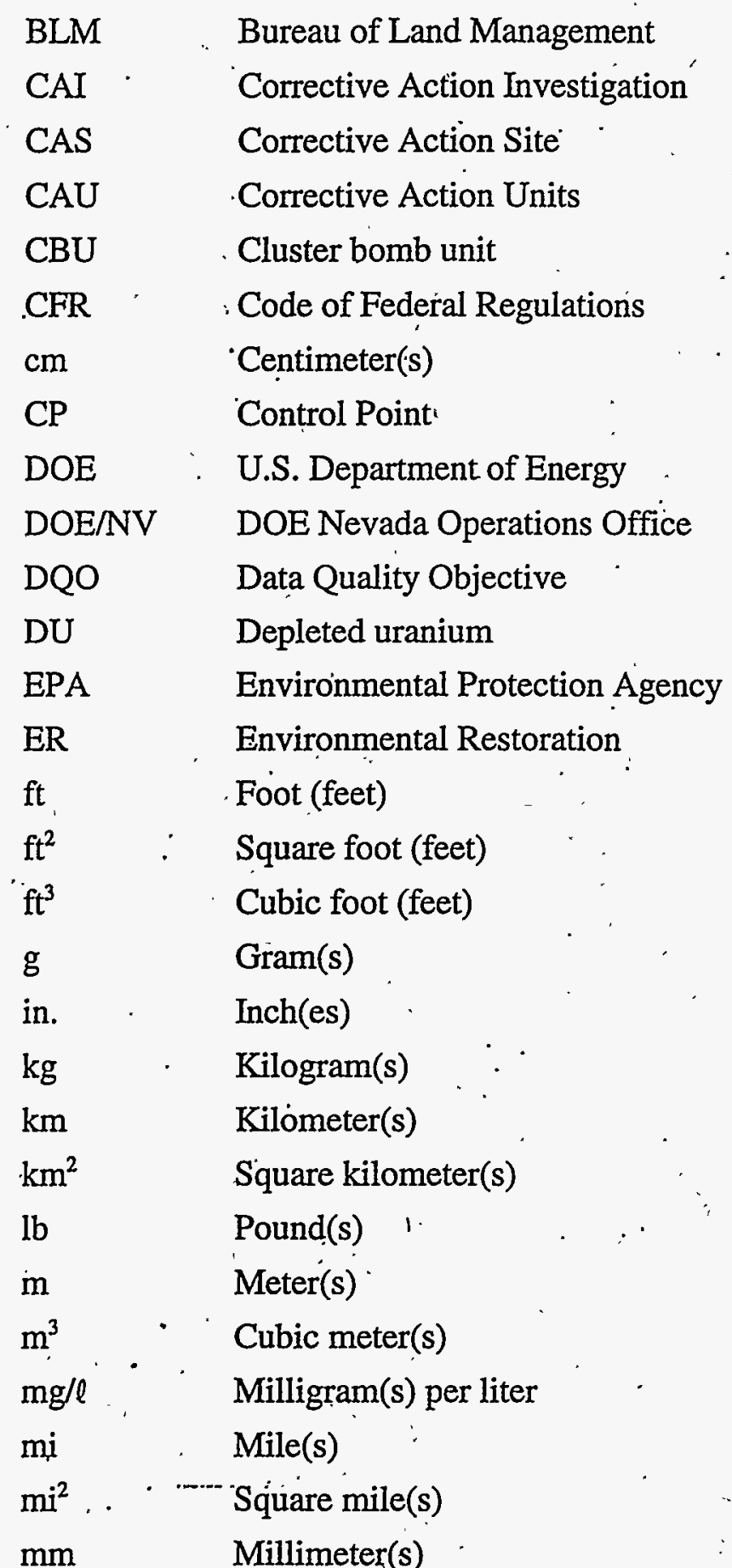

NDEP . Nevada Division of Environmental Protection

NRC U.S. Núclear Regulatory Commission

NTS : Nevada'Test Site 


\section{List of Acronyms and Abbreviations (Continued)}

PETN - Pentaerythritol tetranitrate

QA Quality Assurance

QAPP Quality Assurance Project Plan

RCRA Resource Conservation and Recovery Act

RDX Hexahydro-1,3,5-trinitro-1,3,5-triazine

SAFER Streamlined Approach for Environmental Restoration

SEM Standard Error of the Mean

SNL - Sandia National Laboratories

SSHASP $\quad$ Site-Specific Health and Safety Plan

TCLP - Toxicity Characteristic Leaching Procedure

TNT Trinitrotoluene

TTR - Tonopah Test Range

UXO Unexploded ordnance

VCA Voluntary Corrective Action 


\subsection{Introduction}

This plan was prepared under the Streamlined Approach for Environmental Restoration (SAFER) concept. The SAFER process is employed at Corrective Action Units (CAUs) where enough information exists about the nature and extent of contamination to propose an appropriate corrective action prior to the implementation of a Corrective Action Investigation (CAI). This. process combines elements of the Data Quality Objectives (DQO) process and the observational approach to help plan and conduct corrective actions. DQOs are used to identify the problem and define the type and quality of data needed to complete the investigation phase of the process. The observational approach provides a framework for managing uncertainty and planning decision-making. The purpose of the investigation in the SAFER process is to document and verify the adequacy. of existing information (such as process knowledge); to affirm the decision for clean closure, closure in place, or to take no further action; and to provide sufficient data to implement the corrective action.

The SAFER concept recognizes that technical decisions may be based on incomplete, but sufficient, information and the experience of the decision-maker. Any uncertainties are addressed by documented assumptions that are verified by sampling and analysis, data evaluation, and on-site observations as planned activities progress and by contingency plans as necessary. The remediation and closure may proceed simultaneously with site characterization as sufficient data are gathered to confirm or disprove the assumptions made in selecting the closure method. If, at any time during the site closure, new information is developed that indicates that the closure method or underlying assumptions should be revised, the decision-makers will . redirect the closure actiyities to more appropriately protect human health and the environment; the Nevada Division of Environmental Protection (NDEP) will be notified as soon as practical; and this plan will be amended. Following the completion of SAFER activities, a closure report will be prepared and submitted to the NDEP.

This plan addresses verification sampling for the clean closure of CAU No. 400 which includes the Bomblet Pit (CAS No. TA-55-001-TAB2) and the Five Points Landfill (CAS No. TA-19-001-05PT), two sites that were used for the disposal of unexploded ordnance: (UXO) and other solid waste at the U.S. Department of Energy (DOE) Tonopah Test Range (TTR) in south-central Nevada. This plan describes activities that have taken place at the 
Bomblet Pit and Five Points Landfill as well as the steps that will be taken to gather adequate data to obtain a notice of completion from NDEP.

It is believed that adequate process knowledge exists to predict clean closure as the proposed corrective action for the Bomblet Pit and Five Points Landfill. The process knowledge-includes research of historical records and removal of ordnance and debris from both the Bomblet Pit and Five Points Landfill. This process knowledge was used to determine what constituents of concern may be present and the most appropriate SAFER methods.

Corrective action at the Bomblet Pit and Five Points Landfill will be achieved in two phases. The first phase has been completed and included the removal of UXO and other solid waste contained within each unit, as addressed in the Voluntary Corrective Action (VCA) Work Plan for Ordnance Removal from Five Disposal Pits at the Tonopah Test Range (DOE, 1995) (hereafter referred to as the VCA Work:Plan). The only evidence of soil contamination observed during ordnance and debris removal activities was radioactive contamination at the Five Points Landfill. The contaminated soil was excavated until no further contamination was detectable, using portable field instrumentation, and was drummed, pending formal waste characterization.

Phase two of the corrective action at the Bomblet Pit and Five Points Landfill is described in this SAFER Plan. Verification samples will be collected and analyzed to determine if additional soil excavation and remediation are required. If the verification samples indicate that constituents of concern are present in the soil above closure standard levels, as presented in Section 3.0 of this plan, additional excavation will take place; the excavated soil will be stockpiled and managed as waste; and additional verification samples will be collected and analyzed. This sequence may be repeated as necesșary until all areas are demonstrated to meet the standards stated in Section 3.0 of this plan. Figure 1-1 illustrates this iterative process. After the sites have been verified to be free of constituents of concern above closure standard levels and a notice of completion has been received from NDEP, deep excavations will be refilled with clean fill from existing borrow pits, and shallow excavations will be graded so it does not present a hazard to animals. Efforts will be made to revegetate the Five Points Landfill with native plant species.

This plan reflects the assumptions delineated in the following text. If, at any time during the closure, information is developed that invalidates any assumption, this plan may be amended, and those amendments will be provided to NDEP for approval. 


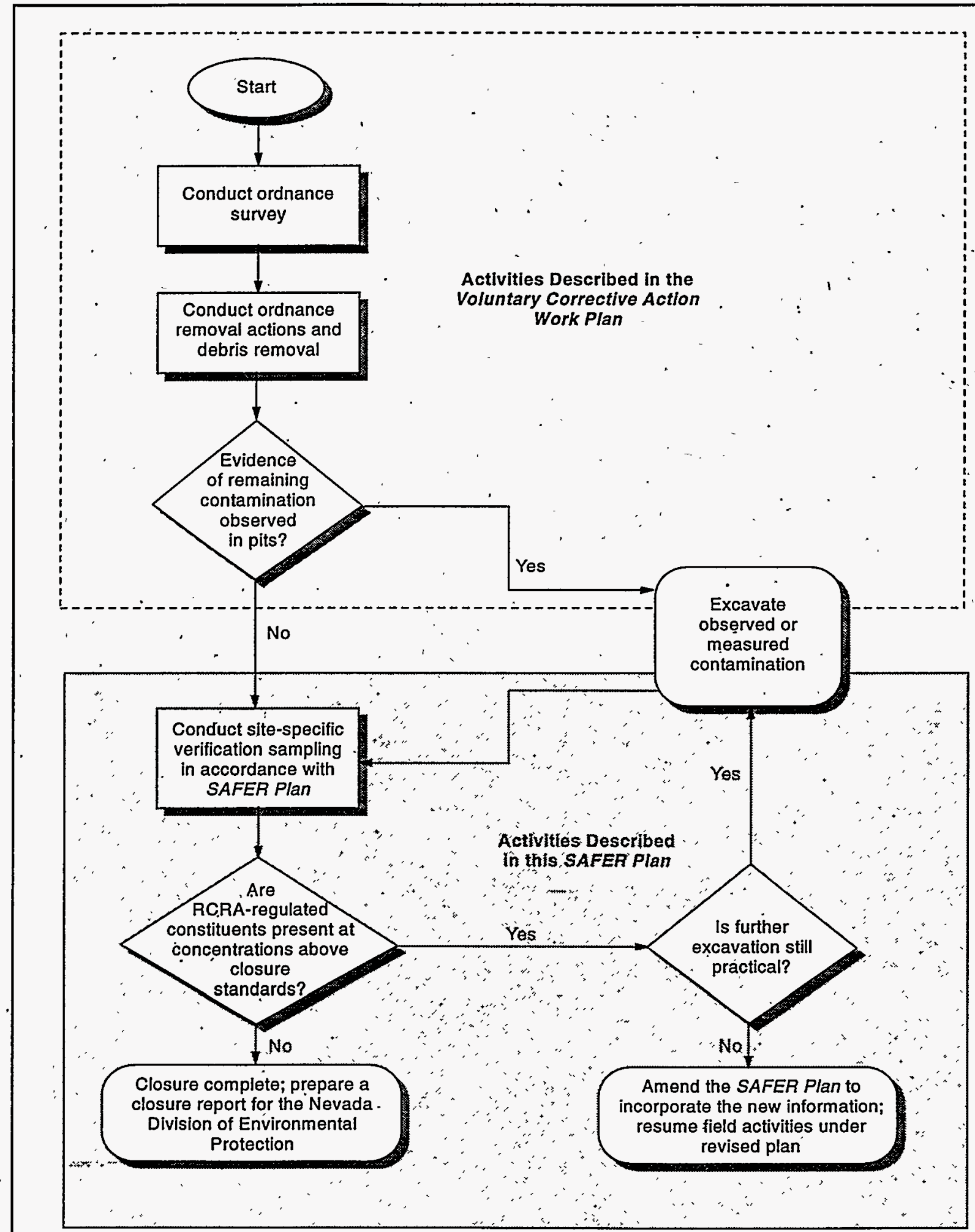

Figure 1-1 
- Explosives are entirely consumed when they are detonated or burned, resulting in residual gases rather than liquid or solid residuals because they are made to derive their energy from breaking and forming chemical bonds to the maximum extent possible.

- Clean closure of these units is a practical alternative because residual wastes or hazardous constituents will not remain after the removal of UXO and other solid waste has been completed.

- Solid-fuel rocket boosters disposed of in the pits have had the entire contents of their fuel load expended during flight with little or no residue coating the inside of the booster fuel chamber (Hay, 1991). Process knowledge from debris and UXO removal activities has verified this assumption.

- None of the ordnance located in these pits contains radioactive materials. This assumption was confirmed through field screening. However, targets'and soil contaminated with depleted uranium (DU) were, discovered in the Five Points Landfill and are described in Section 2.0 of this Plan.

- Resource Conservation and Recovery Act (RCRA)-regulated substances have not been released to the soil-underlying the ordnance and other debris. This assumption will be confirmed through soil sampling. If any RCRA-regulated substances have been released, the impacted soil' will be removed and properly disposed.

- Process knowledge for the two disposal sites indicates that both units were used as disposal pits for range clean-up activities that consisted of the removal of ordnance and other solid debris only. No stained soil was observed during ordnance and debris removal activities. Therefore, volatile and semivolatile constituents (except UXO byproducts, i.e., nitroaramatics and nitroamines) are not potential constituents of concern. 


\subsection{Unit Descriptions}

The Bomblet Pit and the Five Points Landfill are located on the TTR, a DOE research facility - located in Nye County, Nevada, on the northern portion of the Nellis Air Force Range (Figure 2-1).

\subsection{Tonopah Test Range}

The TTR is approximately 260 kilometers $(\mathrm{km})$ (160 miles [mi]) northwest of Las Vegas by air and approximately $64 \mathrm{~km}$ ( $40 \mathrm{mi}$ ) southeast of Tonopah, Nevada, by road. The nearest occupied community is Goldfield, which is $42 \mathrm{~km}$ ( $26 \mathrm{mi}$ ) west of the western TTR boundary (ERDA, 1975).

The TTR occupies about 1,616 square kilometers $\left(\mathrm{km}^{2}\right)$ (624 square miles [ $\left.\left.\mathrm{mi}^{2}\right]\right)$. It is bordered on the south, east, and west by the Nellis Air Force Range and on the north by sparsely populated public land administered by the U.S. Bureau of Land Managementt (BLM) and the U.S. Forest Service (DOE, 1992).

Since 1957, the TTR has been operated for the DOE by Sandia National Laboratories (SNL) and used for weapons test-support activities varying from simple tests of hardware components or systems needing limited support to rocket launches or air drops of test vehicles requiring full range support for the U.S. Air Force, Army, and Navy operational and test groups as well as some defense contractors (ERDA, 1975).

The TTR is divided into various areas (Figure 2-2). Areas 3 and 9 and a Test Area along the flight line are under SNL control; Areas 3 and 9 are the main centers of SNL activities. Area 3 is also known as the Control Point (CP) Area and includes support facilities for maintenance and operations. Area 9 is the center for rocket and gun firings, with impact areas to the southeast, as well as ordnance storage and related test support operations. The Test Area is a series of dry lakes that begin at Main Lake near Area 9, continue south for about $21 \mathrm{~km}$ (13 mi), and end with Antelope Lake (ERDA, 1975). Area 10 and other remote parts of the range are under control of the U.S. Air Force. 

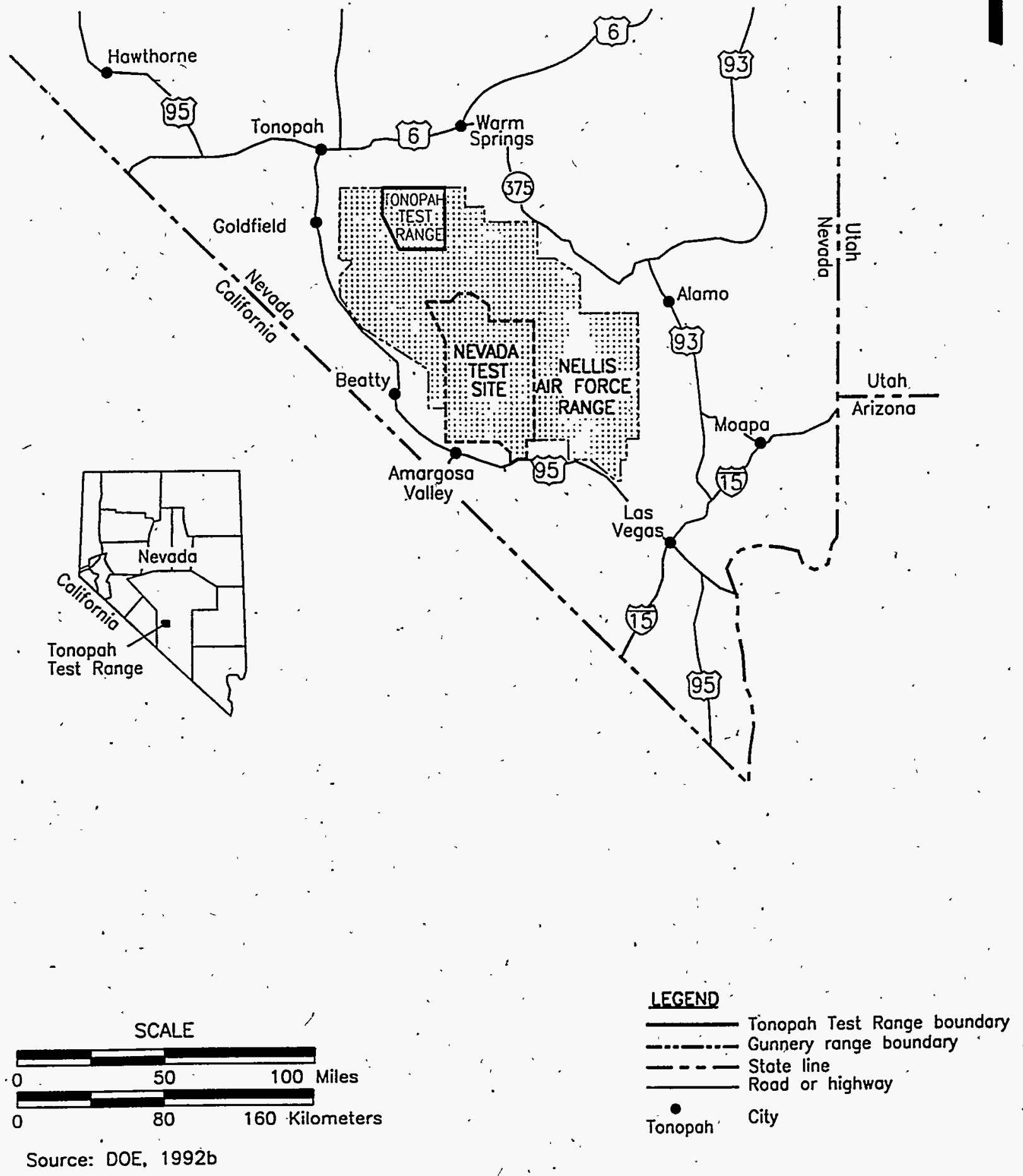

Figure 2-1

Location Map, Tonopah Test Range 


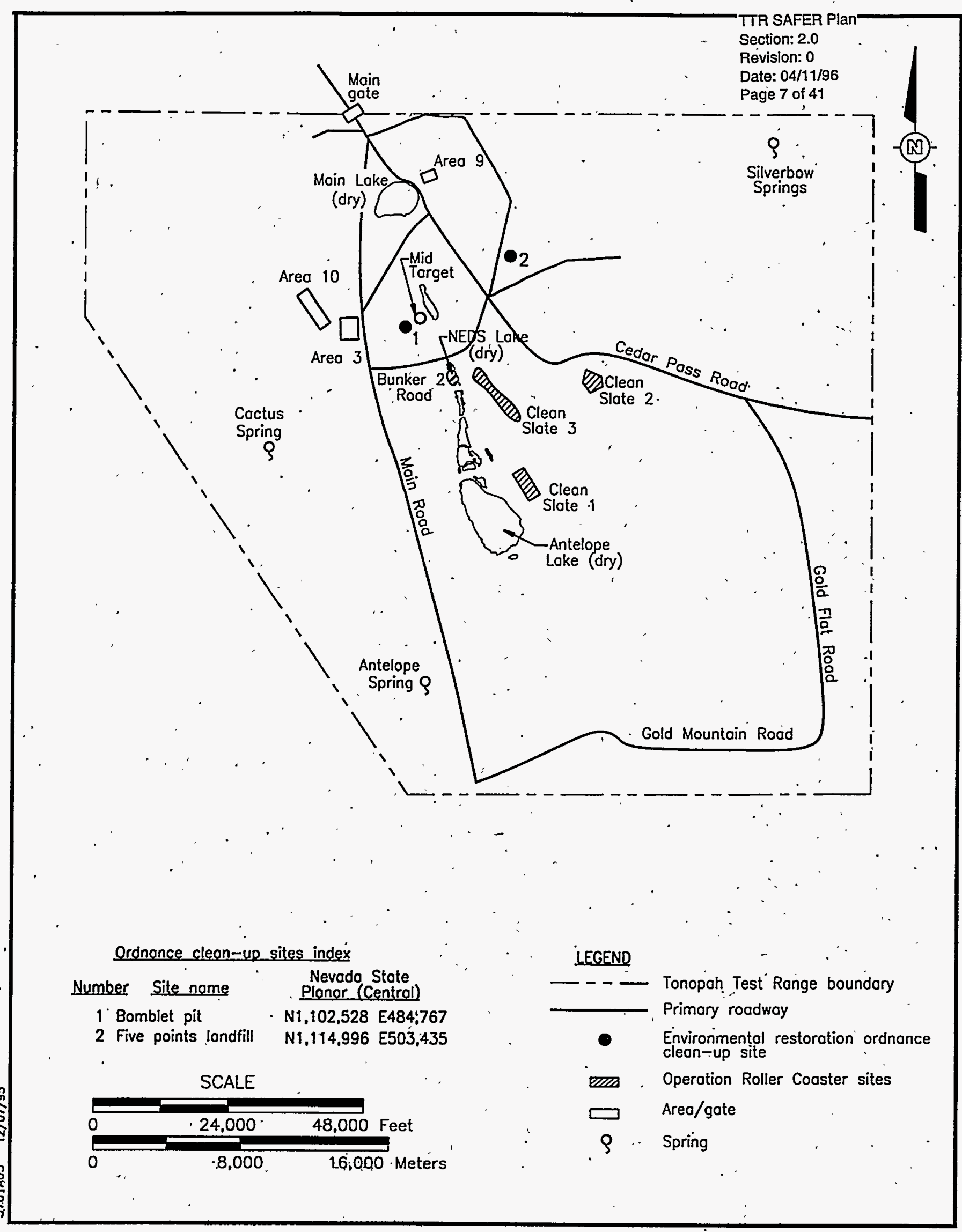

Figure 2-2

Site Layout, Tonopah Test Range 


\subsection{Site Location and Description}

\subsubsection{Bomblet Pit}

The Bomblet Pit is located approximately one mile northwest of Bunker 2 Road, as shown in Figure 2-2. The Bomblet Pit is approximately 13 meters (m) (42 feet [ft]) long, 3 to $5 \mathrm{~m}$ (10 to $15 \mathrm{ft}$ ) wide, and $1 \mathrm{~m} \mathrm{(3} \mathrm{to} 4 \mathrm{ft}$ ) deep. A geophysical investigation conducted at this site found . five buried metallic anomalies which are labeled A1 through A5 (Figure 2-3) (IT, 1994):

The pit and four of the five associated subsurface anomalies were found to contain approximately 22,000 bomblets, bomblet dispenser clamshell sections, one guidance section, two spent rocket motors; four unfuzed, inert MK84 2,000-pound (lb) bombs; two unfuzed, inert MK82 500-lb bombs; and other assorted debris. Nothing was found in the fifth anomaly. As part of the $V C A$ Work Plan activities, all UXO and debris were removed from the Bomblet Pit, and all anomalies were excavated and removed. There were three processing areas established and used in conjunction with the UXO removal activities at the Bomblet Pit and other UXO disposal sites. These processing areas were designed for the detonation of bomblets and other UXO through the use of linear-shaped charges and other explosives (i.e., Compound C-4) as described in Section 3.2.3.2 of the VCA Work Plan and associated records of technical change.

After several detonations, soil was excavated from the processing area, sifted for fuze removal, and placed in two stockpiles (Figure 2-3). Each soil stockpile contains approximately $1.5 \mathrm{~m}^{3}$ $\left(54 \mathrm{ft}^{3}\right)$ of soil.

\subsubsection{Five Points Landfill}

The Five Points Landfill is located approximately $2 \mathrm{~km}$ (1.2 mi) north of Five Points along

Perimeter Road (Figure 2-4). The site consists of a fenced depression approximately $11.5 \mathrm{~m} \times 25 \mathrm{~m} \times 3 \mathrm{~m}$ ( $375 \mathrm{ft} \times 80 \mathrm{ft} \times 10 \mathrm{ft}$ ) with a mostly flat bottom. Surface debris (consisting of approximately 200 spent rocket motors, five 105 -millimeter [mm] inert projectiles, five MK82 500-lb inert bombs, four half-round corrugated metal and steel structures, four rocket motor ignitors, six bomblets, miscellaneous rocket motor parts (i.e., fins), concrete, wood, and wires) - was found mostly along the north and south slopes of the depression. However, $\bar{a}$ fragment of a spent rocket motor was found in an arroyo east-northeast of the fenced area. All UXO and other debris have been removed from the Five Points Landfill as part of the VCA Work Plan activities. 


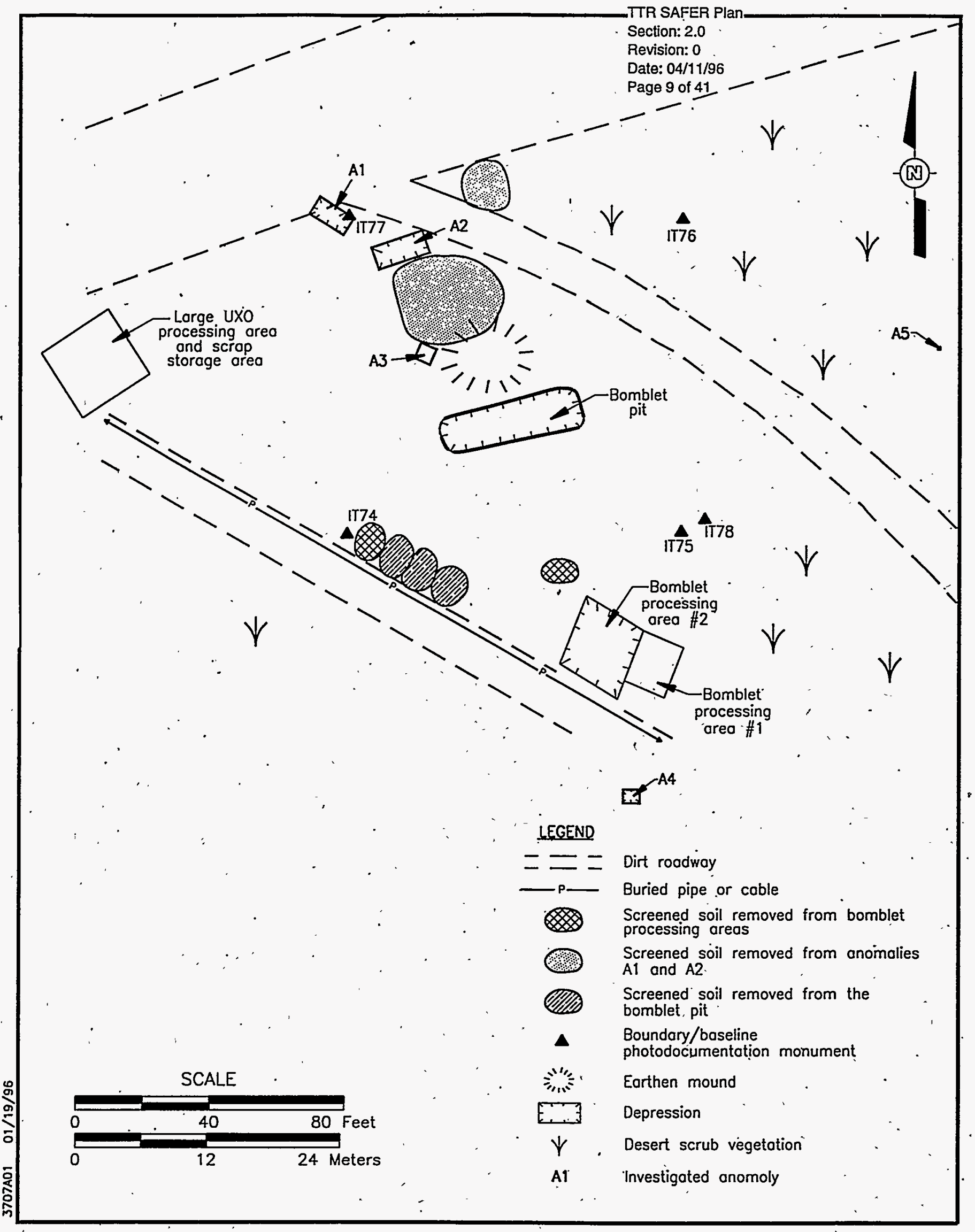

Figure 2-3

Site Location Map, Bomblet Pit, Tonopah Test Range 


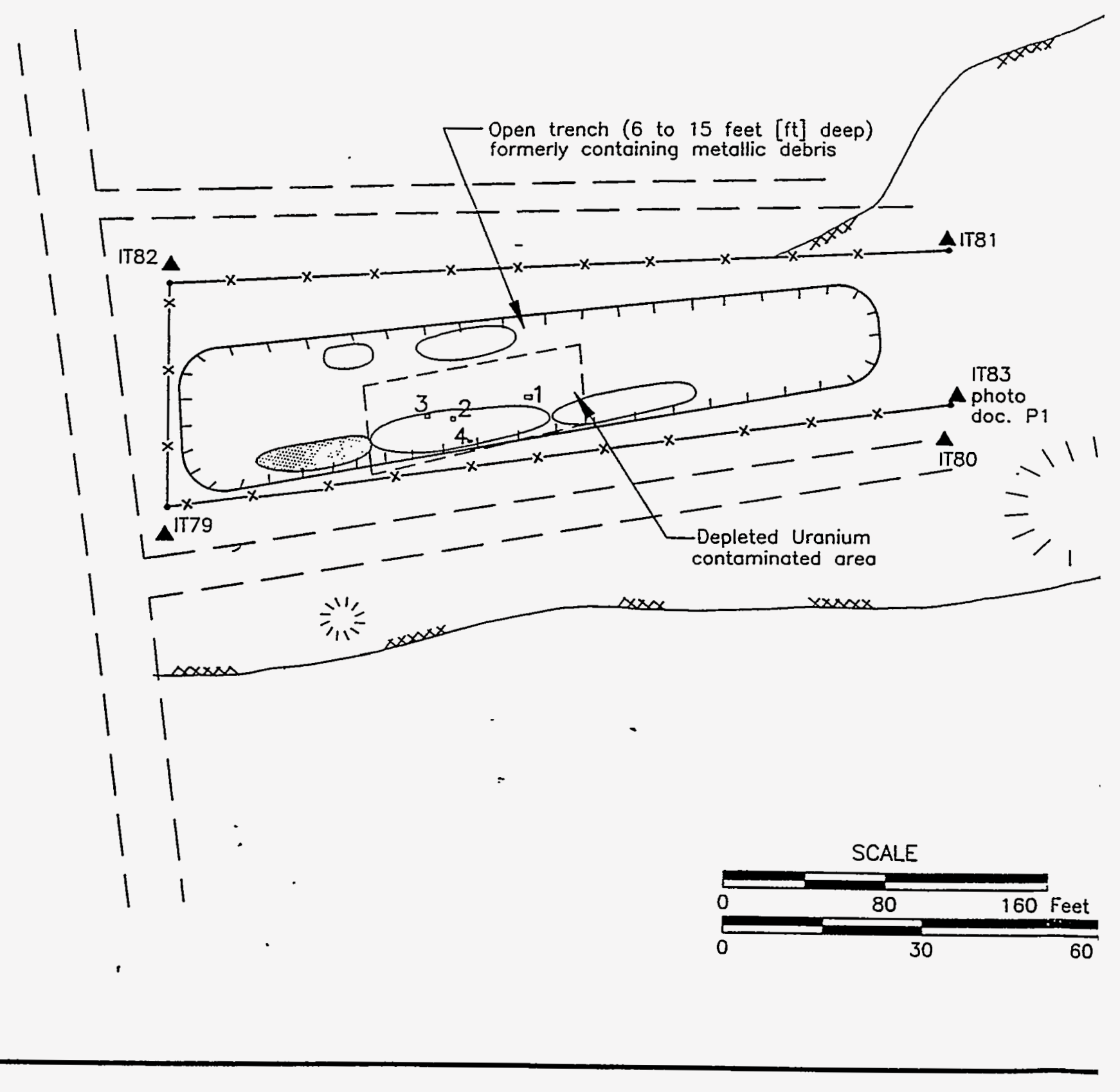


Revision: 0

Date: 04/11/96

Page 10 of 41
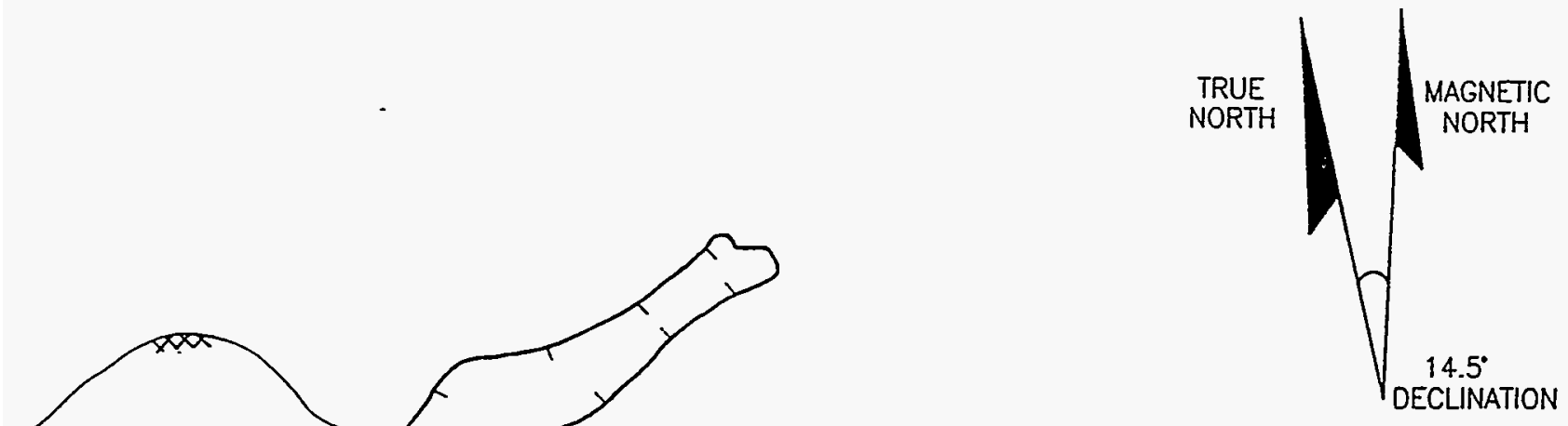

$1111111 \%$

\section{LEGEND}

ニニニニニ Dirt road

- $x-x-$ Fence

$1111_{x x x} 11111=$

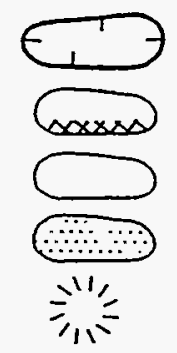

$\Delta \quad B o u n d a r y /$ baseline photodocumentation

. Depleted uranium removal areo

FIGURE 2-4

SITE LOCATION MAP

Meters

FIVE POINTS LANDFILL

TONOPAH TEST RANGE

$\therefore$ 
Refer to Section 3.2.4 of the VCA Work Plan and associated records of technical change for UXO removal activities (Figure 2-4).

\subsection{Process Knowledge}

- Process.knowledge is based on interviews, review of historical records, geophysical surveys, and logs of field activities during the first phase of the corrective action process. All process knowledge records are available for review at the IT Corporation offices in Las Vegas. . Interviews and historical records used to compile process knowledge are listed in the Section 8.0, "References," of this plan.

General range cleanup operations were performed after test activities were conducted at TTR during the late 1960s and 1970s. Cleanup operations entailed gathering solid test objects that had been used in rocket-launch and air-drop tests on the range. Through interviews, it was found that various pits located around the TTR were used for the disposal of the solid objects and debris based on their proximity to the cleanup operations (Karas, 1993a). There is no information to suggest that liquids were ever disposed of in either of the pits. No soil staining was observed düring removal operations.

\subsubsection{Bomblet Pit}

The Bomblet Pit and five associated anomalies were used for the disposal of debris from antipersonnel and antivehicular bomblet (or cluster bomb unit [CBU]) tests that were conducted between the north end of Antelope Lake and Mid-Target (Figure 2-1) during the 1970s: Each test involved the aerial drop of one or more dispensers containing hundreds of bomblets which had fuzes that would arm during free fall (West, 1993). The fuzes are known to contain approximately $1 \mathrm{gram}(\mathrm{g})$ of explosives. There were four unfuzed, inert MK84 2,000-1b bombs and one unfuzed, inert MK82 500-1b bomb located in the pit, and these were removed and processed according to the VCA Work Plan and associated records of technical change. Process knowledge of UXO obtained from review of manufacturers' specifications shows that trinitrotoluene (TNT) and hexahydro-1,3,5-trinitro-1,3,5-triazine (RDX) are common components of the explosives used to process UXO. This process knowledge also indicates that chromium, lead, and mercury are common components of the fuzes used during UXO detonation operations. 
The soil excavation, resulting in the soil stockpiles previously discussed in Section 2.2.1, was repeàted several times during UXO processing to ensure that bomblet fuzes were removed from the processing areas. The impacted soil resulting from the detonations has already been removed from the processing area, and only native soil remains. 'Only limited detonations occurred in the Bomblet Pit (over the course of one day's operations) which left a thin layer of gray material. If this material proves to contain regulated constituents, it will be removed until native soil is encountered (see Section 3.3).

\subsubsection{Five Points Landfill}

The Five Points Landfill originated as a borrow pit for construction of TTR roads. When it was no longer needed as a borrow pit, it was turned into a disposal pit for ordnance and solid debris gathered during range cleanup operations (Karas, 1993b). Most debris in the Five Points Landfill probably resulted from range clean-up operations within the last ten years.

During initial corrective action field activities, four half-round corrugated metal and steel structures were removed from the Five Points Landfill. . The structures are approximately $2 \mathrm{~m} \times 2 \mathrm{~m} \times 1 \mathrm{~m}(6 \mathrm{ft} \times 6 \mathrm{ft} \times 3 \mathrm{ft})$ in size and partially full of soil. Due to the bullet-sized holes, these structures are believed to have been used as targets. The metal around several of the holes was found to be radiologically contaminated through field screening, and it is believed that DU bullets were shot into the targets. The DU that remained within the soil in the targets was oxidized and bright yellow in color. During target removal operations, some of the soil within the targets fell onto the ground. Approximately $0.1 \mathrm{~m}^{3}\left(3.7 \mathrm{ft}^{3}\right)$ of soil and DU pieces were removed from four areas within the pit ranging in size from 2.5 centimeters $(\mathrm{cm}) \times 2.5 \mathrm{~cm}$ to $0.5 \mathrm{~m}$ to $1.4 \mathrm{~m}$ ( 1 in $\times 1$ in to $1 \frac{1}{2} \mathrm{ft} \times 4 \frac{1}{2} \mathrm{ft}$ ) and placed in a 55-gallon drum. The four removal areas are within an 8-m $\times 6-\mathrm{m}(26-\mathrm{ft} \times 20-\mathrm{ft})$ area along the south slope of the pit.

\subsection{Waste Inventory}

Estimates of the inventory of hazardous wastes on site over the active life of each of the sites are as follows:

Bomblet Pit: Approximately 22,000 bomblets were removed from the pit and adjacent anomalies. The maximum amount of explosives within the Bomblet Pit (assuming each fuze to be intact with $1 \mathrm{~g}$. [0.05 ounce] of explosives) is 13 kilograms $(\mathrm{kg})(28.7 \mathrm{lb})$. Other UXO removed from the site was determined not to contain explosive charges. The quantity of 
Table 2-1,

\section{Amount and Type of Explosive Used during UXO Detonation at the Bomblet Pit and Associated Processing Areas}

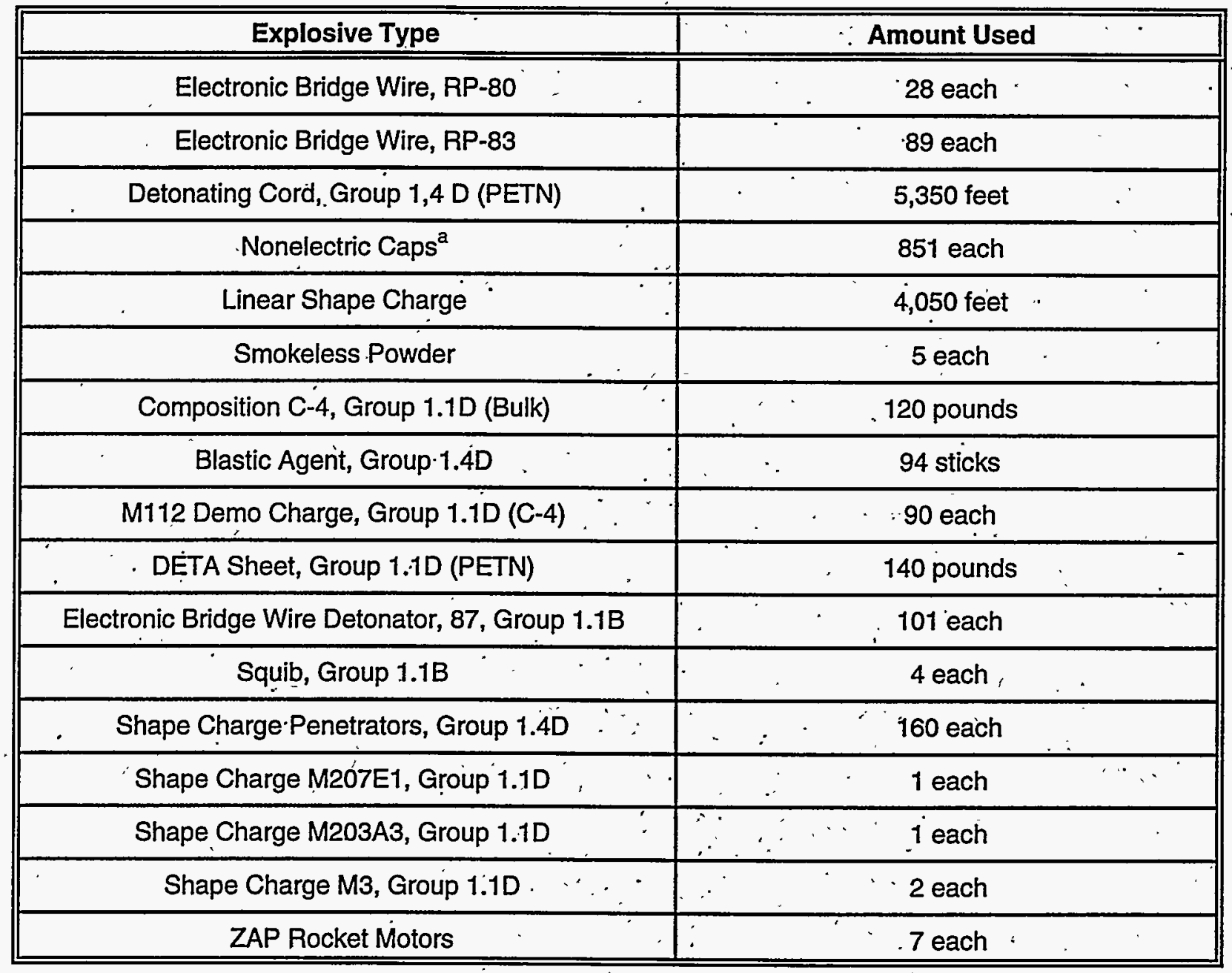

${ }^{a}$ Process knowledge indicates that nonelectric caps contain mercury, chromium and lead; Zap Rocket Motors contain chromium; remaining items in Table 2-1 contain only reactive substances.

explosives contained in the Bomblet Pit and associated processing areas, was documented during UXO removal activities and is provided in Table $2-1$.

Five Points Landfill: No known hazardous waste is contained in the Five Points Landfill. All UXO removed from the site was determined not to contain explosive charges. 
Radioactively contaminated soil and debris (i.e., DU fragments and targets) were removed from the Five Points Landfill; however, no suspect RCRA-regulated waste was discovered during field operations.

There were no explosives contained in the Five Points Landfill, and this was documented during UXO removal activities: 


\subsection{Field Activities}

Field activities to obtain clean closure of the Bomblet Pit and the Five Points Landfill will be achieved through:

- Removing ordnance and nonhazardous waste as discussed in the VCA Work Plan

- Verifying that RCRA hazardous constituents do not remain in the environment at the Bomblet Pit above regulatory action levels.

- Verifying that radiological constituents do not remain at the Five Points Landfill above action levels set forth in this plan.

Verifiçation analyses at the Bomblet Pit will include the Toxicity Characteristic Leaching . Procedure (TCLP) for RCRA metals (Title 40 CFR \$261.24), TCLP semivolatile organics method SW 846-8270 (EPA, 1986), and SW 846-8330 (EPA, 1986) methods for nitroaromatics and nitramines. At the Five Points Landfill, verification analysés will include gamma spectroscopy and isotope-specific analysis for uranium and plutonium. If evidence of unexpected contamination is discovered through analysis, further soil removal, sampling, and analysis will be performed in accordance with Section 3.2 of this plan.

\subsection{Constituents of Concern}

Based on the process knowledge discussed in Section 2.3 of this plan, the most likely constituents of concern for the Bomblet Pit are chromium, mercury, and lead from processing various UXO and the explosive compounds of TNT, RDX, and PETN, which are common components of the explosives used to process the UXO. Depleted uranium is the constituent of concern at the Five Points Landfill. Since UXO were not processed at the Five Points Landfill, chromium, mercury, lead, TNT, PETN, and RDX are not constituents of concern. The analytical methods and requirements for the verification samples have been tailored to be consistent with constituents of concern (Tables 3-1 and 3-2) to demonstrate that process knowledge is correct and complete. For example, because the information on components of UXY was obtained from third parties (i.e., manufacturers of UXO), all TCLP metals will be analyzed to verify that the information provided was correct and complete. 
Table 3-1

\section{Suspected Constituents of Concern and Closure Standards}

\begin{tabular}{|c|c|c|c|c|c|}
\hline Site & Group & Individual Constituents & Method $^{\mathrm{a}}$ & $\begin{array}{l}\text { Closure } \\
\text { Standard } \\
\text { (mg/l) }^{\mathrm{b}}\end{array}$ & $\begin{array}{l}\text { Source of } \\
\text { Standard }\end{array}$ \\
\hline Bomblet Pit & TCLP Metals $^{c}$ & $\begin{array}{l}\text { Arsenic } \\
\text { Barium } \\
\text { Cadmium } \\
\text { Chromium } \\
\text { Lead } \\
\text { Mercury } \\
\text { Selenium. } \\
\text { Silver }\end{array}$ & $\begin{array}{l}1311 / 6010 \mathrm{~A} \\
1311 / 6010 \mathrm{~A} \\
1311 / 6010 \mathrm{~A} \\
1311 / 6010 \mathrm{~A} \\
1311 / 6010 \mathrm{~A} \\
1311 / 7470^{\mathrm{d}} \\
1311 / 6010 \mathrm{~A} \\
1311 / 6010 \mathrm{~A}\end{array}$ & $\begin{array}{c}5 \\
100 \\
1 \\
5 \\
5 \\
0.2 \\
1 \\
5\end{array}$ & $\begin{array}{l}\text { TCLP } \\
\text { TCLP } \\
\text { TCLP } \\
\text { TCLP } \\
\text { TCLP } \\
\text { TCLP } \\
\text { TCLP } \\
\text { TCLP }\end{array}$ \\
\hline Bomblet Pit & $\begin{array}{l}\text { Semivolatile } \\
\text { Organics }^{c} \text { : }\end{array}$ & $\begin{array}{l}\text { Nitrobenzene } \\
\text { 2,4-Dinitrotoluene, }\end{array}$ & $\begin{array}{l}1311 / 8270 \\
1311 / 8270\end{array}$ & $\begin{array}{c}2 \\
0.13\end{array}$ & $\begin{array}{l}\text { TCLP } \\
\text { TCLP }\end{array}$ \\
\hline Bomblet Pit & . & $\begin{array}{l}\text { Octahydro-1,3,5,7-tetranitro-1,3,5,7-tetrazocine } \\
\text { Hexahydro-1,3,5-trinitro-1,3,5-triazine } \\
\text { 1,3,5-Trinitrobenzene } \\
\text { 1,3-Dinitrobenzene } \\
\text { Methyl-2,4,6-trinitrophenylnitramine } \\
\text { 2,4,6-Trinitrotoluene } \\
\text { 4-Amino-2,6-dinitrotoluene } \\
\text { 2-Amino-4,6-dinitrotoluene } \\
\text { 2,6-Dinitrotoluene } \\
\text { 3-Nitrotoluene } \\
\text { 4-Nitrotoluene }\end{array}$ & $\begin{array}{l}8330^{\mathrm{e}} \\
8330 \\
8330 \\
8330 \\
8330 \\
8330 \\
8330 \\
8330 \\
8330 \\
8330 \\
8330\end{array}$ & $\begin{array}{c}4000 \\
63.6 \\
4 \\
8.000 \\
800 \\
233.3 \\
1.029^{+} \\
1.029^{\ddagger} \\
80 \\
800 \\
800\end{array}$ & $\begin{array}{l}\text { Subpart S } \\
\text { Subpart S } \\
\text { Subpart S } \\
\text { Subpart S } \\
\text { Subpart S } \\
\text { Subpart S } \\
\text { Subpart S } \\
\text { Subpart S } \\
\text { Subpart S } \\
\text { Subpart S } \\
\text { Subpart S }\end{array}$ \\
\hline $\begin{array}{l}\text { Five Points } \\
\text { Landfill }\end{array}$ & $\begin{array}{c}\text { Gamma } \\
\text { Spectroscopy }\end{array}$ & Uranium-238 & $\begin{array}{l}\text { HASL } 300 \\
4.5 .2 .3^{f}\end{array}$ & $500 \mathrm{pCi} / \mathrm{g}^{\mathrm{g}}$ & RESRAD ${ }^{h}$. \\
\hline
\end{tabular}

${ }^{a}$ From SW-846 (EPA, 1986)

${ }^{b}$ Milligrams per liter

CToxicity Characteristic Leaching Procedure from Title 40 CFR \$261.24, Table 1

Method for Mercury .

Peroposed for addition to SW-846 (EPA, 1986)

Environmental Measurements Laboratory Procedure Manual, HASL-300, U.S. Department of Energy

$\mathrm{g}_{\text {Picocuries per gram }}$

hRESRAD calculation (see Section 3.3 of this plan)

†All RCRA Subpart $S$ values were calculated by Art Graveristein - State of Nevada. Subpart $S$ is a proposed section of 40 CFR \$264. (IT Telecon with Barbara Deshler, January 3, 1996)

¥Uses value for dinitrotoluene mixture per Art Gravenstein - State of Nevada. (IT Telecon with Barbara Deshler, January 3, 1996). 
Table 3-2

Site Characterization and Closure Verification Analytical Chemical Requirements

(Page 1 of 2)

\begin{tabular}{|c|c|c|c|c|c|c|c|c|c|c|c|}
\hline Parameter & Method & Medium & $\begin{array}{l}\text { Sample } \\
\text { Contalner }\end{array}$ & $\begin{array}{l}\text { Minimum } \\
\text { Amount of } \\
\text { Sample } \\
\text { Required }\end{array}$ & $\begin{array}{c}\text { Preservative } \\
:\end{array}$ & $\begin{array}{l}\text { Holding } \\
\text { Time }\end{array}$ & $\begin{array}{l}\text { TCLP } \\
\text { Analyte }\end{array}$ & $\begin{array}{c}\text { Minimum } \\
\text { Detectable } \\
\text { Concentration } \\
(\text { mg/l) }\end{array}$ & $\begin{array}{l}\text { Regulatory } \\
\text { Limit (mg/l) }\end{array}$ & $\begin{array}{l}\text { Acceptable } \\
\text { Precislon } \\
\text { (RPD) }\end{array}$ & $\begin{array}{c}\text { Acceptable } \\
\text { Accuragy } \\
\text { (\%R) }\end{array}$ \\
\hline \multirow{2}{*}{$\begin{array}{l}\text { Nitroaromàtics } \\
\text { and Nitramines }\end{array}$} & \multirow[t]{2}{*}{$8330^{\circ}$} & Watẹr & $G^{f}$, amber & $2 \times 1$ liter & \multirow{2}{*}{$\begin{array}{l}\text { Cool to } 4^{\circ} \mathrm{C} \pm \\
2^{\circ} \mathrm{C} \text { with ice }\end{array}$} & \multirow[t]{2}{*}{7 days } & \multirow{2}{*}{$\begin{array}{c}\text { 2,4- } \\
\text { Dinitrotoluene } \\
\text { Nitrobenzene }\end{array}$} & $45 \mu \mathrm{g} / \mathrm{l}^{\mathrm{g}}$ & \multirow[t]{2}{*}{0.13} & \multirow{2}{*}{$\begin{array}{r}20 \\
.30\end{array}$} & \multirow{2}{*}{$\begin{array}{l}53 \text { to } 133 \\
22 \text { to } 157\end{array}$} \\
\hline & & Soil & $\begin{array}{l}\text { G, amber } \\
\text { Teflon }{ }^{T M} \text {. } \\
\text { lined cap }\end{array}$ & $\begin{array}{c}\begin{array}{c}\text { 4-ounce, } \\
\text { wide-mouth } \\
\text { jar }\end{array} \\
\end{array}$ & & & & $2.5 \mathrm{mg} / \mathrm{kg}^{\mathrm{h}}$ & & & \\
\hline \multirow[t]{3}{*}{ TCLP Motals } & \multirow{3}{*}{$\begin{array}{c}1311 / 6010 \mathrm{~A}^{\mathrm{h}} \\
74700^{\circ} .\end{array}$} & Water & \multirow[t]{3}{*}{$P E^{k}$ or $G$} & 1 liter & $\mathrm{pH}<2, \mathrm{HNO}_{3}^{\prime}$ & \multirow{3}{*}{$\begin{array}{c}180 \text { days to } \\
\text { leaching; } 180 \\
\text { days to } \\
\text { analysis }\end{array}$} & \multirow{3}{*}{$\begin{array}{l}\mathrm{As} \\
\mathrm{Ba} \\
\mathrm{Cd} \\
\mathrm{Cr} \\
\mathrm{Pb} \\
\mathrm{Hg} \\
\mathrm{Se} \\
\mathrm{Ag}\end{array}$} & 0.500 & \multirow{3}{*}{$\begin{array}{r}5.0 \\
100.0 \\
1.0 \\
5.0 \\
5.0 \\
0.20 \\
1.0 \\
\quad 5.0 \\
\end{array}$} & \multirow[t]{3}{*}{20} & \multirow[t]{3}{*}{80 to 120} \\
\hline & & & & & $2^{\circ} \mathrm{C}$ with ice & & & 0.010 & & & \\
\hline & & Soll & & $\begin{array}{l}\text { 8-ounce, } \\
\text { wide-mouth } \\
\text { jar }\end{array}$ & $\begin{array}{l}\text { Cool to } 4^{\circ} . C_{ \pm} \\
2^{\circ} \mathrm{C} \text { with ice. }\end{array}$ & & & $\begin{array}{l}0.150 \\
0.0002 \\
0.500 \\
0.020 \\
\end{array}$ & & & \\
\hline \multirow{2}{*}{$\begin{array}{l}\text { Gamma. } \\
\text { Spectroscopy } \\
\text { (based on } \\
{ }^{137} \mathrm{Cs} \text { ) }\end{array}$} & EPA $901.1^{n}$ & Water & \multirow[t]{2}{*}{ PE or $G$} & 1 liter & $\begin{array}{c}\mathrm{HNO}_{3} \text { to } \\
\mathrm{pH}<2\end{array}$ & \multirow[t]{2}{*}{6 months } & \multirow[t]{2}{*}{$N A^{p}$} & \multirow[t]{2}{*}{$\begin{array}{c}20 \mathrm{pCi} / \ell^{q} \\
1 \mathrm{pCi} / \mathrm{g}\end{array}$} & \multirow[t]{2}{*}{ NA } & \multirow[t]{2}{*}{ \pm 20} & \multirow[t]{2}{*}{80 to 120} \\
\hline & $\begin{array}{c}\text { HASL } 300^{\circ} \\
4.5 .2 .3\end{array}$ & Soll & & 1 llter & None & & & & & & \\
\hline \multirow[t]{2}{*}{$\begin{array}{l}\text { Uranium 234- } \\
235\end{array}$} & \multirow[t]{2}{*}{$\begin{array}{l}\text { NAS-NS- } \\
3050^{\circ}\end{array}$} & Water & PE or $\mathrm{G}$ & $1,000 \mathrm{me}^{\mathrm{s}}$ & $\begin{array}{l}\mathrm{HNO}_{3} \text { to } \\
-\mathrm{pH}<2\end{array}$ & \multirow{2}{*}{$\begin{array}{l}6 \text { months } \\
\text { after } \\
\text { collection }\end{array}$} & \multirow[t]{2}{*}{ NA } & \multirow[t]{2}{*}{$\begin{array}{l}1 \mathrm{pCl} / \mathrm{l} \\
1 \mathrm{pCl} / \mathrm{g}\end{array}$} & \multirow[t]{2}{*}{ NA } & \multirow[t]{2}{*}{ \pm 25} & \multirow[t]{2}{*}{70 to 120} \\
\hline & & Soll & & 50 grams & None & & & & & & \\
\hline
\end{tabular}

Refer to footnotes at end of table. 
Table 3-2

Site Characterization and Closure Verification Analytical Chemical Requirements

(Page 2 of 2)

\begin{tabular}{|c|c|c|c|c|c|c|c|c|c|c|c|}
\hline Parameter & Method & Medium & $\begin{array}{l}\text { Sample } \\
\text { Contalner }\end{array}$ & $\begin{array}{l}\text { Minimum } \\
\text { Amount of } \\
\text { Sample } \\
\text { Required } \\
\end{array}$ & $\begin{array}{c}. . \\
\text { Preservative }\end{array}$ & $\begin{array}{l}\text { Holding } \\
\text { TIme }\end{array}$ & $\begin{array}{l}\text { TCLP } \\
\text { Analyte }\end{array}$ & $\begin{array}{c}\text { Minimum } \\
\text { Detectable } \\
\text { Concentration } \\
(\text { mg/l) } \\
\end{array}$ & $\begin{array}{l}\text { Regulatory } \\
\text { Limit (mg/l) }\end{array}$ & $\begin{array}{l}\text { Acceptable } \\
\text { Preclsion } \\
\text { (RPD) }^{\text {c }}\end{array}$ & $\begin{array}{l}\text { Acceptable } \\
\text { Accuragy } \\
\text { (\%R) }\end{array}$ \\
\hline \multirow[t]{2}{*}{ Uranium.238 } & $\begin{array}{c}\text { NAS-NS- } \\
3050\end{array}$ & Water & \multirow[t]{2}{*}{$P E$ or $G$} & $1,000 \mathrm{me}$ & $\begin{array}{c}\mathrm{HNO}_{3} \text { to } \\
\mathrm{pH}<2\end{array}$ & \multirow{2}{*}{$\begin{array}{l}6 \text { months } \\
\text { after } \\
\text { collection }\end{array}$} & \multirow[t]{2}{*}{ NA } & \multirow[t]{2}{*}{$\begin{array}{r}1 \mathrm{pCi} / \mathrm{l} \\
1 \mathrm{pCi} / \mathrm{g}\end{array}$} & \multirow[t]{2}{*}{ NA } & \multirow[t]{2}{*}{ \pm 25} & \multirow[t]{2}{*}{70 to 120} \\
\hline & $\begin{array}{c}\text { HASL } 3000 \\
. \quad 4.5 .2 .3\end{array}$ & Soil & & 50 grams & None & & & & & & \\
\hline \multirow[t]{2}{*}{ Plutonium 239} & \multirow{2}{*}{$\begin{array}{l}\text { NAS-NS- } \\
3058^{\circ}\end{array}$} & Water & \multirow[t]{2}{*}{ PE or G } & i liter & $\mathrm{HNO}_{3}$ to $\mathrm{pH}<2$ & \multirow[t]{2}{*}{6 months } & \multirow[t]{2}{*}{ NA } & \multirow{2}{*}{$\begin{array}{l}1 \mathrm{pCV} / \mathrm{\ell} \\
\mathrm{i} \mathrm{pCi} / \mathrm{g}\end{array}$} & \multirow[t]{2}{*}{ NA } & \multirow[t]{2}{*}{ \pm 25} & \multirow[t]{2}{*}{75 to 125} \\
\hline & & Soil & & 4 ounces & None & & & & & & \\
\hline
\end{tabular}

a Toxjcity Characteristic Leaching Procedure from Title 40 CFR §261.24, Table 1

Milligram per liter

Pelative percent difference

dercent recovery

Proposed for addition to SW-846 (EPA, 1986)

Glass

${ }_{\text {Microgram per liter }}$

$\mathrm{h}_{\text {Milligram per kilogram }}$

i Miligram perklogram.

From SW-846 (EPA, 1986)

Kolyethylene

Nitric acid

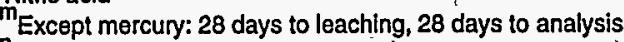

"Standard Methods for the Examination of Water and Wastewater, American Public Health Association

${ }^{\circ}$ Environmental Measurements Laboratory Procedure Manual, HASL-300, U.S. Department of Energy

PNot applicablo

${ }^{q}$ Picocurie per liter

'Milliliter

${ }^{8}$ National Academy of Sclence, Nuclear Science Series, September 1963

tNational Academy of Science, Nuclear Science Series, September 1962 


\subsection{Closure Standards}

The proposed closure standards are presented in Table 3-1. The closure standards for TCLP metals are the regulatory limits found in Title 40 CFR 261. Nitroaromatics and nitramines from the detonation of UXO are not naturally occurring, and there is no regulatory limit. Soil found to contain contaminants above the closure standard will result in excavation of impacted soil, containerization, and appropriate management of the impacted soil as waste in accordance with Section 5.0 of this Plan. There will be additional sampling to verify that the remaining soils are below the closure standard. This process is described in more detail in Sections 3.5 and 3.6 of this Plan.

\subsection{Depleted Uranium (DU) Closure Standard}

A radiological risk assessment methodology was developed to supplement previous efforts at the Nevada Test Site.(NTS) to develop pathways and exposure scenarios applicable to the U.S. Department of Energy Nevada Operations Office (DOE/NV) Environmental Restoration (ER) activities. The radiological risk assessment was performed to determine the relationship between the concentration of DU in soil at the Five Points'Landfill and the dose to an individual and to determine a reasonable closure standard concentration.

\subsubsection{RESRAD Risk Assessment Calculations}

RESRAD is a microcomputer program which utilizes the dose assessment methodology recommended for use in deriving site-specific soil guidelines. The méthodology and resultant code were adapted from a manual developed in 1989. for implementing.DOE residual radioactive material guidelines." The manual and the code are used widely by DOE and its contráctors and, to some extent, by the U.S. Nuclear Regulatory Commission (NRC) and licensing states. The program is issued by the Environmental Assessment Division of Argonne National Laboratory.

\subsubsection{RESRAD Risk Assessment Methodology}

The result of the analysis is to recommend a closure standard for DU in soil, and it demonstrates that the recommended closure standard would not present an unacceptable risk. Analysis of radiation exposure pathways is used to translate radiation dose guidelines, which are generally not directly measurable, into derived concentration guidelines, i.e., concentration of a radionuclide in soil. This particular methodology was developed and implemented in order to

"The DOE guidelines were incorporated into DOE Order 5400.5 in February 1990 and were included in proposed Title 10, Part 834 of the Code of Federal Regulations (March 1993). 
relate the concentration of DU in soil at the Five Points Landfill, Tonopah Test Range, and the dose to a maximally exposed individual. The primary objective is to establish the DU concentration in soil that relates to a maximum effective dose equivalent of $100 \mathrm{mrem} / \mathrm{year}$.

The pathways analysis relates DU concentration in soil to the 100 mrem/year dose guidelines for the maximum exposed dose receptor. The analysis requires:

- Development of scenarios that describe potential exposures modes

- Selection and use of mathematical models of radiation exposure and radionuclide transport

- Reasonable numeric values for parameters used in the mathematical models

The development; selection, and analysis for reasonable numeric values is an involved process beyond the scope of this plan. A "white paper" which illustrates the-scenarios, selection of mathematical models, values selection, and the complete set of data and calculations is forthcoming. Only the results are presented in this document.

\subsubsection{Summary and Recommendations for Depleted Uranium Closure Standard Using RESRAD.}

The radiological risk assessment was performed in order to determine the relationship between the concentration of DU in the soil at the Five-Points Landfill and the dose to potential receptors. The analysis demonstrates that given a conservative and limiting exposure scenario, a site resident, a concentration of $590 \mathrm{pC} \mathrm{i} / \mathrm{g}$ of depleted uranium would be required to obtain a dose of $100 \mathrm{mrem} /$ year. The radiological risk assessment was performed to ensure that the soil guideline criteria chosen would not present an unacceptable risk. Therefore, à concentration of $500 \mathrm{pCi} / \mathrm{g}$ of DU as a soil guideline for the environmental restoration at the Five-Points Landfill is suggested.

\subsection{Clean Closure}

The objective of the SAFER activities at the Bomblet Pit and Five Points Landfill is to gather adequate data to affirm the decision for clean closure. The first phase of the corrective action has been completed and included removal of UXO and other solid waste contained within each unit as addressed in the VCA Work Plan, associated records of technical change, and field logs. The second phase of SAFER activities will be accomplished through sampling and analysis to verify 
adequacy, correctness, and completeness of process knowledge. Verification samples will be collected and analyzed to determine if additional soil excavation and remediation are required. If the verification samples indicate that constituents of concern are present in the soil above closure standard levels as presented in Section 3.0 of this plan, additional excavation will take place; the excavated soil will be stockpiled and managed as waste. Additional verification samples will be collected and analyzed, and this sequence may be repeated as necessary until all areas are demonstrated to meet the closure standards presented in Table 3-1.

Complete removal of impacted soils will be verified by collecting and analyzing soil samples at the locations shown in Figures 3-1 through 3-3. If each sample meets the standards described in Table 3-1, the site may be restored and clean-closed. All verification samples will be collected and managed in accordance with U.S. Environmental Protection Agency (EPA) quality protocols as reflected below and in the Quality Assurance Project Plan (QAPP) (Appendix A)..

\subsubsection{Sampling}

Soil samples will be collected with a decontaminated trowel or equivalent. Surface-śoil samples will be collected at the sites at an interval of 0 to 15 centimeters $(\mathrm{cm})(0$ to 6 inches [in.]) below surface. As discussed in Section 2.3, impacted soil has already been removed from the UXO processing areas, and only limited detonations occurred within the Bomblet Pit. Therefore, sampling at depth was deemed to be unnecessary. Samples will be collected from the locations shown in Figures 3-1 through 3-5, and all sampling activities and locations will be documented. The number of verification samples is in the following text, and the analytical requirements for each sample are given in Table 3-2.

Data Quality Objectives and Quality Assurance (QA) objectives, including precision, accuracy, representativeness, comparability, and completeness have been established for the project to ensure that the data collected are sufficient and of adequate quality for their.intended uses. In general, the DQOs and QA objectives are discussed in the QAPP (Appendix A). Quality control requirements specific to these assessment activities include the following and are also discussed. in detail in the QAPP (Appendix A):

- One duplicate sample will be collected per sample delivery group (not less than 1 per 20 samples).

- One rinsate blank will be collected per decontamination process. Dedicated trowels may be used to preclude decontamination between sample locations. 


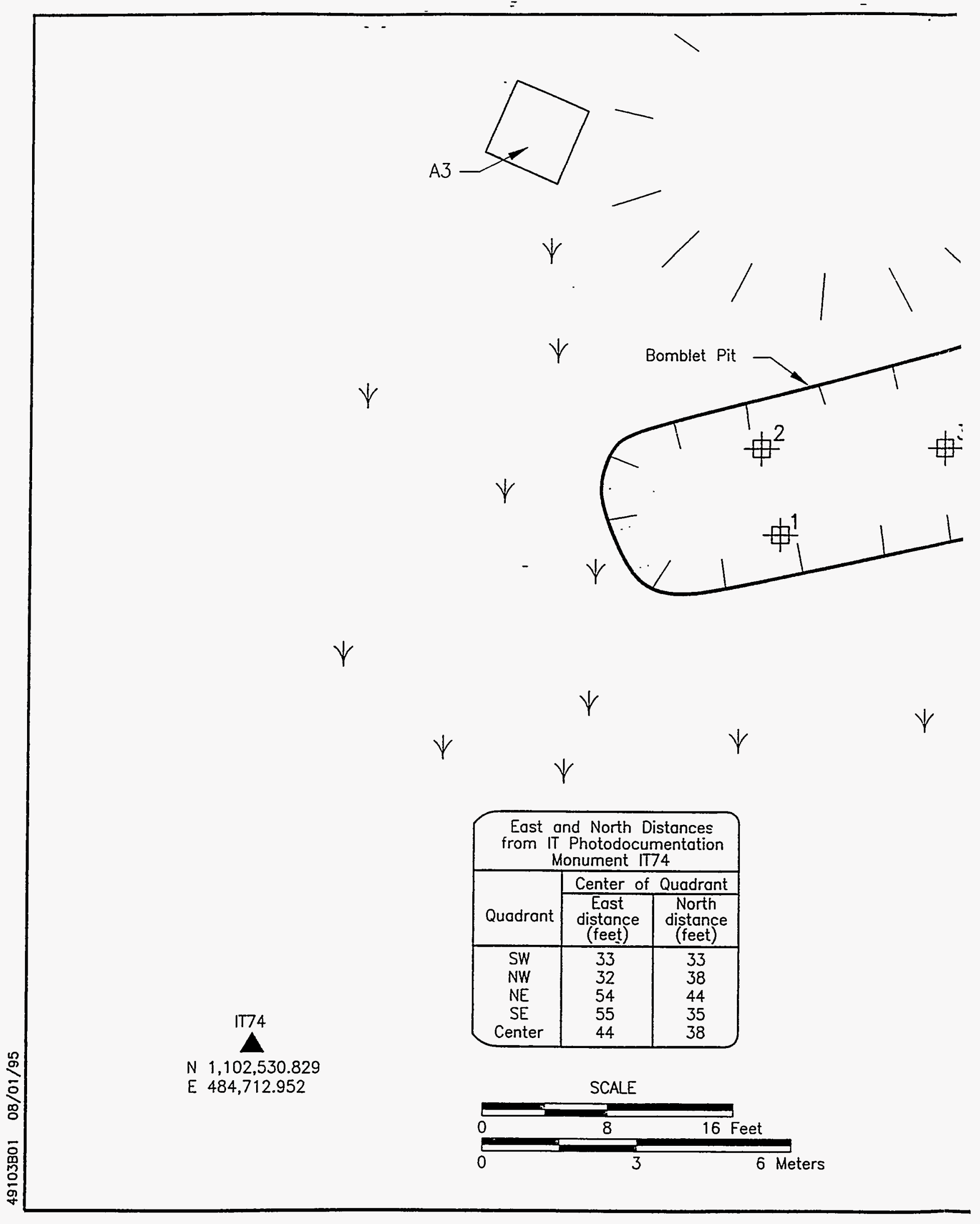




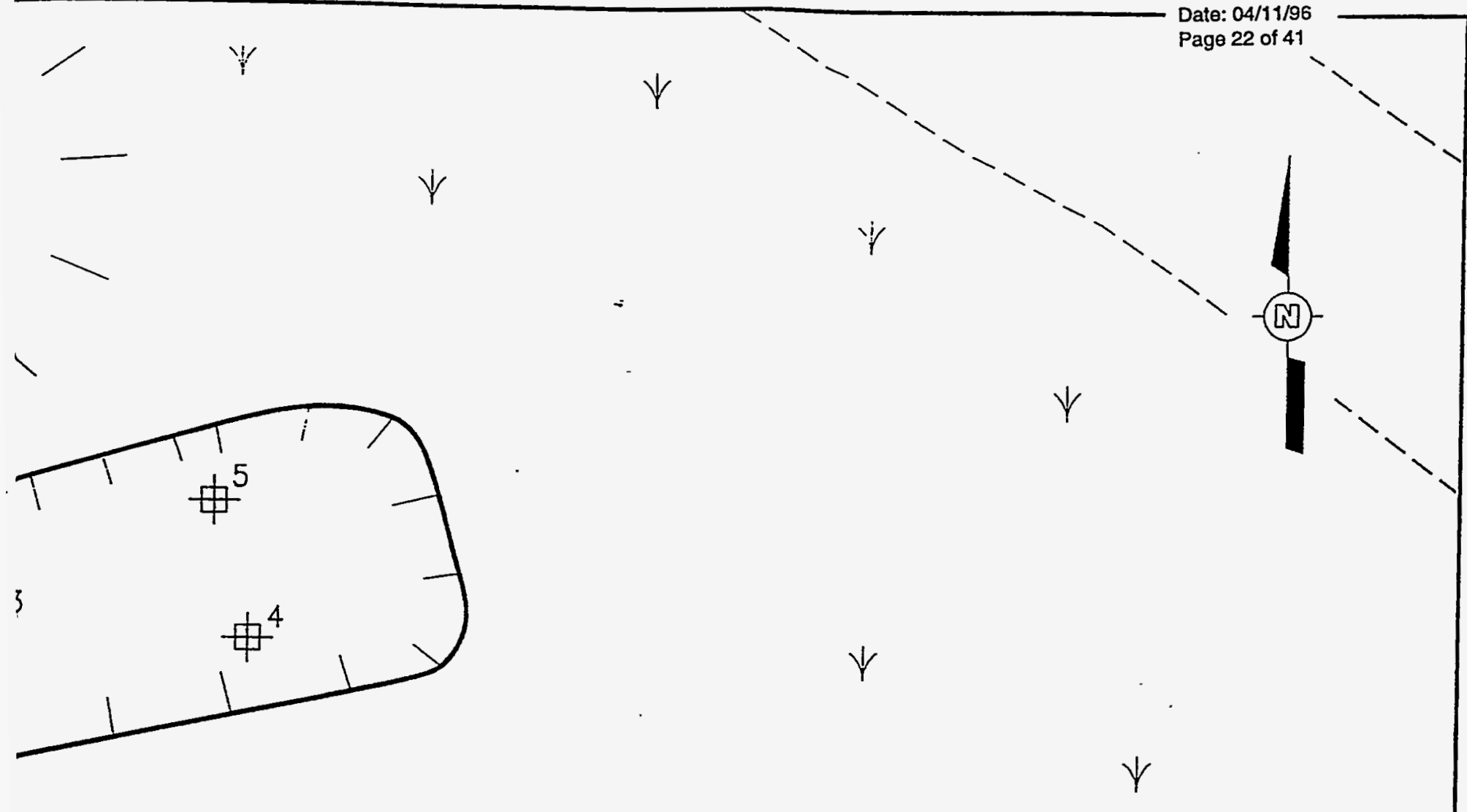

\section{LEGEND}

丹 Approximate surface-soil sample location

ニニニニ Dirt road

$\overline{\prime \prime}^{\prime \prime \prime}=$ Earthen mound

E] Depression

$\psi \quad$ Deseri scrub vegetation

A Bounciary/baseline photodocumentation monument

A3 investigated anomaly

FIGURE 3-1

SAMPLE LOCATION MAP BOMBLET PIT TONOPAH TEST RANGE 

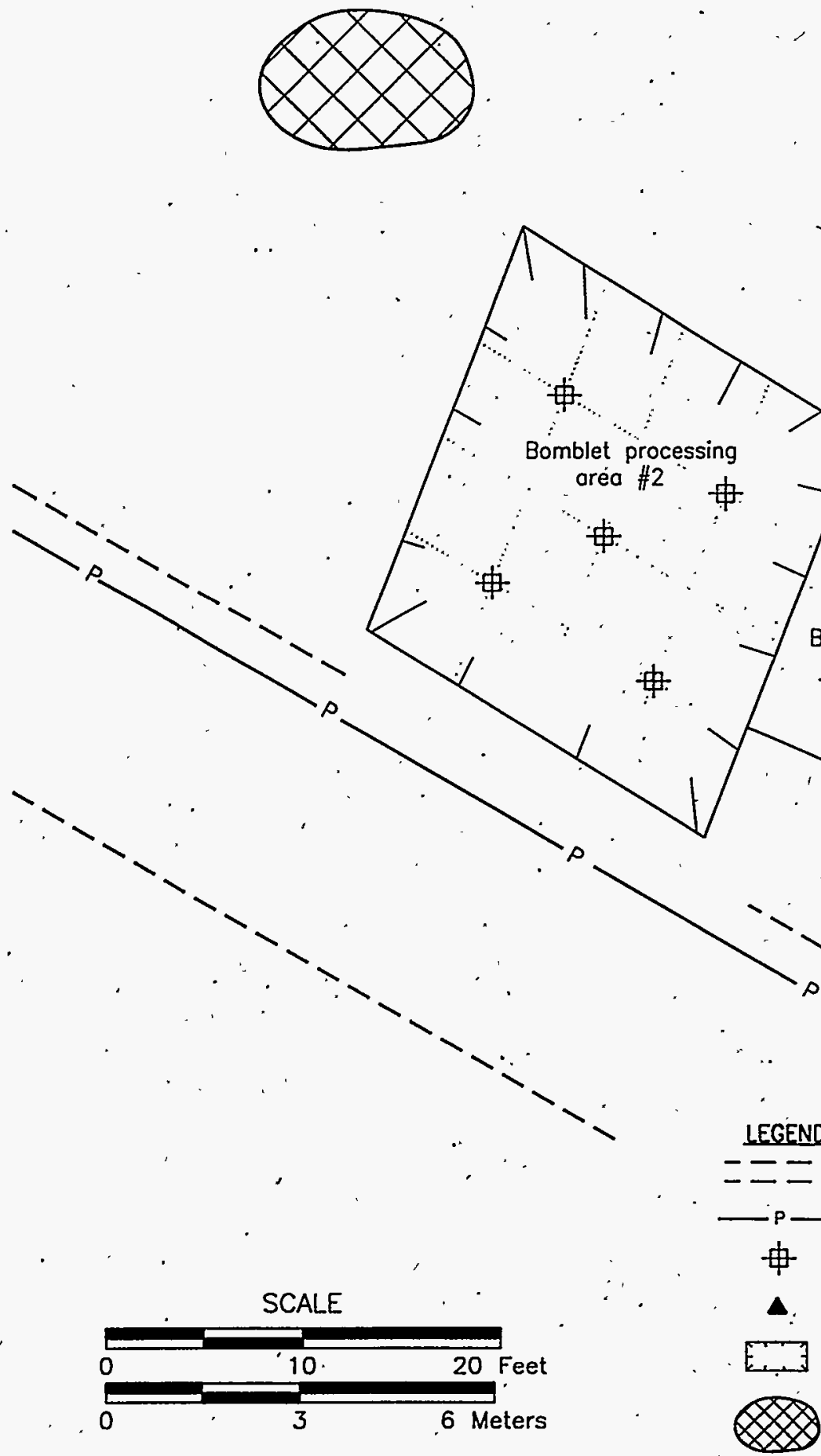

Figure, 3-2

Sample Location Map, Bomblet Pit, Processing Areas 1 and 2, Tonopah Test Range 


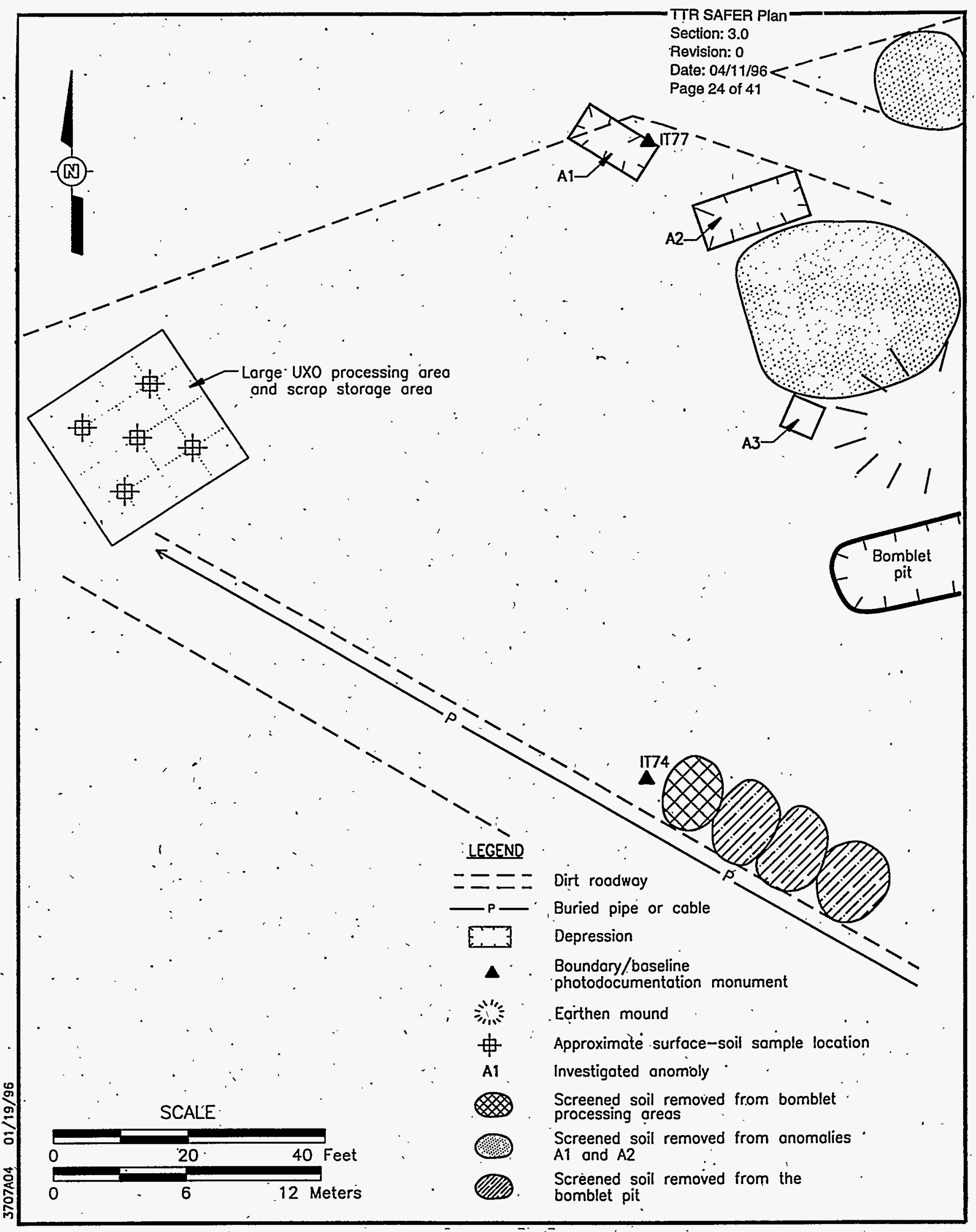

Figure 3-3

Sample Location Map, Large UXO Processing Area, Bomblet Pit, Tonopah Test Range 


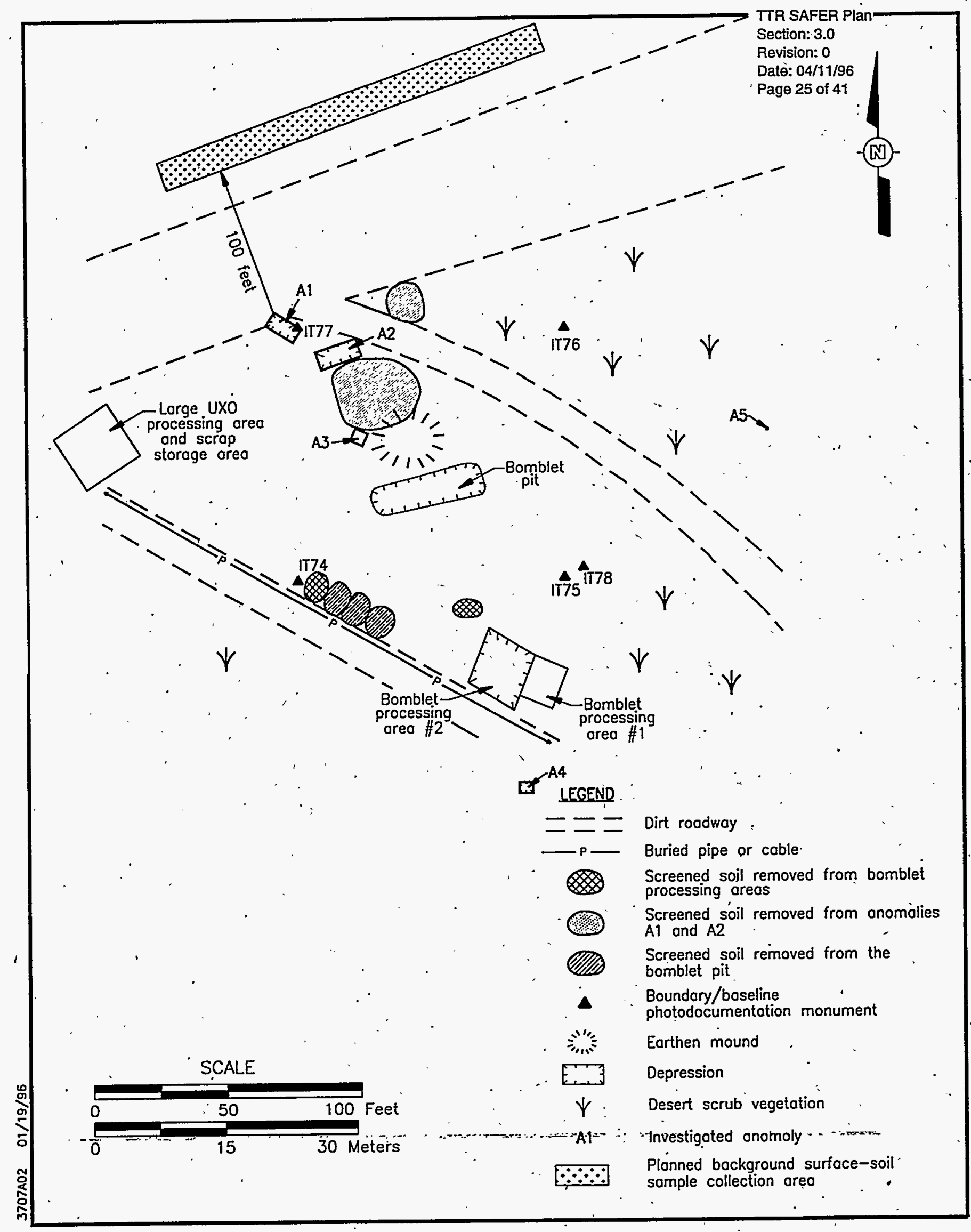

Figure 3-4

Sample Location Map, Planned Background Surface-Soil Collection Area Bomblet Pit, Tonopah Test Range 


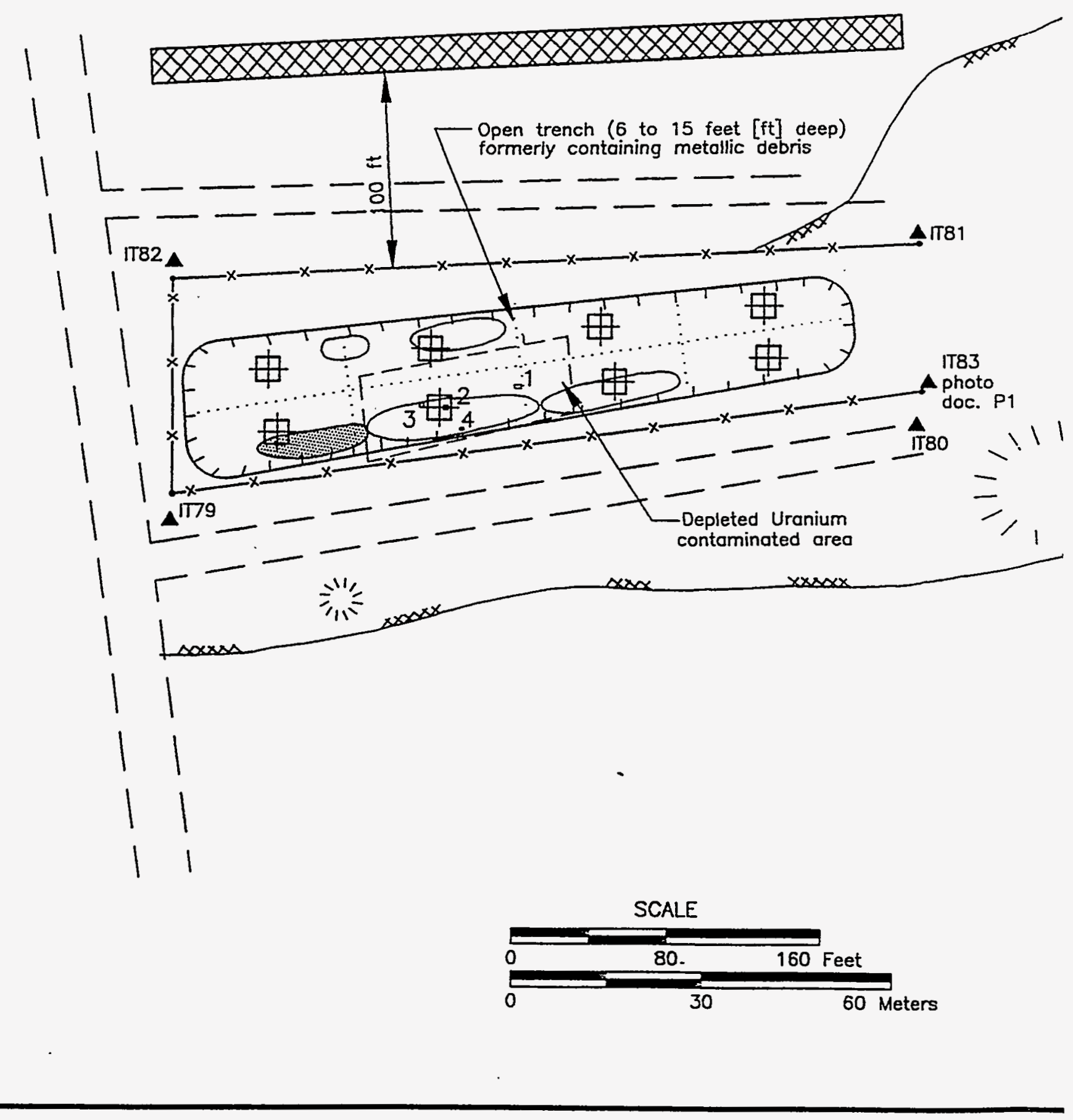


Statistical methods were employed in order to form a basis for determining the appropriate number of samples to verify that constituents of concern are present below closure standard levels (Table 3-1). Equation 8 of Chapter 9 of SW-846 gives the calculation of the number of samples required to measure the sample mean of the sampled area $\mathrm{X}$, assiociated with a sample standard deviation of $s$, with an acceptably small probability of error, $\alpha$, as:

$$
n=\left(t_{1-\alpha / 2} \frac{s}{[R T-X]}\right)^{2}
$$

where

$t_{1-\alpha / 2}=$ the corresponding Student $t$ value for the appropriate probability and number of degrees of freedóm $(=\mathrm{n}-1)$

. $\quad \cdot=$ the sample standard deviation

$\mathrm{RT}=$ the regulatory threshold for the constituent of concern

$\mathrm{X} .=$ the mean concentration of the constituent of concern.

For the Bomblet Pit and Five Points Landfill at the TTR; there is no preliminary information regarding the mean or standard deviation of the constituents of concern. In the absence of this - information, each area of concern will be divided into equal grid spaces; and a systematic, random sampling pattern will be followed. The required number of samples will then be calculated from the analytical results using the above equation. If additional samples are required to demonstrate that the site meets closure standards, they will be collected at a later time." If the initial sampling effort shows that there are areas which are above the closure standard, the contaminated areas will be excavated and resampled. The data showing the presence of. constituents of concern above the closure standard will be discarded for purposes of calculation, and Equation 8 will be applied again, using the new data. This will confirm that an adequate number of samples were collected and analyzed to demonstrate that the site meets closure standard requirements.

\subsubsection{Bomblet Pit}

There are six areas of concern at the Bomblet Pit. Four are shown in.Table 3-3; the two soil stockpiles are discussed separately. As shown in this table, five surface soil samples will be collected from the Bomblet Pit and two of the three UXO processing areas. Four surface soil 
samples will be collected from the small UXO processing area. The surface-soil samples will be analyzed for the parameters listed in Table 3-4. The sample locations were determined by. dividing the Bomblet Pit and processing areas into four quadrants of approximately equal size and then dividing each of these quadrants into four quadrants. The intersection of the lines that meet in the center of each subdivided quadrant mark the approximate locations for sample locations. In addition, the lines that meet in the center of the Bomblet Pit and the two large processing areas will mark the approximate locations for sampling. Because the smaller UXO processing area is only about one-half as large as the Bomblet Pit and two larger processing areas, it was determined that a-sample from the center of the small UXO processing area would not be required. The sample locations are referenced to the surveyed location of IT photo documentation monument IT74 and are given in Figure 3-1. Actual sampling locations will be documented in the field.

The two soil stockpiles of concern were created by excavating soil from the processing areas as described in Section 2.2.1; therefore, the soil samples from the processing areas should be representative of the stockpiles. To confirm this process knowledge, five' soil samples will be collected from each soil stockpile and composited into one sample. The five soil sampling locations will be selected from approximately the top of the stockpile and the north, south; east, and west sides of the soil stockpile. If the stockpile samples indicate that constituents of concern are not present above closure standard, the stockpiles may be used as fill during site recontouring. If constituents of concern (or other RCRA-regulated metals) are present above closure standards, the stockpiles will be excavated and the soil.containerized and managed as waste as noted in Section 5.0. If excavation of the stockpiles is required, a sample will be collected from beneath each excavated stockpile and analyzed for the detailed constituents of concern above closure standards in the stockpile. If constituents of concern are still detected above closure ștandards, additional exçavation will be conducted and samples collected again. This process will be repeated until clean closure is achieved beneath the stockpiles.

\subsubsection{Five Points Landfill}

The Five Points Landfill will be treated as a single area of concern having a rectangular shape as indicated in Table 3-5. Samples will be collected from the surface of the pit only. No samples will.be collected at depth. The area will be divided into eight equal cells measuring approximately $26 \mathrm{~m}$ long $\mathrm{x} 13 \mathrm{~m}$ wide ( $86 \mathrm{ft}$ x $44 \mathrm{ft}$ ). Exact sample collection locations will be documented in the field. These samples will be analyzed for the parameters listed in Table 3-6. 
Table 3-3

Number and Location of Samples for the Bomblet Pit and Processing Areas

\begin{tabular}{||c|c|c|c|c|c||}
\hline $\begin{array}{c}\text { Area of } \\
\text { Concern }\end{array}$ & $\begin{array}{c}\text { Length, } \\
\text { meters (feet) }\end{array}$ & $\begin{array}{c}\text { Width, meters } \\
\text { (feet) }\end{array}$ & $\begin{array}{c}\text { Area, square } \\
\text { meters } \\
\text { (square feet) }\end{array}$ & \# Samples & Where \\
\hline \hline $\begin{array}{c}\text { Processing } \\
\text { Area 1 }\end{array}$ & $5(16)$ & $4(13)$ & $20(208)$. & 4 & $\begin{array}{l}\text { Center of each } \\
\text { quarter }\end{array}$ \\
\hline $\begin{array}{c}\text { Processing } \\
\text { Area 2 }\end{array}$ & $6.4(21)$ & $6.7(22)$ & $43(462)$ & 5. & $\begin{array}{l}\text { Center of each } \\
\text { quarter and } \\
\text { center of area }\end{array}$ \\
\hline $\begin{array}{c}\text { Large } \\
\text { Processing } \\
\text { Area }\end{array}$ & $7.3(24)$ & $7(23)$ & $51(552)$ & 5 & $\begin{array}{l}\text { Center of each } \\
\text { quarter and } \\
\text { center of area }\end{array}$ \\
\hline $\begin{array}{c}\text { Bomblet Pit } \\
.\end{array}$ & $4(13)$ & $12.8(42)$ & $51(546)$ & 5 & $\begin{array}{l}\text { Center of each } \\
\text { quarter and } \\
\text { center of area }\end{array}$ \\
\hline
\end{tabular}

Table 3-4

Analytical Requirements for the Bomblet Pit and Processing Areas

\begin{tabular}{|c|c|c|c||}
\hline Parameter & Method $^{\mathrm{a}}$ & $\begin{array}{c}\text { Number of Soil } \\
\text { Samples }\end{array}$ & $\begin{array}{c}\text { Number of Duplicate } \\
\text { Samples }\end{array}$ \\
\hline \hline TCLP $^{\mathrm{b}}$ Metals & $1311 / 6010 \mathrm{~A} / 7470^{\prime}$ & $21^{\mathrm{c}}$ & 2 \\
\hline TCLP Semivolatiles & $1311 / 8270$ & 21 & 2 \\
\hline $\begin{array}{c}\text { Nitroaromatics and } \\
\text { Nitramines }\end{array}$ & EPA $8330^{\circ}$ & 21 & 2 \\
\hline
\end{tabular}

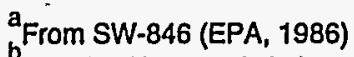

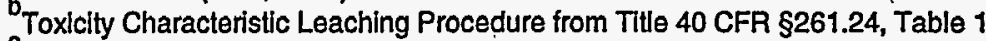

Includes two composite samples from soil stockpiles; does not include samples from beneath the stockpiles

dProposed for adoption into SW-846 (EPA, 1986)

Table 3-5

Number and Location of Samples for the Five Points Landfill

\begin{tabular}{|c|c|c|c|c|c|}
\hline $\begin{array}{c}\text { Area of } \\
\text { Concern }\end{array}$ & $\begin{array}{c}\text { Length, } \\
\text { meters (feet) }\end{array}$ & $\begin{array}{c}\text { Width, meters } \\
\text { (feet) }\end{array}$ & $\begin{array}{c}\text { Area, square } \\
\text { meters } \\
\text { (square feet) }\end{array}$ & \# Samples & Where \\
\hline \hline $\begin{array}{c}\text { Five Points } \\
\text { Landfill }\end{array}$ & $104.8(344)$ & $26.8(88)$ & $2,812(30,272)$ & 8 & $\begin{array}{c}\text { Center of each } \\
\text { grid cell }\end{array}$ \\
\hline
\end{tabular}


Table 3-6

Analytical Requirements for the Five Points Landfill

\begin{tabular}{|c|c|c|c||}
\hline Parameter & Method & $\begin{array}{c}\text { Number of Soil } \\
\text { Samples }\end{array}$ & $\begin{array}{c}\text { Number of Duplicate } \\
\text { Samples }\end{array}$ \\
\hline $\begin{array}{c}\text { Gamma Spectroscopy } \\
\left.\text { (based on }{ }^{137} \mathrm{Cs}\right)\end{array}$ & HASL 300 ${ }^{\mathrm{b}} 4.5 .2 .3$ & 8 & 1 \\
\hline Uranium-234/235 & NAS-NS-3050 & 8 & 1 \\
\hline Uranium-238 & HASL 300 4.5.2.3 & 8 & $\ddots$ \\
\hline Plutonium-239 & NAS-NS-3058 & & 1 \\
\hline
\end{tabular}

a Standard Methods for the Examination of Water and Wastewater, American Public Health Association

bnvironmental Measurements Laboratory Procedure Manual, HASL-300, U.S. Department of Energy

CNational Academy of Science, Nuclear Science Series, September 1963

-National Academy of Science, Nuclear Science Series, September 1962

\subsubsection{Local Background Sampling}

In order to establish background levels for radionuclides and TCLP metals, two background sampling areas have been chosen from areas least likely to have been impacted by test activities at TTR and which best represent the soil type of the Bomblet Pit and Five Points Landfill. Establishment of background levels is beneficial because there are no minimum levels for radioisotopes in soils and because it can help determine if constituents of concern are naturally occurring or present due to operational activities. As discussed previously, if metals or radionuclides are found to be naturally occurring as a result of background sampling, the closure standard will be adjusted accordingly. Because the Bomblet Pit has different constituents of concern than the Five Points Landfill, each group of background samples will be analyzed accordingly. Each background area is $100 \mathrm{ft}$ upgradient from the disposal site being investigated (Figures 3-4, and 3-5). Five surface soil samples will be collected from the least disturbed location in each area. The five background samples will be located approximately equidistant on . the long axis of the designated background area to maximize spatial variability and, hence, representativeness. The sampling locations will be documented. The background samples will be analyzed for the parameters listed in Table $3-7$. 
Table 3-7

Analytical Requirements fọ Background Sampling Locations

\begin{tabular}{||c|c|c|c||}
\hline Site & Parameter & Method & Number of Soil Sàmples \\
\hline \hline Bomblet Pit & TCLP ${ }^{\mathrm{b}}$ Metals & $1311 / 6010 \mathrm{~A} / 7470$ & 5 \\
\hline $\begin{array}{c}\text { Five Points Landfill } \\
\cdot\end{array}$ & $\begin{array}{c}\text { Gamma } \\
\text { (basectroscopy on }{ }^{137} \mathrm{Cs} \text { ) }\end{array}$ & HASL 300 ${ }^{\mathrm{d}} 4.5 .2 .3$ & $\ddots$ \\
\hline Five Points Landfill & Uranium 234/235 & NAS-NS-3050 & 5 \\
\hline Five Points Landfill & Uranium 238 & HASL 300 4.5.2.3 & $\cdot$ \\
\hline Five Points Landfill & Plutonium 239 & NAS-NS-3058 & 5 \\
\hline \hline
\end{tabular}

${ }^{a}$ Reflects total number from background sampling locations (i.e., 3 from each location):

Toxicity Characteristic Leaching Procedure from Title 40 CFR §261.24. Table 1

Standard Methods for the Examination of Water and Wastewater, American Public Health Association

Environmental Measurements Laboratory Procedure Manual, HASL-300, U.S. Department of Energy

'National Academy of Sciences, Nuclear Science Series, September 1963

'National Academy of Sciences, Nuclear Science Series,'September 1962

In order to determine the number of background samples required, the following calculation was performed. The standard error of the sample mean is given by the equation

$$
s_{\overline{\mathrm{x}}}=\frac{s}{\sqrt{n}},
$$

where

$\mathrm{s}=$ the sample standard deviation .

$\mathrm{n}=$ the number of samples (Gilbert, 1987).

This inverse proportionality to the square root of the number of samples is shown for three assumed values of $s$ in Figure 3-6: Note that as the sample standard deviation increases from 0.5 to 1 to 5 , the slope of the curve below $n=5$ increases significantly. It is desirable to minimize the standard deviation of the mean of the background samples, since it is this mean to which the results of verification samples will be compared. A confidence limit of 90 percent is assumed. Soil is inherently heterogeneous; therefore, the sample standard deviation would be expected to be high. Five background samplès represent a reasonable trade-off between 


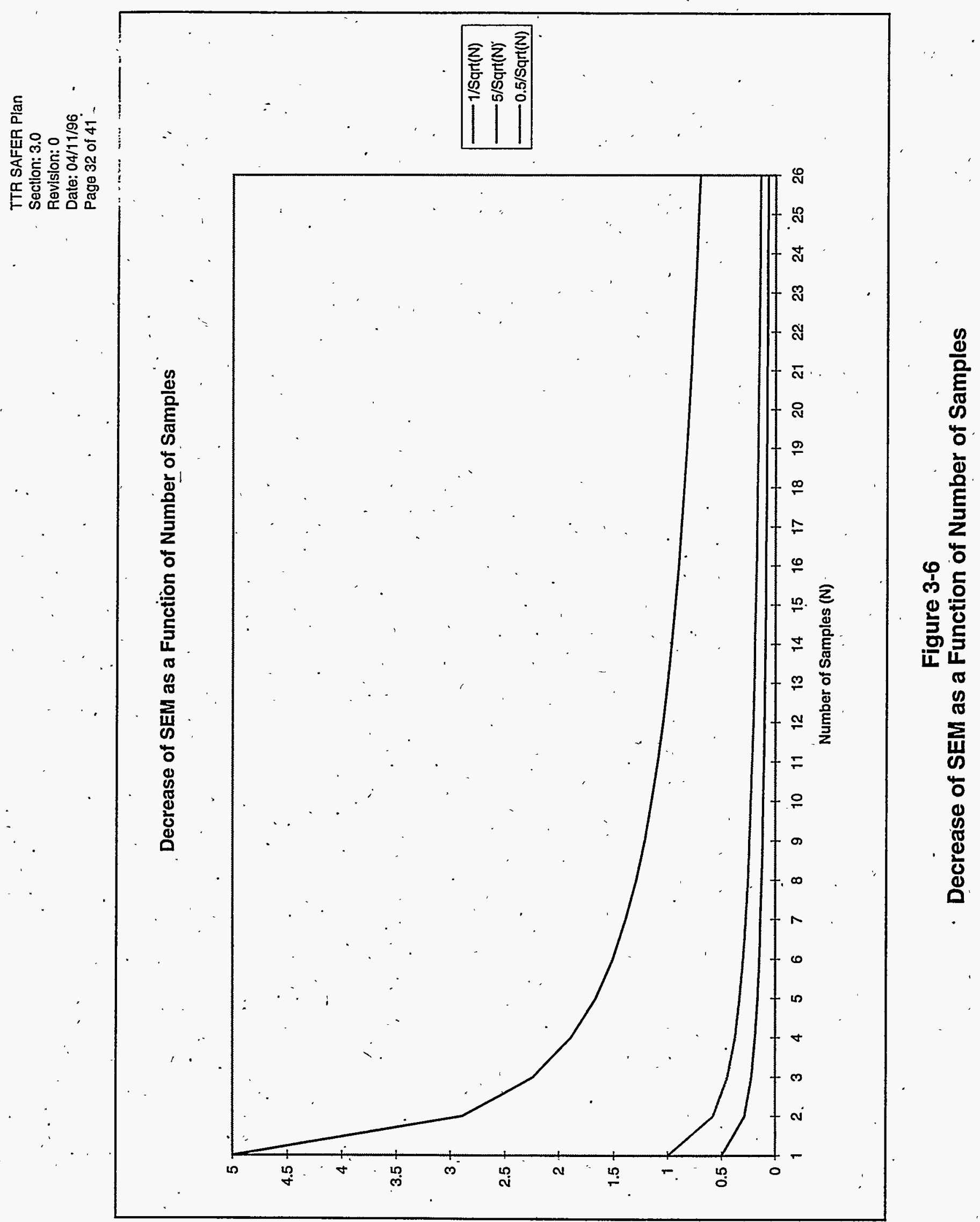


minimizing the standard error of the mean of the background samples and minimizing sampling' and analysis costs.

\subsubsection{Alpha, Beta, and Gamma Radiation Field Surveys}

All soil samples will be screened for alpha, beta, and gamma radiation in accordance with the NV/YMP Radiological Control Manual (DOE, 1994) before being removed from the TTR. The following sections discuss the completed and planned characterization and remedial activities in addition to other planned activities associated with the clean closure of the site.

\subsection{Assessment}

\subsubsection{Bomblet Pit}

All UXO and miscellaneous debris have been removed from the Bomblet Pit or excavated from the anomalies during. UXO removal activities. A visual examination of the Bomblet Pit, anomaly excavations, and UXO processing area; a field magnetometer survey; and a comprehensive review of UXO removal activities documentation were performed as part of prior field activities. The soil within these areas will be sampled and analyzed in accordance with Section 3.2. If the analytical results meet the closure standards, no other RCRA-regulated constituents are found, and concurrence is obtained from NDEP, no further action will be required, and the site can be restored and closed. If additional contamination is detected, additional soil and sampling excavation will be performed as described in Section 3.5. -

\subsubsection{Five Points Landfill}

All UXO, miscellaneous debris, and radioactively-contaminated soil have been removed from the Five Points Landfill. A visual examination of the landfill, field magnetometer and radiation surveys, and a comprehensive review of UXO removal activities information was performed as' part of prior field activities. The soil within the Five Points Landfill will be sampled and analyzed in accordance with Section 3.2. If the analytical results meet the closure standards and NDEP concurrence is obtained, no further action will be required, and the site can be restored and closed. If contamination is detected, additional soil and sampling excavation will be performed as described in Section 3.5. 


\subsection{Remediation}

Soil excavation will be required if the sampling described in Sections 3.4.1:1 and 3.4.1.2 demonstrate contamination. At the Five Points Landfill, an area with a radius of $0.5 \mathrm{~m}(1.5 \mathrm{ft}$ ) around the contaminated sample location will be excavated to a depth of $0.3 \mathrm{~m}(1 \mathrm{ft})$ and resampled directly below the original sample location for analysis. At the Bomblet Pit and UXO processing areas, the soil within the quadrant from which the contaminated sample location is located will be excavated to a depth of $0.3 \mathrm{~m}(1 \mathrm{ft})$ and resampled directly below the original location and analyzed. If the results of the analysis are lower than the closure standards, that area will be considered clean. If the results are greater than the closure standards, additional soil will be excavated as previously described. This process will be repeated as necessary until analyses indicate that the closure standard has been achieved. The site may be restored when the analytical results of all samples collected from the area(s) of contamination are lower than the closure standards.

The excavation process will be performed using a backhoe or other effective means. An openhead drum will be placed on a sheet of plywood covered with polyethylene, sheeting next to the excavation, and the excavated soil will be placed into the drum and shipped off site for proper disposal in accordance with Section 5.0 of this plan. If it is determined that excavation is no - longer practical or cost-effective, work will be stopped; NDEP will be notified as soon as practical; and this plan will be amended (or a new plan written) to encompass subsurface investigation.

\subsection{Site Restoration}

Upon confirmation that the site has metclosure standards and upon receipt of a notice of completion from NDEP, all deep excavations will be refilled with clean fill from existing borrow pits, and shallow excavations will be graded so they are not hazardous to animals. The landscape of the site will be recontoured to grade. Soil erosion at the site will be controlled, if necessary.

Efforts will be made to revegetate the Five Points Landfill. A site survey has been conducted to assess the potential for revegetation; topsoil replacement, and seeding with native plant species.

\subsection{Schedule}

Sampling will begin after the approval of this SAFER Plan by the NDEP. Upon approval of this plan, NDEP will be notified of the scheduled start date of field activities at least 10 working days 
prior to the start of field work. The expected șchedule of completion dates (in working days) is as follows:

- Day 0: : Begin sample collection at the Bomblet Pit and Five Points Landfill.

- Day 10: Complete verification sampling of the Bomblet Pit and Five Points Landfill.

- Day 55: Complete any required excavations and a second round of sampling if required. If not required, confirm site remediations are complete through analytical results and waste removal.

Factors beyond DOE/NV's control, such as weather, classified TTR activities, or delays in receipt of laboratory results, may delay field activities. If such delays oćcur, NDEP will be verbally notified.

Within six months of receipt of validated laboratory results from final field activities, a closure report will be submitted to NDEP as discussed in Section 4.0. 


\subsection{Reports}

Reports during field activities and after completion of the SAFER process will be provided to NDEP by DOE/NV.

Reports of field activities will be provided to NDEP while field activities are ongoing. This will be accomplished through informal fax transmittal of daily field reports. In addition, DOE/NV will verbally inform NDEP as soon as practical of any substantial changes in scope or schedule. If it is determined that this plan requires significant amendments, such as:subsurface investigation of soils underlying the Bomblet Pit or Five Points Landfill, NDEP will be notified as soon as practical; this plan will be amended; and NDEP's concurrence with the modified plan will be solicited.

If clean closure is achieved, within six months of receipt of validated laboratory results from final field activities, DOE/NV will provide a written closure report to the NDEP documenting that closure was completed in accordance with this plan and include all analytical results to verify that clean closure did occur. Both radiological (for the Five Points Landfill) and chemical (for the Bomblet Pit) laboratory analytical results, in addition to waste characterization and

- disposition information, will be included in the closure report. The report will describe the SAFER Plan activities for each unit and request a notice of completion from NDEP. 


\subsection{Waste Management}

All waste generated through the performance of field activities from each of the sites will be managed in accordance with existing Federal and State of Neváda regulations, DOE waste minimization and pollution prevention objectives, waste management programs, and radiological control programs. The waste will be categorized (i.e., as sanitary, low-level, or hazardous waste) through application of process knowledge and/or confirmatory sampling and analysis. Soil shown to be uncontaminated may be returned to the location from which it was excavated.

The absence or removal of radiological constituents will be demonstrated through the use of radiological screening instrumentation such' as a beta-gamma detector ("pancake probe") and an alpha detector as well as laboratory analyses. In addition, swipes will be collected on all sample containers prior to shipment off site for analysis. These swipes will be analyzed using a gasproportional detector for radiological constituents per the Radiological Control Manual (DOE, 1994). Off-site release limits listed in the Radiological Control Manual shall apply. Waste will be determined to be radioactive if sampling and analysis indicate the addition of manmade radioactivity above closure standards as described in Table 3.1. Low-level radioactive waste will be stored at the designated TTR Radioactive Material Area pending disposal at one of the Nevada Test Site's Radioactive Waste Management Sites.

Hazardous waste is defined in Title 40 CFR Part 261. Hazardous waste will be managed in accordance with applicable Federal and State regulations and DOE Order 5400.1, General Environmental Protection Program. Wastes to be disposed off the TTR will be packed in containers that meet all U.S. Department of Transportation criteria for shipment and any additional criteria specified by the receiving disposal site. Hazardous wastes will be disposed of at an off-site commercial, permitted treatment; storage, and disposal facility or recycling facility. Hazardous waste may be shipped to the Nevada Test Site for storage at the permitted Area 5 . Hazardous Waste Storage Site pending shipment to a commercial facility.

Nonrecyclable wastes that are nonhazardous and nonradioactive will be disposed of at the TTR Area 10 Landfill operated by the U.S. Air Force. Generation of mixed, transuranic, high-level, or biological waste is not anticipated. In the event that one of these waste types is generated, work will stop; NDEP will be notified; and this plan will be amended to assure proper waste disposition. 


\subsection{Site-Specific Health and Safety Plans}

The health and safety protocols for the field activities related to the implementation of this SAFER Plan will be delineated in a Site-Specific Health and Safety Plans (SSHASP). This SSHASP, controlled separately from this SAFER Plan, is not included as part of this plan but will available upon request prior to start of field activities. The SSHASP sets forth the specific requirements and procedures that will be followed while performing operations under this SAFER Plan. The SSHASPs includes the following information:

- Engineering and administrative protective measures

- Monitoring for site-specific chemical and radiological contaminants

- Use of Personal protective equipment

- Site control

- Emergency communications

- Emergency reporting protocol

- Decontamination

- Site characterization.

- Training

All field activities will be performed in accordance with the applicable SSHASP. All. field personnel involved in these activities will be familiar with,requirements of the SSHASP. All visitors to the work sites will be required to abide by these procedures.

The objective of the SSHASP is the protection of workers during SAFER Plan activities. This will be accomplished through compliance with DOE Orders, Occupational Safety and Health Administration Regulations, and the DOE/NV NV/YMP Radiological Control Manual DOE, 1994, as well as the SSHASPs. Many of the operations conducted under the DOE/NV ERP are regulated under the DOE Orders and.Title 29 of the Code of Federal Regulations.

Due to unique logistics, hazards, and site conditions, individual groups of sites and/or tasks require the production of a SSHASP. The SSHASP is considered a living document, and as new information becomes available, changes will be made, as appropriate, with concurrence and approval of the Subproject Manager. 


\subsection{Community Relations Plan}

A Public Involvement Plan is being developed for environmental restoration activities at Nevada sites operated by DOE/NV. Under this plan, specific public-involvement activities will be outlined for the Environmental Restoration Project, including the TTR.

Until the Public Involvement Plan is developed, public-participation activities for the Environmental Restoration Project are referenced in the Public Participation Plan for the ERWM Program, Nevada Operations Office (DOE, 1993). Any public-participation activities specifically relating to DOE/NV environmental restoration activities at the TTR will be publicly. announced through press releases and/or newspaper advertisements.

A notice announcing the public availability of this SAFER plan was given out at the January 1996 meeting of the Community Advisory Board for NTS programs. In the notice, the public was invited to comment on the document's contents. A three-week deadline was imposed.

A fact sheet, poster board, and video covering environmental restoration activities at the TTR also has been prepared. These and other public information materials can be obtained by writing to the following address:

U.S. Department of Energy

Nevada Operations Office

Public Affairs Office

P.O. Box 98518

Las Vegas, Nevada 89193-8518 


\subsection{References}

Code of Federal Regulations. 1993. 10 CFR 834, "Radiation Protection of the Public and the Environment;" Proposal Rule. Washington, DC.

Code of Federal Regulations. 1993. 40 CFR'261 and 265, "Protection of the Environment." Washington, DC.

DOE, see U.S. Department of Energy.

EPA, see U.S. Environmental Protection Agenicy.

ERDA, see U.S. Energy Research and Administration.

Gilbert, R. O. 1987. Statistical Methods for Environmental Pollution Monitoring.

New York, NY: Van Norstrand Reinhold.

Hay, R.G. 1991. Lead Content of Nike Exhaust Products. Albuquerque, NM: Sandia National Laboratories.

IT, see IT Corporation.

IT Corporation. 1994. 'Initial Surface Geophysical Survey Report for the Tonopah Test Range Environmental Restoration Sites, DỌE/NV/10972-93, Draft Report. Las Vegas, NV.

IT Corporation. 1996. Barbara Deshler to Art Gravenstein. State of Nevada, Personal Communication, 3 January. Las Vegas, NV.

Karas; P. Sandia National Laboratories. 1993a. Transcript of TTR ER Interview, 28 June.

Karas, P. Sandia National Laboratories. 1993b: Transcript of TTR ER Interview, 6 July.

U.S. Department of Energy. 1988: General Environmental Protection Program Requirements, DOE Order 5400.1. Washington, DC.

U.S: Dèpartment of Energy. 1990. Radiation Protection of the Public and the Environment, DOE Order 5400.5. Washington, DC.

U.S. Department of Energy, Nevada Operations Office. 1992. Tonopah Test Range Tour, 28 April. Las Vegas, NV.

U.S. Department of Energy, Nevada Operations Office. 1993. Public Participation Plan for the ERWM Program. Las Vègas, NV. 
U.S. Department of Energy, Nevada Operations Office. 1994. NV/YMP Radiological Control Manual. Las Vegas, NV.

U.S. Department of Energy, Nevada Operations Office. 1995. Voluntary Corrective Action (VCA) Work Plan for Ordnance Removal from Five Disposal Pits at the Tonopah Test Rangé. Las Vegas, NV.

U.S. Department of Transportation. Environmental Measurements Laboratory Procedure Manual, HASL-300. Washington, DC.

U.S. Energy Research and Development Administration. 1975. Environmental Assessment, Tonopah Test Range, Tonopah, Nevada. Washington, DC.

. U.S. Environmental Protection Agency. 1986. Test Methods for Evaluating Solid Waste, Physical/Chemical Methods, SW-846, 3rd Edition. Washington, DC.

West, G. Sandia National Laboratories. 1993. Personal Communication. 


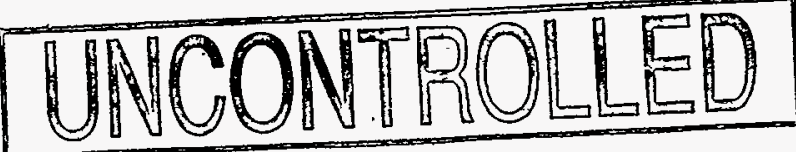

Appendix A

Quality Assurance Project Plan : 


\section{Table of Contents}

List of Figures iii

List of Tables iii

List of Acronyms and Abbreviations iv

A.1.0 Organizations and Responsibilities 1

A.1.1 DOE/NV Environmental Restoration Project Director $\ldots \ldots \ldots \ldots \ldots \ldots \ldots$

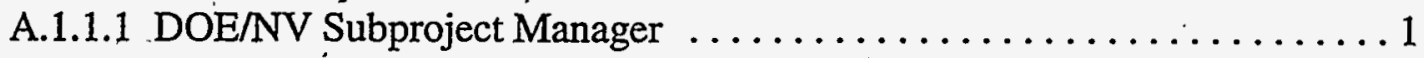

A.1.1.2 DOE $/ \mathbb{N V}$ Quality Assurance Coordinator $\ldots \ldots \ldots \ldots \ldots \ldots \ldots \ldots$

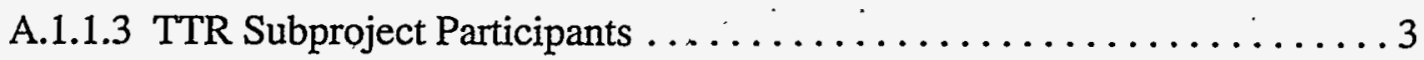

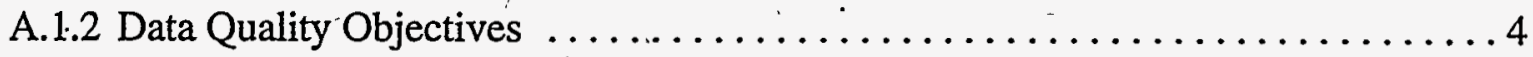

A.1.2:1 Bomblet Pit .......................... 4

A.1.2.2 TTR Five Points Landfill . . . . . . . . . . . . . . . . 6

A.1.3 Quality Assurance Objectives for Measurements $\ldots \ldots \ldots \ldots \ldots \ldots \ldots \ldots . \ldots$

A.1.3.1 Precision $\ldots \ldots \ldots \ldots \ldots \ldots \ldots \ldots \ldots \ldots \ldots \ldots \ldots$

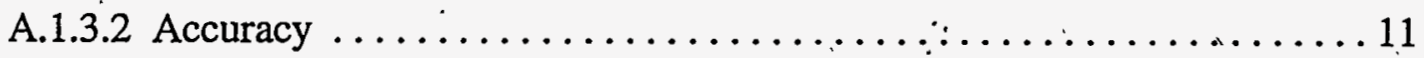

A.1.3.3 Representativeness . . . . . . . . . . . . . . . . . . . . .

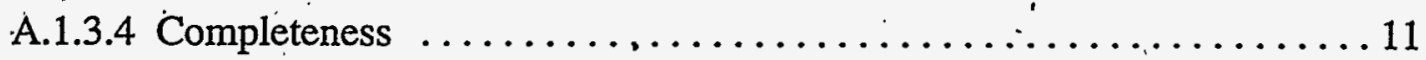

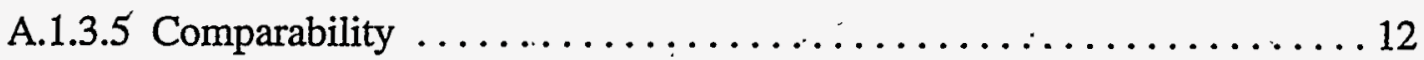

A.1.4 Reports to Management $\therefore \ldots \ldots \ldots \ldots \ldots \ldots \ldots \ldots \ldots \ldots \ldots \ldots \ldots \ldots$

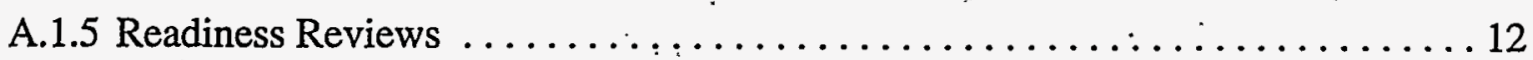

A.1.6 Stop Work Order . . . . . . . . . . . . . . . . . . . . . . 13

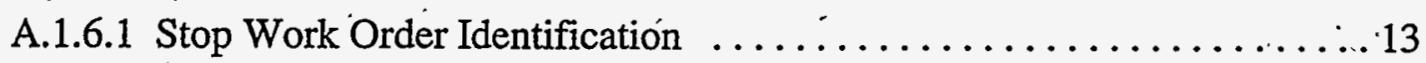

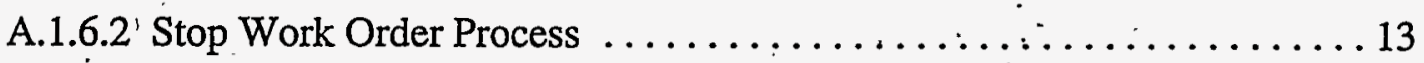

A.2.0 Personnel Training and Qualifications $\because \ldots \ldots \ldots \ldots \ldots \ldots \ldots \ldots \ldots \ldots \ldots$

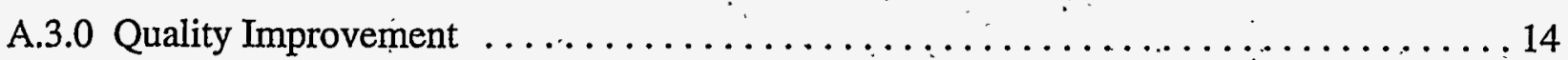

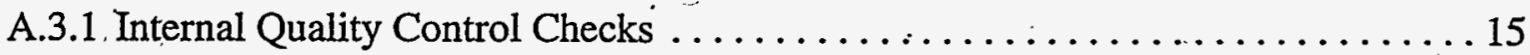

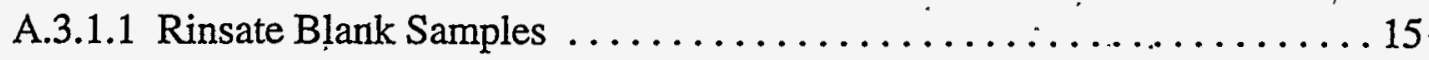

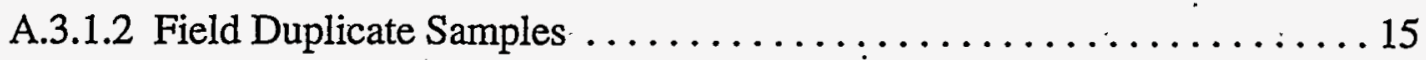

A.3.1.3 Laboratory Quality Control ..................... 15 


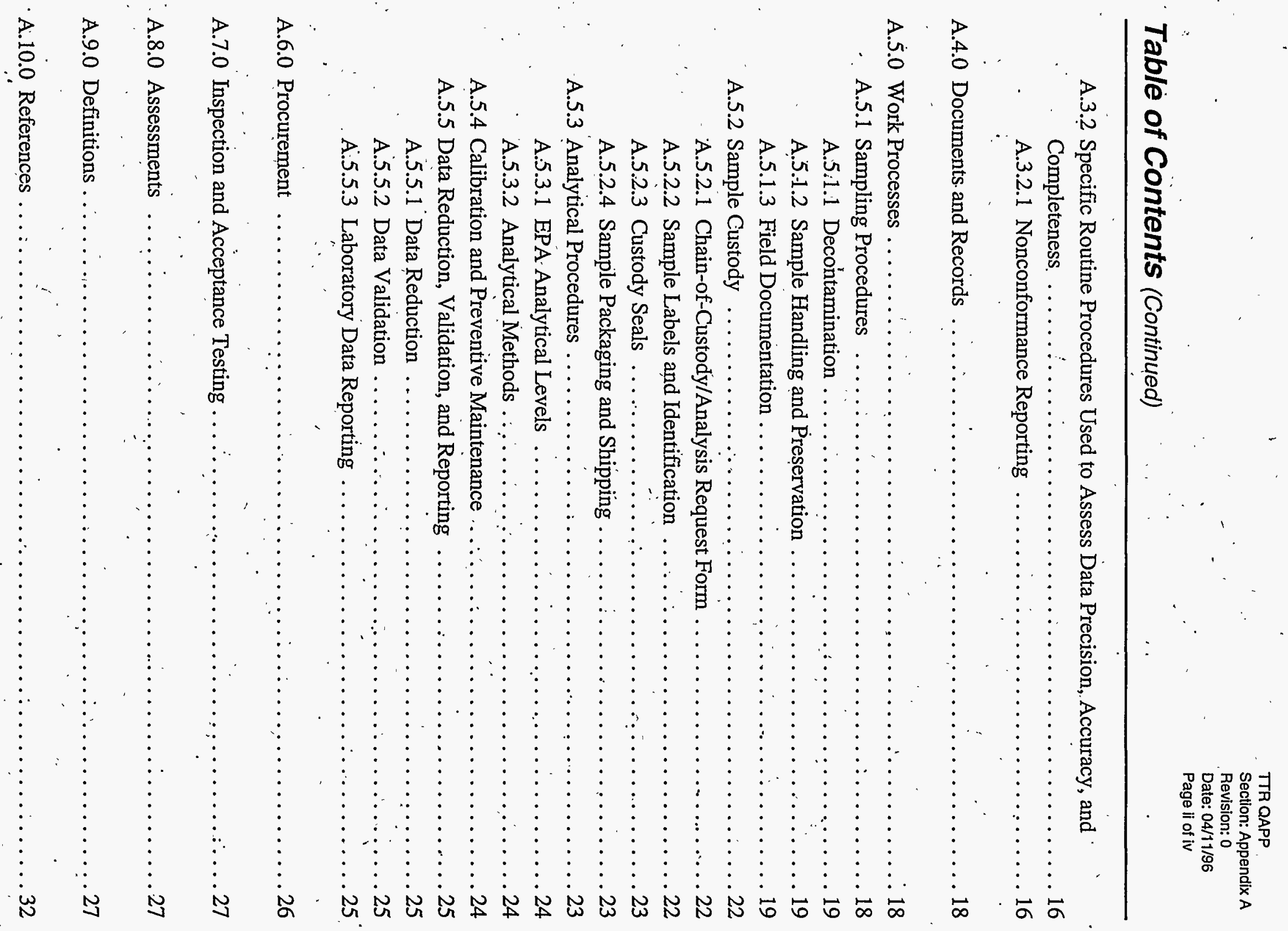




\section{List of Figures}

Number

Title

Page

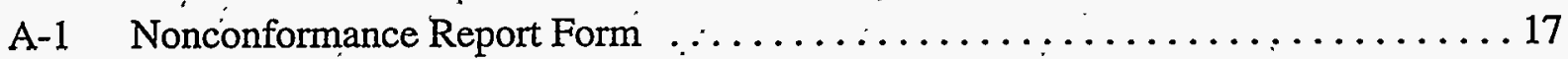

\section{List of Tables}

Number

Title

Page

A-1 Assessment of Analytical Data Quality $\ldots \ldots \ldots \ldots \ldots \ldots \ldots \ldots \ldots \ldots$

A-2 Assessment of Sampling Data Quality $\ldots \ldots \ldots \ldots \ldots \ldots \ldots \ldots \ldots \ldots \ldots \ldots \ldots \ldots \ldots \ldots$

A-3 . Sampling and Laboratory Analytical Protocols $\ldots \ldots \ldots \ldots \ldots \ldots \ldots \ldots \ldots \ldots$ 


\section{Acronyms and Abbreviations}

CDRL Contract required detection limit

CLP

Contract Laboratory Program

COC/AR

Chain-of-custody and analysis request

DOE/NV

U.S. Department of Energy, Nevada Operations Office

DOT

U.S. Department of Transportation

DQO

Data Quality Objective(s)

DU

Depleted uranium

EPA

U.S. Environmental Protection Agency

$\mathrm{H}_{0}$

Null hypothesis .

LCS

M\&TE

Laboratory control sample(s)

NAS:

Measurement and test equipment

NCR

National Acadèmy of Sciences

NIST

Nonconformance Report

PQL

National Institute of Standards and Technology

QA

Practical quantitation limit

QC

Quality Assurance

QAC

Quality Control

QAPP

Quality Assurance Coordinator

RAS

Quality Assurance Project Plan

RCRA .

Routine Analytical Services

$\mathrm{RCW}$

Resource Conservation and Recovery Act

RFI

Revised Code of 'Washington

RPD

RCRA Facility Investigation

SAFER

Relative percent difference

SWO

Streamlined Approach for Environmental Restoration

TCLP

Stop Work Order

TTR

Toxicity Characterization Leaching Procedure

UCL

Tonopah Test Range

UXO

Upper confidence limit

Unexploded ordnance 


\section{Quality Assurance Project Plan}

This Quality Assurance Project Plan (QAPP) has been prepared to supplement the site-specific activities required to accomplish the Streamlined Approach for Environmental Restoration of the TTR Bomblet Pit and.Five Points Landfill (hereafter referred to as SAFER activities). The closure áctivities are site-specific activities being conducted as one portion of the TTR subproject. This plan pertains to all field-investigation, analytical-laboratory, and data-review activities for the TTR subproject and closure of the Bomblet Pit and Five Points Landfill.

This QAPP has been prepared based on guidance from the following U.S. Environmental Protection Agency (EPA) documents: RCRA Facility Investigation (RFI) Guidance (EPA, 1989a) and Data Quality Objectives for Remedial Response Activities (EPA, 1987a). This QAPP includes all of the essential elements of a QAPP, as defined in Interim Guidelines and Specifications for Preparing Quality Assurance Project Plans (EPA, 1983).

\section{A.1.0 Organizations and Responsibilities}

A synopsis of roles and responsibilities of the U.S. Department of Energy, Nevada Operations Office (DOE/NV) and its contractors follows.

\section{A.1.1 DOE/NV Environmental,Restoration Project Director}

The DÓE Environmental Restoration Project Director has technical oversight and management responsibilities for all subprojects within the Environmental Restoration Project. The Environmental Restoration Project Director is the senior management official responsible for ensuring that this QAPP is established and implemented and that opportunities for improvement are identified and incorporated into the activities of the TTR subproject, which include the . closure activities for the Bomblet Pit and Five Points Landfill.

\section{A.1.1.1 DOE/NV Subproject Manager}

The DOE/NV Subproject Manager reports directly to and is the prime point of contact with the DOE/NV Ėnvironmental Restoration Project Director. The DOE/NV Subproject Manager has day-to-day mạnagement responsibilities for technical, financial, and scheduling issues. The DOE/NV Subproject Manager shall monitor contractor performance and manage subproject 
activities. At a minimum, the DOE/NV. Subproject Manager shall be responsible for the following tasks:

- Review, approve, and verify the implementation of subproject plans.

- Participate in the organization and planning of activities in order to consistently meet project quality objectives.

- Disseminate pertinent information from DOE/NV to subproject participants.

Review and approve variances to subproject documents.

- Notify the Environmental Restoration Project Director, the DOE/NV Quality Assurance Coordinator (QAC), and other involved personnel of significant conditions adverse to quality or any identified trends.

- Monitor the quality-achieving activities of participating organizations and provide direction and guidance for improvement.

- Perform audits and surveillances to verify compliance with applicable requirements.

\section{A.1.1:2 DÒE/NV Quality Assurance Coordinator}

The DOE/NV QAC reports to the Environmental Restoration Project Director and has a direct line of communication with the DOE/NV Subproject Manager. The DOE/NV. QAC is responsible for assisting subproject management in the development, verification, and implementation of this QAPP and will provide the overall direction of the Quality Assurance (QA) function. At a minimum, the DOE/NV QAC shall have the following responsibilities:

- Identify and respond to QA/Quality Control (Q̀C) needs, resolve problems, and provide guidance or assistance.

- Review and evaluate quality-related changes to the work, closure, and sampling plans; the QAPP; and other documents that contain QA criteria.

- Verify that appropriate corrective actions are taken for nonconformances.

- Notify the Environmental Restoration Project Director, the DOE/NV Subproject Manager, and other involved personnel of significant conditions adverse to quality or any adverse trends. 


\section{A.1.1.3 TTR Subproject Participants}

All participants in the TTR subproject are responsible for developing procedures and for ensuring that all work is performed in accordance with applicable federal, state, local; and DOE/NV regulations; this QAPP; and approved subproject plans and procedures. To fulfill responsibilities specific to QA, the subproject participants shall, at a minimum, be tasked with these duties:

- Report to the DOE/NV Subproject Manager on schedule, cost, technical execution, and quality achievement of task order activities.

- Ensure that proper resources and budget are provided for QA personnel, and ensure that QA activities are integrated into subproject activities.

- Evaluate task order activities to ensure that planning document requirements.are implemented.

- Develop and implement procedures and instructions that govern TTR subproject activities.

- Ensure that work is technically sound, of acceptable quality, and consistent with subproject objectives.

- Evaluate the qualifications of personnel; identify and provide additional training, as needed.

- Ensure that personnel are trained and qualified to consistently achieye initial proficiency, maintain their proficiency, and adapt to changes in technology, methods, or job responsibilities.

- Provide orientation and any necessary activity-specific training to field personnel about the requirements of this QAPP and other subproject plans prior to the start of work. .

- ' Perform audits and surveillances to verify compliance with applicable requirements.

- Identify deficient areas, and implement effective corrective actions for quality problems.

- Notify the DOE/NV Subproject Mánager and other involved personnel of significant conditions adverse to quality or any adverse trends.

- Verify that appropriate corrective actions are taken for nonconformances.

- Track and trend nonconformances for conditions adverse to quality. 
- Ensure that all measurement and test equipment (M\&TE) is calibrated and that calibration is documented prior to use.

- Establish and maintain a records management system.

\section{A.1.2 Data Quality Objectives}

The data quality objectives (DQO) process (EPA, 1994) is a systematic planning tool.for establishing criteriá for data quality and for developing data collection designs. It is a seven-step process which results in a design to collect the right type, quality, and number of data needed to support an environmental decision. The DQO process has been applied to proposed corrective action at the TTR Bomblet Pit and the Five Points landfill. Each site will be discussed separately.

\section{A.1.2.1 Bomblet Pit}

\section{Step 1: State the Problem}

The Bomblet Pit at the TTR was used for the disposal of unexploded ordnance (UXO) which was collected and:detonated under controlled conditions. The site is now to be closed.

\section{Step 2: Identify the Decision}

This SAFER plan is designed to characterize and, if necessary, remediate the site so that it can be closied under clèan-closure status. The data collected must be acceptable to support clean closure of the site.

\section{Step 3: Identify the Inputs to the Decision}

Complete detonation of UXO should have resulted in the production of carbon dioxide, water, and nitrogen dioxide only. These gaseous products dissipated during the detonation process. Incomplete detonation of UXO may have resulted in the generation of certain. nitroaromatics or nitramines that may remain in the soil or be present in the waste piles. The concentration of these partial detonation products will be a factor in the decision to close the site under cleanclosure standards.

In addition to UXO, fuzes used in the processing of bomblets contained various combinations of detonatable chromium, lead, or mercury compounds. All three of these metals are RCRAregulated as toxic constituents, and the Toxicity Characterization Leaching Procedure (TCLP) levels of these and other TCLP metals will provide further input to the clean-closure decision. 


\section{Step 4: Define the Study Boundaries}

The temporal boundary of the study will be the time at which the SAFER plan is implemented. No follow-up study. of the site is planned. The spatial boundaries of the study will include the six areas of concern discussed in Section 3.3.1.1 of this SAFER plan: the bomblet pit itself, the two bomblet processing areas, the large UXO processing area, and two soil stockpiles. A separate clear-closure decision will be made for each spatial area.

\section{Step 5: Develop' a Decision Rule}

The decision rules for each constituent of concern at the Bomblet:Pit are given in Table 3-1 of this Corrective Action Plan. The $90 \%$ upper confidence limit (UCL) of each parameter will be compared to the mean background level of that parameter (established by a background sampling process described in Section 3.3.1.3). The area will only be declared to be clean if the UCL is less than the mean background level for that parameter. If not, remediation will continue until resampling demonstrates the site is clean.

Note that the null hypothesis $\left(\mathrm{H}_{0}\right)$ for each parameter is that "the UCL is" greater than the action level (mean background level)," $\mathrm{i}$.e., the site is dirty. . Only if statistically, valid results prove that the UCL is less. than the action level will the site be considered "clean." Thus, the burden of proof is on the data to demonstrate that the site is clean.

\section{Step 6: Specify Limits on the Decision Errors}

There are two types of decision errors possible in conducting the SAFER process for the Bomblet Pit site. These errors are described as a Type I error ("false positive," judging a clean area to be dirty, referred to by statisticians as the "confidence level" or $1-\alpha$ ) and a Type II error ("false negative," judging a dirty area to be clean, referred to by statisticians as the "power" or 1- $\beta$ ). This SAFER plan is designed to minimize both types of errors.

For a planned removal or remedial response operation involving potentially contaminated soil, Type I and Type II errors are of about equal significance and are usually established at 90-95\% (EPA, 1989b): For the purposes of this SAFER plan, the confidence level and power will both be assigned at $90 \%$. 


\section{Step 7: Optimize the Design for Obtaining Data}

Based upon the considerations previously discussed, the sampling and analysis plan for the Bomblet Pit is presented in Section 3.3.1.1 of this SAFER plan.

\section{A.1.2.2 TTR Five Points Landfill}

\section{Step 1: State the Problem}

The Five Points Landfill was used for the disposal of solid waste at TTR. The site is now to be closed.

\section{Step 2: Identify the Decision}

"This SAFER plan is designed to remediate the site so that it can be closed under clean-closure status. The data collected must adequately support clean closure of the site.

\section{Step 3: Identify the Inputs to the Decision}

The Five Points Landfill was used as a disposal pit for ordnance and solid debris gathered during range cleanup operations. All ordinance was removed during the first phase of corrective action; none were detonated in the Five Points Landfill. Ordnance byproducts (nitroaromatics, nitramines, chromium, lead, and mercury) are not constituents of concern at the, Five Points Landfill.

Radiological contamination was found around several bullet holes which had been fired into corrugated metal structures previously removed from the landfill. It is believed that depleted uranium (DU) bullets had been shot into the structures. Because of the presence of radiological contamination in these structures and the potential of such contamination in the landfill soil, the levels of uranium 234/235, uranium 238 , plutonium 239 , and gamma-emitting isotopes at this site will provide data for input into the clean-closure decision.

\section{Step 4: Define the Study Boundaries .}

The temporal boundary of the study will be the time at which the SAFER plan is implemented. No follow-up study of the site is planned. The spatial boundary of the study will be the boundary of the open trench which formerly contained the metallic debris. There are no additional areas of concern at the Five Points Landfill. 


\section{Step 5: Develop a Decision Rule}

The decision rules for each constituent of concern at the Five Points Landfill are given in Table 3-1 of this corrective action plan. The 90\% upper confidence limit of each parameter will be compared to the mean background level of that parameter (established by a background sampling process described in Section 3.2.1.3): Only if the UCL is less than the mean background level for that parameter will the area be declared clean. If not, remediation will continue until resampling demonstrates the site as being clean.

Note that the $\mathrm{H}_{0}$ for each parameter is that "the UCL is greater than the action level (mean background level);" i.e., the site is dirty. Only if the statistically valid results prove that the UCL is less than the action level will the site be considered "clean." Thus the burden of proof is' on the data to demonstrate that the site is clean.

\section{Step 6: Specify Limits on the Decision Errors}

There are two types of decision errors possible in conducting the SAFER process for the Five Points Landfill site. These errors are described as a Type I error ("false positive," judging a clean, area to be dirty, referred to by statisticians as the "confidence level" or 1- $\alpha$ ) and a Type II error ("false negative," judging a dirty area to be clean, referred to by statisticians as the "power," or $1-\beta)$. This SAFER plan is designed to minimize both types of errors.

For a planned removal or remedial response operation involving potentially contaminated soil, Type I and Type II errors are of àbout equal significance and are usually established at 90-95\% (EPA, 1989b). For the purposes of this SAFER plan, the confidence level and power will both be assigned at $90 \%$.

\section{Step 7: Optimize the Design for Obtaining Data}

'Given the considerations previously discussed, the sampling and analysis plan for the Five Points Landfill is presented in Section 3.3.1.2 of this SAFER plan.

Based upon these data quality objectives, specific quality assurance objectives for measurements are described in the next section of this QAPP. 


\section{A.1.3 Quality Assurance Objectives for Measurements}

Quality assurance objectives are qualitative and quantitative statements that specify the quality of data required to support subproject objectives. The overall objective of the closure activities is to collect accurate and defensible data to support clean closure of the Bomblet Pit and Five.Points Landfill. The indicators of data quality, as related to sampling and laboratory analysis, include precision, accuracy, representativeness, completeness and comparability. The values selected for these data quality indicators are based on requirements for the field sampling and laboratory analytical programs and analytical data reporting. Specific QA objectives are discussed in detail in the following sections and in Tables A-1 and A-2. .

\section{A.1.3.1 Precision}

Precision is a quantitative measure of the variability of a group of measurements from their average value. Precision measures the reproducibility of measurements under a given set of conditions (EPA, 1987a). Precision shall be assessed by collecting and analyzing duplicate field samples and then by creating and analyzing laboratory duplicates from one or more field samples. Precision shall be reported as relative percent difference (RPD). The RPD is calculated as the difference between the measured concentrations of Sample 1 and Sample 2, divided by the average of the two concentrations, and multiplied by 100 .

Overall measurement precision is determined from the analytical results of duplicate field samples. Analytical results for laboratory dupplicates provide a measure of analytical precision. The difference between measurement and analytical precision defines sampling precision.

Precision goals have been standardized for analytical laboratories under the EPA Contract Laboratory Program (CLP) (EPA, 1987b). The historical precision of CLP Routine Aralytical Services (RAS) methods has been determined from laboratory spike and quarterly blind performance evaluation samples. The precision goals for each parameter are either \pm 20 - or 25-percent relative deviation from the average value, depending upon the parameter. Variations between field duplicates should not exceed these limits. Values outside these limits may trigger corrective actions.

Subsample precision of less than or equal to \pm 20 percent is difficult to obtain for soils and waste due to inherent heterogeneities of these media and may not require corrective action measures in accordance with this QAPP as determined by the DOE/NV Subproject Manager. 
Table A-1

Assessment of Analytical Data Quality

\begin{tabular}{|c|c|c|c|}
\hline Parameter & $\begin{array}{c}\text { Minimum } \\
\text { Requirement(s) }\end{array}$ & $\begin{array}{c}\text { Impact(s) of Failure to } \\
\text { Meet Objectives }\end{array}$ & Corrective Action(s) \\
\hline Completeness & $80 \%$ & $\begin{array}{l}\text { Incomplete content and site } \\
\text { characterization. } \\
\qquad .\end{array}$ & $\begin{array}{l}\text { Determine whether the } \\
\text { missing data are needed. } \\
\text { Can remaining sample } \\
\text { volumes be used or do } \\
\text { they need to be } \\
\text { resampled? }\end{array}$ \\
\hline Comparability & $\begin{array}{l}\text { Equivalent samples } \\
\text { analyzed as per the } \\
\text { SAFER Plan; same } \\
\text { analytical methods and } \\
\text { same units of } \\
\text { measurement and } \\
\text { detection limits must be } \\
\text { used for like analyses. }\end{array}$ & Increase in overall error. & $\begin{array}{l}\text { Implement comparable } \\
\text { analytical techniques or } \\
\text { change laboratories. } \\
\therefore \\
\therefore\end{array}$ \\
\hline Representativeness & $\begin{array}{l}\text { Sample preparation } \\
\text { requirements as per the } \\
\text { SAFER Plan that will } \\
\text { not introduce a bias. } \\
\end{array}$ & $\begin{array}{l}\text { Inaccurate identification or } \\
\text { estimate of concentration of } \\
\text { contaminant. Insufficient } \\
\text { data to make decision(s). }\end{array}$ & $\begin{array}{l}\text { Reanalyze, resample, or } \\
\text { document site areas that } \\
\text { are poorly characterized. }\end{array}$ \\
\hline Precision & $\begin{array}{l}\text { Laboratory duplicates } \\
\text { and/or matrix } \\
\text { spike/matrix spike } \\
\text { duplicate per analytical } \\
\text { batch on required } \\
\text { samples. Variation } \\
\text { between duplicates } \\
\text { shall not exceed } 20 \% \\
\text { rélative deviation from } \\
\text { the average value. } \\
\end{array}$ & $\begin{array}{l}\text { Increased variability in data } \\
\text { can cause loss of } \\
\text { completeness which } \\
\text { diminishes } \\
\text { representativeness so that } \\
\text { laboratory QA objectives } \\
\text { cannot be satisfied. }\end{array}$ & $\begin{array}{l}\text { Reanalyze, resample, } \\
\text { review laboratory } \\
\text { protocols, or use a } \\
\text { different analytical } \\
\text { technique. }\end{array}$ \\
\hline Accuracy & $\begin{array}{l}\text { Laboratory spikes within } \\
\text { quality control criteria } \\
\text { as specified in the } \\
\text { analytical method. } \\
\text { Laboratory method } \\
\text { blanks below required } \\
\text { detection limit. }\end{array}$ & $\begin{array}{l}\text { Decrease in reliability can } \\
\text { cause loss of completeness } \\
\text { which diminishes } \\
\text { representativeness so that } \\
\text { laboratory QA objectives } \\
\text { cannot be satisfied. }\end{array}$ & $\begin{array}{l}\text { Reanalyze or use different } \\
\text { analytical approach. } \\
\end{array}$ \\
\hline
\end{tabular}


Table A-2

Assessment of Sampling Data Quality

\begin{tabular}{|c|c|c|c|c|}
\hline \multicolumn{2}{|c|}{ Parameter } & $\begin{array}{c}\text { Minimum } \\
\text { Requirement(s) }\end{array}$ & $\begin{array}{l}\text { Impact(s) of Failure to } \\
\text { Meet Objectives }\end{array}$ & Corrective Action \\
\hline Completen & less & $80 \%$ & $\begin{array}{l}\text { Lack of complete content } \\
\text { and site characterization. }\end{array}$ & $\begin{array}{l}\text { Resample or provide } \\
\text { additional analysis of } \\
\text { samples at laboratory to. } \\
\text { complete data set for lost } \\
\text { samples. }\end{array}$ \\
\hline Comparabi & & $\begin{array}{l}\text { All samples are collected } \\
\text { as per the SAFER Plan. } \\
\text { Procedures shall be } \\
\text { followed to ensure } \\
\text { comparability of sample } \\
\text { collection. }\end{array}$ & $\begin{array}{l}\text { Reduction in data } \\
\text { confidence and ability to } \\
\text { detect data anomalies. }\end{array}$ & $\begin{array}{l}\text { Redesign sample } \\
\text { collection methods } \\
\text { and/or add more samples } \\
\text { to increase confidence. }\end{array}$ \\
\hline Represent & ativeness & $\begin{array}{l}\text { Sufficient numbers of } \\
\text { samples muist be } \\
\text { collected. Samples must } \\
\text { be representative of the } \\
\text { potentially contaminated } \\
\text { medium. Sample } \\
\text { collection must not alter } \\
\text { sample. }\end{array}$ & $\begin{array}{l}\text { Generation of false } \\
\text { negative data. } \\
\text { Data biased either high or } \\
\text { low for contaminant } \\
\text { concentration. }\end{array}$ & $\begin{array}{l}\text { Additional sampling } \\
\text { required. } \\
\text { Redesign sample } \\
\text { collection methods. }\end{array}$ \\
\hline Precision & $\therefore$ & $\begin{array}{l}\text { At least } 5 \text { percent of } \\
\text { samples, with not less } \\
\text { than one duplicate per } \\
\text { sample group. For water } \\
\text { samples, variations } \\
\text { between field duplicates } \\
\text { should not exceed } 20 \% \\
\text { relative deviation from } \\
\text { the average value. }\end{array}$ & $\begin{array}{l}\text { Unacceptable levels of } \\
\text { uncertainty. } \\
\text { Erroneous final } \\
\text { decision(s). }\end{array}$ & $\begin{array}{l}\text { Resample or add more } \\
\text { samples. } \\
\text { Adjust performance } \\
\text { objectives. }\end{array}$ \\
\hline Accuracy & . & $\begin{array}{l}\text { Adequate documentation } \\
\text { that every validated } \\
\text { datum is traceable to a } \\
\text { specific location in the } \\
\text { prescribed sequence. } \\
\text { Sample spikes within } \\
\text { quality control criteria as } \\
\text { specified in the analytical } \\
\text { method (may reflect } \\
\text { matrix-induced bias). } \\
\text { Trip, rinsate, and } \\
\text { equipment blanks below } \\
\text { required detection limit. }\end{array}$ & $\begin{array}{l}\text { Loss of } \\
\text { representativeness and } \\
\text { possible invalidation of all } \\
\text { project data. }\end{array}$ & Resample. \\
\hline
\end{tabular}




\section{A.1.3.2 Accuracy}

Analytical accuracy is defined as the nearness of a measurement to the true or accepted reference value. It is the composite of the random and systematic components of the measurement system and measures bias in that measurement system. The random component of accuracy shall be measured and documented through the analyses of spiked samples. Sampling accuracy shall be assessed by evaluating the results of field or trip blanks and laboratory control samples. Matrixspike samples shall be analyzed for metal analytes, and surrogate-spike samples shall be analyzed for organic analytes. Accuracy measurements for spike samples and laboratory. control samples shall be calculated as percent recovery; which is calculated by dividing the measured sample concentration by the true concentration and multiplying the quotient by 100 . The percent ${ }^{\circ}$. recovery shall be within the limits specified in the analytical method.

Field accuracy shall be assessed by confirming that the documents of record track the sample from its origin through transfer of custody to its disposal. The goal of field äccuracy is that all samples be collected from the right locations at the right time and then placed in a correctly labeled container with the correct preșervative and sealed with custody tape to prevent tampering.

\section{A.1.3.3 Representativeness}

Representativeness expresses the degree to which sample data accurately and precisely represent a characteristic of a population, parameter variations at a sampling point, or an environmental condition (EPA; 1987b). Sample representativeness shall be achieved through the implementation of a sampling program designed to ensure proper sampling locations and number and the use of validated analytical methods. Representativeness shall be assessed by the collection and analysis of duplicate samples.

\section{A.1.3.4 Completeness}

Completeness is defined as a measure of the amount of usable, valid data obtained from a measurement system compared to the amount that was expected under correct, normal conditions. Completeness is affected by unexpected conditions that may occur during the data collection process. Completeness shall be determined by comparison of the number of samples. planned to be collected to the number of samples for which acceptable analytical results are received. Sample data completeness shall be achieved through quality sampling practices and standard analytical techniques that have been demonstrated to be 80 to $85 \%$ complete on a nationwide basis (EPA, 1987b). A completeness objective is set at $80 \%$. 


\section{A.1.3.5 Comparability.}

Comparability is a qualitative parameter expressing the confidence with which one data set can be compared to another (EPA, 1987b). Standardization of the sampling approach and analytical methods should result in comparability of data. To ensure comparability, all field and laboratory activities shall be performed and documented in accordance with approved procedures.

\section{A.1.4 Reports to Management}

Laboratory and field management shall be aware of subproject activities, as applicable, and shall participate in the development, review, and operation of the subproject. Management shall be informed of quality-related activities through the receipt, review, and/or approval of the following:

- Subproject- or site-specific QA plans and procedures

- Corrective action and schedules

- Corrective action requests

- Nonconformance reports

- Surveillance reports

\section{A:1.5 Readineșs Reviews}

Readiness reviews shall verify that all planining documents and systems are in place for the successful and efficient accomplishment of the mission.

Readiness reviews shall be performed prior to the start of any major scheduled activity and prior to restarting work following Stop.Work Orders (SWOs) to verify and document that subproject planning and prerequisites have been satisfactorily completed. These reviews shall include subproject management, health and safety, and QA personnel. At a minimum, readiness reviews shall verify that:

- The scope of work.is compatible with subproject objectives

- The planned work is appropriate to meet objectives

- Work instructions have been reviewed for adequacy and appropriateness, formally approved, and issued to personnel who will be performing the work

- Proper resources (e.g., personnel, equipment, and materials) have been identified and are available 
- Assigned personnel have read the applicable work instructions and have been trained and qualified

- Internal and external interfaces have been defined

- Proper work authorizations and permits have been obtained

- The calibration of all M\&TE is current

\section{A.1.6 Stop Work Order}

A SWO shall be initiated when a condition adverse to quality is identified that, if allowed to . continue, would result in personal injury, damage to DOE equipment or property, or have an adverse impact on mission accomplishment, budget, or schedule. If imminent danger exists, a SWO may be verbally imposed. A SWO may be limited to a specific activity, item, or design, or. it may be broad in scope and encompass all activities relating to the deficiency or violation.

\section{A.1.6.1 Stop Work Order Identification}

All individuals are empowered with the authority to stop work when continuing work may result in the following:

- Failure to adequately control the processing, delivery, installation, modification, or operation of a nonconforming item

- Serious failure or breakdown of the QA program

- Significant hazard to those items or activities that are important to health and safety, the environment, or the mission of the project.

Resumption of work shall begin only upon completion of the necessary actions specified on the SWO and approval of the DOE/NV Subproject Manager.

\section{A.1.6:2 Stop Work Order Process}

In accordance with DOE/NV Order $5700.6 \mathrm{C}$, all project participants shall develop and implement procedures governing SWOs. These procedures shall clearly delineate the reporting responsibilities and lines of communication. At a minimum, the procedures shall include:

- Immediate verbal notification to the supervisor or manager of the responsible organization of the intent to issue a SWO 
- Verbal notification to DOE and contractor subproject management when a SWO has been verbally imposed

- A written SWO isșued to the responsible organization.

\section{A.2.0 Personnel Training and Qualifications}

Contractor subproject management shall ensure that personnel are qualified and knowledgeable in the activities they perform. All TTR subproject participants shall be responsible for maintaining personnel qualification and training records as quality documents.

\section{Project Personnel}

Personnel assigned to the TTR subproject shall be trained and qualified to perform the tasks to which they are assigned. Objective evidence of qualifications may include academic credentials, personal resumes, registrations and/or certifications, licenses, and training records. Any additional training needs shall be identified, provided, and documented.'

. Contractor subproject management shall be responsible for providing personnel with the instructions necessary to perform quality-related activities. Training may take the form of orientation and/or indoctrination, formal classroom training, or on-the-job training. On-the-job training shall be connducted and documented by.personnel qualified to perform the task. Any work performed by a trainee shall be under the supervision of a qualified individual.

\section{Analytical Labóratory Personnel}

Each analytical laboratory shall establish job descriptions for positions affecting data quality. These descriptions shall provide the minimum qualifications in terms of education, experience, and skills necessary for an analyst to carry out duties in the laboratory. Objective evidence of an individual's qualifications may include academic credentials, personal resumes, certifications, qualifying analytical test rèsults, and training records.

\section{A.3.0 Quality Improvement,}

Processes shall be established that prevent, as well as detect and correct, problems that adversely affect quality during all phases of technical and management activities. Personnel at all levels 
are encouraged to identify process improvement opportunities and problems and offer solutions to those problems. The following sections identify processes that, at a minimum, shall be implemented.

\section{A.3.1 Internal Quality Control Checks}

Field and laboratory investigation activities shall include the collection and analysis of QC samples to determine whether data generated meet the Data Quality Objectives of the subproject. These samples shail be introduced into the analytical process in order to assess the overall quality of the sampling and analysis program. This section describes the QC samples that will be generated.

\section{A.3.1.1 Rinsate Blank Samples}

One rinsate blank sample shall be collected for every decontamination process and analyzed to assess the overall cleanliness of the sampling system and the effectiveness of sampling equipment decontamination procedures. Rinsate blanks shall be analyzed in the same manner as the environmental samples.

\section{A.3.1.2 Field Duplicate Samples}

One field duplicate sample shall be collected for every 20 samples collected and analyzed to assess sample-variability. If fewer than 20 samples are collected, one duplicate sample shall be collected for the sample group. For soil or waste matrices; field duplicates are more a measure of inherent heterogeneity; therefore, field duplicates shall not be used for the rejection of data in the data validation process. A unique sample number shall be assigned to the duplicate sample. The duplicate sample number shall not indicate that it is a QC sample to minimize handling, analysis, and data-evaluation bias. Parameters to be analyzed shall be the same as those analyzed for the corresponding environmental samples.

\section{A.3.1.3 Laboratory Quality Control}

Each analytical laboratory shall generate QC samples during each analytical run to assess and document accuracy and precision associated with each analytical measurement. All data from concurrently analyzed laboratory control samples used to demonstrate analytical control shall be included in the analytical report. The requirements for the types and number of laboratory QC samples include laboratory control sámples (LCS), method blanks, surrogate-spike, matrix-spike, and matrix-spike duplicate samples. 


\section{A.3.2 Specific Routine Procedures Used to. Assess Data Precision, Accuracy, and Completeness}

Quality control sample results shall be used to evaluate laboratory and field precision and accuracy. Sample results falling outside acceptable ranges for precision and accuracy shall be brought to the attention of laboratory management for evaluation and corrective action(s), as needed. Completeness shall be determined by comparison of the number of samples expected to be collected to those samples for which acceptable analytical results are received. An objective of $80 \%$ completeness or greater has been set for the TTR subproject.

Laboratory results shall be checked upon receipt. If there appears to be an error in the analysis, the laboratory shall be contacted immediately. If investigation reveals that processes were not in control, corrective action(s) shall be taken.

\section{A.3.2.1 Nonconformance Reporting}

Field participants shall implement approved procedures that are in compliance with DOE/NV requirements for the identification, documentation, and resolution of nonconforming conditions. Field nonconformances for this subproject shall be reported in accordance with DOE/NV Orders, using the approved DOE/NV Nonconformance Report (NCR) form (Figure A-1). The laboratory may use internal forms, providing the forms include the required components listed below. All NCRs shall be processed in accordance with internal procedures. An NCR shall specify the following:

- Originator

- Date of the nonconformance

- NCR number (serialized)

- Responsible organization

- Requirement(s)

- Nature of the nonconformance

- Disposition

- Technical justification

- Approximate cost to implement the disposition

Copies of all NCRs and any related documents and/or correspondence shall be transmitted to an organization's. internal QA department or representative. 


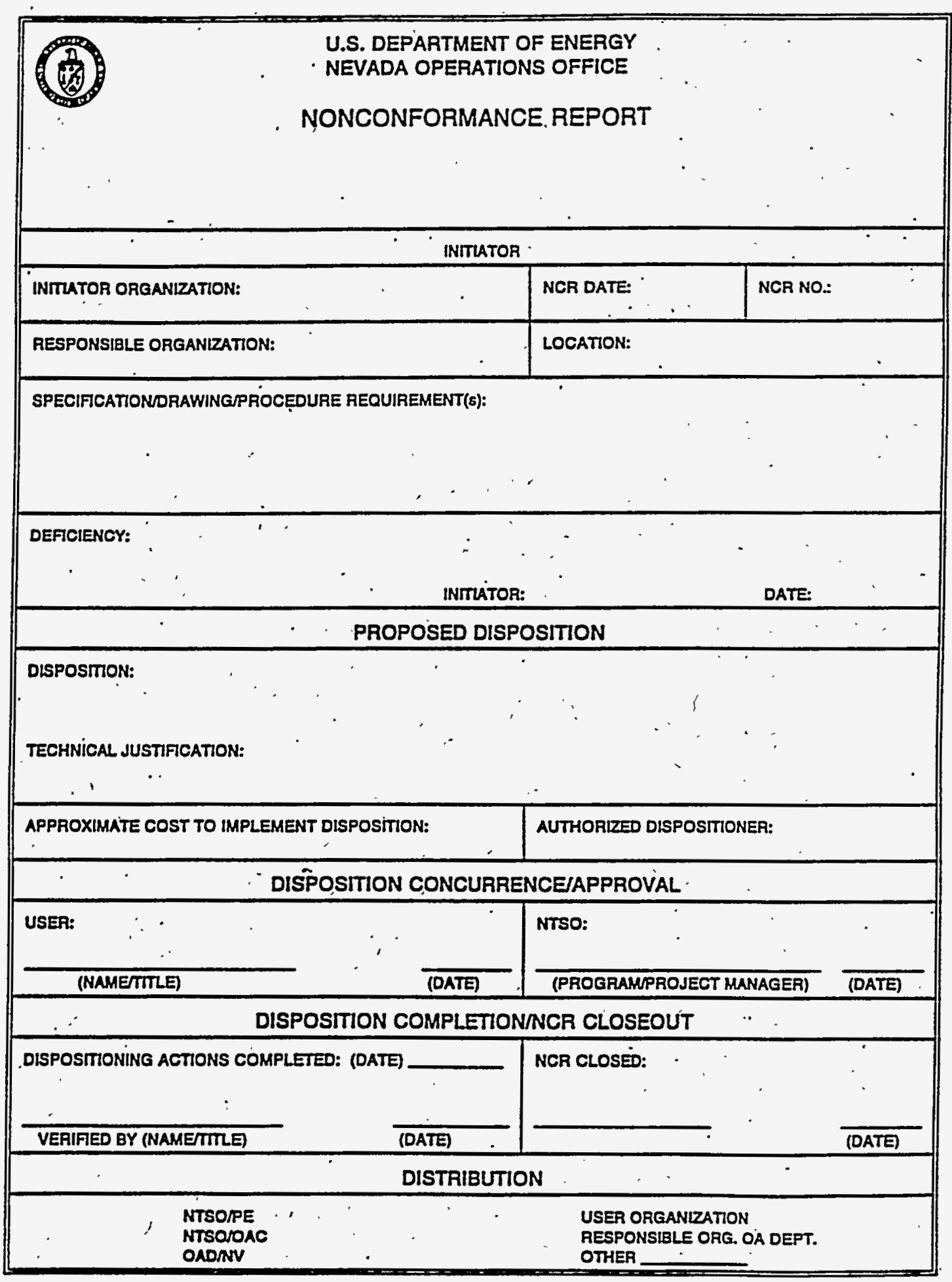




\section{A.4.0 Documents and Records}

The TTR subproject documentation and data reports shall be complete and accurate to the extent that their use in a decision-making procèss can be legally defended. The maintenance of records shall include provisions for retention, protection, preservation, traceability, accountability, and retrievability. Records shall be maintained in accordance with DOE Order 1324.2A, Records Disposition.

\section{A.5.0 Work Processes}

All activities shall be performed in accordance with approved plans and procedures. Contractor-" specific procedures shall comply with all applicable requirements of DOE Orders, Standard Operating Procedures, and subproject planning documents. All deviations from approved subproject plans and procedures shall be documented and approved by the parties authorizing the original plan or procedure.

\section{A.5.1 Sampling Procedures}

All sampling activities shall follow the same general sampling protocol. Details of specific environmental data-collection activities are discussed in the Closure Plan and in contractorspecific procedures. Sampling considerations include the following:

- Rationale for the selection of sample locations, depths, and number of-stations to ensure : that representative samples are collected

- Rationale for the selection of analytical parameters

- Field measurements to be preformed at the time of sampling such as indicator tests used to select samples most likely to be contaminated

- Frequency of sampling

- Media to be sampled

- Laboratory analytical parameters 
All sampling and measurement tasks shall be performed in accordance with approved procedures. Changed or unexpected conditions may require modification of procedures to accomplish investigative objectives. Such changes shall be approved and documented prior to implementation.

\section{A.5.1.1 Decontamination}

To prevent cross contamination of samples, sampling equipment shall be decontaminated prior to use and between sampling locations. Decontamination activities shall be performed in accordance with approved procedures and shall be documented in a daily activity report. Precleaned sample containers shall be cleaned according to EPA'criteria, as applicable, and the documentation of cleanliness shall be maintained in the subproject files.

Rinsate blanks shall be submitted to the analytical laboratory to assess the effectiveness of the decontamination process. If the rinsate blank results indicate possible contamination, corrective actions shall be implemented to preclude recurrence. Sample results obtained using the suspect sampling equipment shall be reviewed to determine whether analytical qualifiers should be assigned to the data. The results of the investigation shall be documented.

\section{A.5.1.2 Sample Handling and Preservation}

Proper. sample handling sháll bé achieved by selecting appropriate sample containers, preservation procedures, and holding times for specific analyses. Sample containers shall be obtained and, as appropriate, certified clean, per EPA protocol. Specified preservatives shall be . added to the proper sample containers by laboratory personnel prior to shipping the containers if containers are obtained from an analytical laboratory. Sample container materials, preservation requirements, sample volumes, holding times, and quantification limits for required analyses can be found in Table A-3.

\section{A.5.1.3 Field Documentation}

Field documentation shall be of sufficient detail to facilitate the reconstruction of field activities. Field personnel shall document activities on a daily activity report or $\log$. 
Table A-3

Sampling and Laboratory Analytical Protocols

(Page 1 of 2)

\begin{tabular}{|c|c|c|c|c|c|c|c|c|c|}
\hline Parameter & Medium & Method & $\begin{array}{l}\text { Sample } \\
\text { Contalner }\end{array}$ & $\begin{array}{l}\text { Minimum Amount } \\
\text { of Sample } \\
\text { Required }\end{array}$ & Holding Time & Preservative & $\begin{array}{l}\text { CRQLCRDL } \\
\text { PQL }^{a}\end{array}$ & $\begin{array}{l}\text { Acceptable } \\
\text { Precision } \\
\text { (RPD) }\end{array}$ & $\begin{array}{c}\text { Acceptable } \\
\text { Accuracy } \\
\text { (\%R) }\end{array}$ \\
\hline \multirow{2}{*}{$\begin{array}{l}\text { Exploslves } \\
\text { Nitroaromatics } \\
\text { and Nitramines }\end{array}$} & Water & \multirow[t]{2}{*}{ EPA $8330^{\circ}$} & G, amber &.$^{2 \times 1 \text { liter }}$ & 7 days & $\begin{array}{c}\text { Cool to } 4^{\circ} \mathrm{C} \pm \\
2^{\circ} \mathrm{C}\end{array}$ & $45 \mu \mathrm{g} / \ell$ & 20 & 53 to 133 \\
\hline & Soil ' & & $\begin{array}{l}\text { G, Teflon }{ }^{\text {TM. }} \\
\text { lined cap. } \\
\text { wide-mouth jar }\end{array}$ & 4. ounces & 7 days & $\begin{array}{c}\text { Cool to } 4^{\circ} \mathrm{C} \pm \\
2^{\circ} \mathrm{C}\end{array}$ & $2.5 \mathrm{mg} / \mathrm{kg}$ & 30 & 22 to 157 \\
\hline \multirow{2}{*}{$\begin{array}{l}\text { Gamma } \\
\text { Spectroscopy } \\
\text { (based on }{ }^{137} \mathrm{Cs} \text { ) }\end{array}$} & Water & $\begin{array}{l}\text { EPA } \\
901.1^{c} .\end{array}$ & PE or G & 1 liter & 6 months & $\begin{array}{c}\mathrm{HNO}_{3} \text { to } \\
\mathrm{pH}<2\end{array}$ & $20 \mathrm{pCl} / \mathrm{l}$ & \pm 20 & $" 80$ to 120 \\
\hline & Soil & $\begin{array}{c}\text { HASL } 300^{\circ} \\
4.5 .2 .3\end{array}$ & PE or $G$ & 1 liter & 6 months & None & i pCi/g & \pm 20 . & 80 to 120 \\
\hline \multirow[t]{2}{*}{ Uranlum 234/235 } & Water & \multirow[t]{2}{*}{$\begin{array}{c}\text { NAS-NS- } \\
3050^{f}\end{array}$} & $P, E, G$ & $1,000 \mathrm{me}$ & $\begin{array}{l}180 \text { days after } \\
\text { collection }\end{array}$ & $\begin{array}{l}\mathrm{HNO}_{3} \text { to } \\
\mathrm{pH}<2\end{array}$ & $1 \mathrm{pCi} / \mathrm{l}$ & \pm 25 & 70 to 120 \\
\hline & Soil & & $P E, G$ & 50 grams & $\begin{array}{l}180 \text { days after } \\
\text { collection }\end{array}$ & None & $1 \mathrm{pCl} / \mathrm{g}$ & \pm 25 & 70 to 120. \\
\hline \multirow[t]{2}{*}{ Uranium 238} & Water & $\begin{array}{c}\text { NAS-NS- } \\
3050\end{array}$ & $P E, G$ & $1,000 \mathrm{me}$ & $\begin{array}{l}180 \text { days after } \\
\text { collection }\end{array}$ & $\begin{array}{l}\mathrm{HNO}_{3} \text { to } \\
\mathrm{pH}<2\end{array}$ & $1 \mathrm{pCi} / \ell$. & \pm 25 & 70 to 120 \\
\hline & Soil & $\begin{array}{c}\text { HASL } 300^{\circ} \\
4.5 .2 .3\end{array}$ & $P E, G$ & 50 grams & $\begin{array}{l}180 \text { days after } \\
\text { collection }\end{array}$ & None & $1 \mathrm{pCl} / \mathrm{g}$ & \pm 25 & 70 to 120 \\
\hline
\end{tabular}


Table A-3

Sampling and Laboratory Analytical Protocols

(Page 2 of 2)

\begin{tabular}{|c|c|c|c|c|c|c|c|c|c|}
\hline Parameter ${ }^{\circ}$ & Medlum & Method & $\begin{array}{l}\text { Sample } \\
\text { Container }\end{array}$ & $\begin{array}{c}\text { Minimum Amount } \\
\text { of Sample } \\
\text { Required }\end{array}$ & Holding Time & Preservative & $\begin{array}{l}\text { CRQL/CRDL } \\
\text {. PQL }\end{array}$ & $\begin{array}{l}\text { Acceptable } \\
\text { Precision } \\
\text { (RPD) }\end{array}$ & $\begin{array}{c}\text { Acceptable } \\
\text { Accuracy } \\
\text { (\%R) }\end{array}$ \\
\hline \multirow[t]{2}{*}{ Plutonium $239^{\circ}$} & . Water & \multirow{2}{*}{$\begin{array}{l}\text { NAS-NS- } \\
3058^{9}\end{array}$} & $P E, G$ & 1 liter & 6 months & $\begin{array}{c}\mathrm{HNO}_{3} \text { to } \\
\mathrm{pH}<2\end{array}$ & $1 \mathrm{pCi} / \ell$ & \pm 25 & 75 to 125 \\
\hline & Soil & & $P E, G$ & . 4 ounces & 6 months & None & 1.pCi/g & \pm 25 & 75 to 125 \\
\hline $\begin{array}{l}\text { Toxicity } \\
\text { Characteristic } \\
\text { Leaching } \\
\text { Procedure (TCLP) } \\
\text { - Metals } \\
\end{array}$ & Soil & $\begin{array}{c}\text { EPA } \\
1311 \% \\
6010 A \\
1311 / 7470\end{array}$ & $\begin{array}{l}\text { G, amber, } \\
\text { wide-mouth jar }\end{array}$ & $2 \times 16$ ounces & $\begin{array}{c}180 \text { days to } \\
\text { leaching; } 180 \\
\text { days to analysis } \\
\text { (except mercury: } \\
28 \text { days to } \\
\text { leaching; } 28 \text { days } \\
\text { to analysis) }\end{array}$ & $\begin{array}{c}\text { Cool to } 4^{\circ} \mathrm{C} \pm \\
2^{\circ} \mathrm{C}\end{array}$ & $\begin{array}{l}\text { Method } \\
\text { specific }\end{array}$ & 20 & 80 to 120 \\
\hline
\end{tabular}

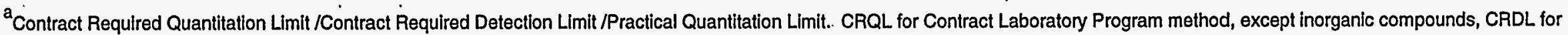
inorganic compounds, and PQLs for all other methods.

bEPA Method SW-846 (EPA, 1987c).

CPrescribed Procedures for Measurement of Radioactivity in Drinking Water, U.S. Environmental Protection Agency.

${ }^{d}$ Standard Methods for the Examination of Water and Waslewater (Franson, 1995).

HASL-300 (Health and Safety Laboratory, 1992).

National Academy of Sciences, Nuclear Science Series, September 1963.

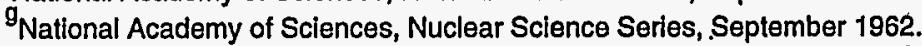

$$
\begin{aligned}
& \mathrm{G} . \dot{=} \text { glass } \\
& \mathrm{HCl}=\text { hydrochloric acid } \\
& \mathrm{HNO} \mathrm{H}_{3}=\text { nitric acid } \\
& \mathrm{TBD}=\text { To be determined } \\
& \mathrm{mg} / \mathrm{kg}=\text { milligrams per kilogram } \\
& \mu \mathrm{g} / \mathrm{g}=\text { micrograms per gram } \\
& \mu \mathrm{g} / \mathrm{kg}=\text { micrograms per kilogram } \\
& \mathrm{mg} / \mathrm{l}^{\circ}=\text { milligrams per liter } \\
& \mathrm{m \ell}=\text { milliliter }
\end{aligned}
$$

\author{
$\mathrm{NA}^{\circ}=$ Not applicable \\ $\mathrm{NaOH}=$ sodium hydroxide \\ $\mathrm{pCl} / \mathrm{g}=$ plcocuries per gram \\ $\mathrm{pCi} / /=$ picocuries per liter \\ PE, = polyethylene \\ RPD : = relative percent difference \\ $\% R=$ percent recovery \\ ${ }^{137} \mathrm{Cs}=$ Cesium -137 \\ ${ }^{\circ} \mathrm{C} \cdot=$ degrees Celsius.
}


Entries in the log shall be made in indelible ink and shall include the following:

- The subproject name

- The date and start time of each field activity

- Names and affiliations of field personnel

- The equipment used

- A general description of the day's field activities, showing the sequence of events

- Problems encountered

- Changes or modifications to the approved sample-collection plan

- Nonconformances and any corrective actions taken

- Weather conditions

- Field measurements or tests performed

- References to associated forms for details of each activity conducted

- The signature of the individual completing the report

Subproject management, or a designee, shall review the field-generated records for correctness and shall document this review by an initial and date. Reviewed records shall be maintained in the project files.

\section{A.5.2 Sample Cusțódy.}

Chain of Custody shall be initiated by field personnel at the sampling location and completed by laboratory personnel upon final disposition of the sample. Subproject management shall monitor the sampling event(s) to ensure that custody procedures and records are being properly implemented. Without exception; sample custody shall be maintained for all samples.

\section{A.5.2.1 Chain-of-Custody/Analysis Request Form}

Each sample shall be assigned a unique identification number that is recorded on both the . individual sample label and the chain-of-custody form: Field teams shall prepare chain-ofcustody and analysis request (COC/AR) forms for samples collected during field activities. The COC/AR form shall accompany the samples during handling and shipment and identify the sample custodian.

\section{A.5.2.2 Sample Labels and Identification}

Identification and traceability of samples collected as part of a data-collection task are critical to the success of the closure activities. Sample labels shall be affixed to containers in a manner that does not obscure any data preprinted on the containers. Unique sample numbers and other sampling information shall be printed on the labels using indelible ink. All information and data for a sample are keyed to each sample's unique sample number. 
Each sample number shall be indicated on both the container and field data/sample collection forms: For samples requiring multiple containers, the same sample identification numbers are required on each container.

\section{A.5.2.3 Custody Seals}

Samples shall be placed in containers and sealed with custody seals. Prior to being relinquished, each sample container shall be sealed over and/or around the cap with custody tape. Sample . custody seals shall be initialed and dated by the sample custodian.

\section{A.5.2.4 Sample.Packaging and Shipping}

Upon completion of sampling, labeling, and custody sealing, each sample shall be placed in a sealable plastic bag, transferred to a cooler, packed with ice or its equivalent, and protected from breakage by using shock-absorbent packing material. Sample packaging and shipping shall be performed in accordance with the approved procedures that comply with U.S.'Department of . Transportation (DOT) regulations and DOE/NV Orders and procedures.

Prior to transport to a laboratory, samples collected at the TTR must be radiologically screened and meet the requirements of the DOE/NV Radiological Control Manual (DOE, 1992).

Samples shall be sent by an overnight delivery service to the laboratory stipulated in the site plans in accordance with EPA guidance and DOT regulations. Copies of the waybill shall be retained in the subproject files. The original COC/AR form shall be returned to subproject management after final sample disposition; and shall become a permanent part of the subproject file.

\section{A.5.3 Analytical Procedures}

Analytical support laboratories are encouraged to review all associated TTR Subproject plans to .obtain background information and sampling strategy information that may be useful for predicting potential impacts to analytical operations and sample loading. Each laboratory performing analyses for the TTR subproject shall have written procedures approved by Contract Laboratory management for each required analysis. These procedures shall be available to the DOE/NV Subproject Manager upon request. Deviations from the procedures shall be documented and filed in the contractor subproject files. 


\section{A.5.3.1 EPA Analytical Levels}

Analytical requirements for methods and documentation are broken into analytical levels.

Whenever Level III or $\mathrm{V}$, as defined below, is used, specific requirements for $\mathrm{QC}$ and documentation shall be developed for the laboratory to ensure adequate records for validation. Analytical levels are defined as follows:

- Level I: Field screening or analyses using portable instruments. Results are often not compound-specific and quantitative, but are available immediately.

- Level II: Field analyses using more sophisticated, portable analytical instruments. In some cases, the instruments may be set up in an on-site mobile laboratory. The quality of data generated depends on the use of suitable calibration standards, reference materials, sample preparation equipment, and the training level of the operator. Results are available immediately or within several hours.

- Level III: All analyses performed in an off-site analytical laboratory using methods other than EPA CLP RAS procedures. This level consists of using standard EPA-approved procedures, such as SW-846 (EPA, 1986). The laboratory may or may not be a CLP . laboratory.

- Level IV: All analyses performed in an off-site laboratory following CLP/RAS procedures. Level IV is characterized by rigorous QA/QC protocols and documentation.

- Level V: CLP Special Analytical Services or analyses by nonstandard methods. All analyses are performed in an off-site analytical laboratory, which may or may not be a CLP laboratory. Method development or method modification may be required for specific constituents or detéction limits.

\section{A.5.3.2 Analytical Methods}

Analytical methods shall follow EPA Test Methods for Evaluating Solid Wäste, 3rd Edition, Parts 1-4 (SW-846) (EPA, 1986). For some radiometric analyses, where no EPA-approved methods exist, laboratories shall follow Standard Methods for the Examination of Water and Wastewater or Environmental Measurements Laboratory Procedures Manual, HASL-300 as indicated on Table A-3. The reporting format selected for non-CLP data types requires the use of modified CLP report forms:

\section{A.5.4 Calibration and Preventive Maintenance}

A system of calibration and preventive maintenance șall be employed to ensure the proper operation of M\&TE. Reference standards of the correct type, range, and acceptable uncertainty 
shall be used for collecting data consistent with the project objectives. All TTR subproject participants are responsible for.implementing calibration and preventive maintenance programs for field and laboratory M\&TE.

\section{A.5.5 Data Reduction, Validation, and Reporting}

Data reduction refers to computations and calculations performed on raw data. Data validation is a systematic process for reviewing data against a set of criteria to ensure that the data are adequate for the intended use. Data reporting is the documentation of data reduction and validation results.

\section{A.5.5.1 Data Reduction.}

Numerical reduction of field and analytical data shall be formally checked using the standard process outlined in this section. Checking must be performed prior to the "final" presentation of results. If unchecked results are to be presented, they shall be marked "preliminary."

\section{A.5.5.2 Data Validation}

The laboratory data shall be validated in a manner consistent with EPA functional guidelines for both organic and inorganic analyses (EPA; 1988a and 1988b). This validation process shall include a review of laboratory reports to ensure that proper analytical methods were used; detection limits were appropriate; data are accurate and precise; the proper number of significant figures were reported; and results were calculated properly. Data validation shall also include the review of analytical instrument calibration and tuning to verify that proper standards were prepared and used during calibration. Data validation shall be performed on $10 \%$ of the Level III and Level V' laboratory data. Data validation shall determine whether qualifiers should be assigned to the data and if the source should be resampled. All laboratory data shall be reviewed for completeness.

\section{A.5.5.3 Laboratory Data Reporting}

Analytical data reports must contain, at a minimum, the following information:

- A cover page with the reviewer's, signature, data qualifiers, and a description of any technical difficulties encountered during the analyses

- The date the sample was received

- The date the sample was prepared 
- The date the sample was analyzed

- The sample identification number

- The laboratory sample identification number

- The analytical method reference number

- Analytical results

- Tabulated QC sample results

- Instrument tuning and calibration results

- The final copy of the COC/AR form with appropriate signatures

Validated data shall be reviewed to determine whether they meet the DQOs of the investigation: The data shall be reviewed to ensure that the required number of samples were collected, critical samples were collected and analyzed, and the,results passed data-validation criteria. The data shall also be reviewed to determine whether detection limits were met. Data-reporting techniques shall be in accordance with the project data-reporting requirements; data-reporting procedures shall be consistent with those found in the User's Guide to the Contract Laboratory Program (EPA, 1991).

\section{A.6.0 Procurement}

Items and services of a technical nature provided to the TȚR subproject shall be of a quality that meets the requirements of the project. Controls shall be established to ensure that procured equipment and services meet or exceed specifications and that systems are in place to track items and confirm the delivery of procured items and services.

Procurement documents shail define the scope of work for the item or service being procured, specifications, and any documentation required. Technical requirements shall either be directly included in the procurement documents or included by reference to specific drawings, specifications, procedures, regulations, or codes that describe the items or services to be furnished. Documentation required to provide evidence that items and services conform to quality standards shall be identified in the procurement documents. 


\section{A.7.0 Inspection and.Acceptance Testing}

Inspections and acceptance testing shall be accomplished in accordance with approved inspection documents and test procedures that reflect acceptance and performance criteria. Individuals. performing inspections and acceptance testing shall be independent of those who performed the work. Measurement and test equipment used in the performance of inspections or acceptance tests shall be calibrated and properly maintained.

\section{A.8.0 Assessments}

Assessments shall be performed based on the potential for adverse affect. The extent and frequency of assessments shall reflect the importance-of the work activity, results of previous assessments and/or audits, trend reports, and the inherent risks involved. Assessments personnel shall be knowledgeable in, and not directly responsible for, the activities being assessed.

\section{A.9.0 Definitions}

Acceptance Criteria - Specified characteristics of an item, process, or service defined in codes, standards, or other requirement documents.

Accuracy - A measure of the degree of agreement of a measurement (or an average of measurements of the same thing or mean of a set of results), X, with an accepted reference or true value, T. Accuracy is a measure of the bias in a system. Accuracy is assessed by means of : reference samples and percent recoveries.

Activities that Affect Quality - Activities that, if not performed properly, could compromise the validity of information or data reported, could result in an unacceptable risk to the environmental health or safety of the public or the workers involved, or could have a detrimental effect on the achievement of the prime objectives of the project.

Blank - A blank is an artificial sample designed to monitor the introduction of artifacts into the process. For aqueous samples, reagent water is used as a blank matrix; however, a universal 
blank matrix does not exist for solid samples, and, therefore, no matrix is used. The blank is taken through the appropriate steps of the process.

A reagent blank is an aliquot of analyte-free water or solvent analyzed with the analytical batch. Field blanks are aliquots of analyte-free water or solvents brought to the field in sealed containers and transported back to the laboratory with the sample containers. Trip blanks and equipment blanks are two specific types of field blanks. Trip blanks are not opened in the field. They are a check on sample contamination originating from sample transport and shipping and from site . conditions. Equipment blanks are opened in the field, and the contents are poured appropriately over or through the sample collection device, collected in a sample container, and returned to the laboratory as a sample. Equipment blanks àre a check on effectiveness of sampling device decontamination.

Checks - The tests, measurements, verifications, or controls placed on an activity by means of investigations, comparisons, or examinations to determine satisfactory condition, accuracy, safety, or performance:

Contamination (Contaminated) - Any unwanted undesirable foreign material on the surface of an item, in the atmosphere, or in process liquids or gases. A parameter in a specific . environmental medium having a maximum sourcé concentration above an action level or regulatory threshold.

Corrective Action - Measures taken to rectify conditions adverse to quality and, where. . necessary, to preclude repetition.

- Data (Technical) - Those data acquired from literature reviews, testing, analysis, measurement, inspection, or observation that relate to engineering or scientific matters.

Data - All administrative, managerial, financial, scientific, test, engineering, and analytical information and doçumentation required for delivery by contract or developed within a program.

Data Quality - The totality of features and characteristics of data that bear on its ability to satisfy a given purpose. The characteristics of major importance are legibility, data accuracy, data ' precision, data completeness, data representativeness, and data comparability. 
Data Quality Objectives - The predetermined objectives or goals for measurement data in terms of precision, accuracy, completeness, and representation.

Defensible - The ability to withstand any reasonable challenge related to veracity or truthfulness.

Deviation - A departure from specified requiremènts.

Document - Any written or pictorial information describing, defining, specifying, reporting, or. certifying activities, requirements, procedures, or results.

Finding - An apparent violation of an applicable federal law, DOE rule, order, a DOE-issued or approved procedure, or other significant deficient practice.

Hazardous Waste - Those waste included in the definitions of Resource Conservation and Recovery Act (RCRA) 1004(5) and Revised Code of Washington.(RCW) 70.105.010(15).

Independent (Personnel) - A condition characterizing an individual or group of individuals qualified to analyzè, review, inspect, test, audit, or otherwise evaluate data and work results because they:

(A) Had no direct responsibility for, or involvement in, performing the activity or work

(B). Are not accountable for the activity or work result

(C) Do not report directly to supervisors who are responsible for performing the activity or work to be evaluated

Indoctrination - Instructions that familiarize a person with a particular subject but do not enable him to perform work.

Inspection - Examination or measurement to verify whether an item or activity conforms to specified requirements.

Item - An all-inclusive term used in place of any of the following: appurtenance, assembly, component, equipment, material, module, part, structure, subassembly, subsystem, system, or unit. 
Measurement and Test Equipment - Devices or systems used to calibrate, measure, gage, test, or inspect to:

(A) Control or acquire data to verify compliance to specified requirements

(B) . Establish characteristics or values

(C) - Make decisions or design facilities or processes

Nonconformance - A deficiency in characteristic, documentation, or procedure that renders the quality of an item or activity unacceptable or indeterminate.

Procedure - A document that specifies or describes how an activity is to be performed.

Procurement Document - Purchase requisitions, purchase orders, drawings, contracts, specifications, or instructions used to define requirements for purchase.

Program - An organized set of activities within a resource area having common objectives based on a strategy set forth to meet assigned góals. 'It may include one or more projects and research and development activities in support of new, improved, or more efficient supply, or conservation systems or procedures.

Qualification (personnel) - The characteristics or abilities gained through education, training, or experience, as measured against established requirements, such as standards or tests, that qualify an individual to perform a required function.

Quality Assurance - Actions that provide confidence that quality is achieved.

Quality Assurance Program - The overall program established by an organization to implement the requirements of DOE Order 5700.6C.

Quality Assurance Project Plan - Project quality assurance plans are written to support work plans or'similar documents and describe how internal organization are to implement their quality assurance responsibilities. 
Quality Control - Activities that provide a means to control and measure the characteristics of an item, process, procedure, or service against established requirements.

Screening -Field or laboratory analyses using same or simpler analytical methods with less rigorous quality assurance/quality control requirements. Screening methods are characterized by quick turn-around time (results are available in real time or within a few hours or days as opposed.to weeks or months typically required for validated laboratory data) and lower costs. However, screening results may not be compound-specific, and the data may be qualitative or semiqualitative.' Screening results may be directly representative of either a single laboratory contaminant parameter or a group of such parameters.

Service - The performance of activities such as design, fabrication, inspection, nondestructive examination, repair, installation, or data'acquisition.

Significant Condition Adverse to Quality - A significant condition adverse to quality is one which, if uncorrected, could have a serious effect on safety or operability.

Site - An aggregate area, operable unit, or waste management unit (as appropriate to the context of the project)-as opposed to the term, "Hanford Site," which refers to the entire DOE reservation.

Site Characterization - The program of exploration and research, both in the laboratory and in the field, that is undertaken to establish the geologic conditions and the ranges of parameters of a particular site. Site characterization includes the analysis and interpretation of data from borings, surface excavations, excavation of exploratory shafts, limited subsurface lateral excavations, and in situ testing at depth as needed to determine the suitability of the site, but does not include preliminary borings and geophysical testing needed to help provide a basis for determining whether site characterization should be undertaken.

'Traceability - The ability to trace the history, application, or location of an item and similar items or activities by means of recorded identification.

Training - Instruction that enables a person to perform a task or tasks. 
Validated Data - Data are valid when the methods, practices, techniques, and equipment used to obtain and treat them are technically sound, based on objectivity, and selected properly. Data that the DOE has determined meet criteria contained in the "Data Validation Guidelines for Contract Laboratory Program Inorganic Analyses" that are contained in the Sample Management Administrative Manual.

Validation Data - The documented confirmation of the adequacy (i.e., the suitability for its intended purpose) of the work under review.

Verification Data - The act of reviewing, inspecting, testing, checking, auditing, or otherwise determining and documenting whether items, processes, services, or documents conform to specified requirements.

Verify - To determine or test the truth or accuracy by comparison or reference.

Waste Characterization - To describe the qualities, features, or traits of wastes such as quantity of radioactive or chemical contaminants, flammability, corrosivity, or reactivity. Characterization is accomplished through sampling and analysis or process knowledge and controls.

\section{A.10.0 References}

Franson, Mary Ann H., Ed. 1995. Standard Methods for the Examination of Water and Wastewater, 19thed. Washington, DC: American Public Health Association.

Health and Safety Laboratory. 1992. Environmental Measurements Laboratory Procedure Manual, HASL-300, 27th ed., Rev. 1. Prepared for U.S. Department of Energy. New York, NY.

U.S. Department of Energy. 1991. "Quality Assurance," DOE Order 5700.6C, Office of Nuclear Energy/Office of Environmental Safety and Health. Washington, DC.

U.S. Department of Energy, Nevada Operations Office. 1992. NV/YMP Radiological Control Manual. Las Vegas, NV. 
U.S. Environmental Protection Agency. 1983. Interim Guidelines and Specifications for Preparing Quality Assuranice Project Plans, QAMS-005/80, EPA-600/4-83-004. Washington, DC.

U.S. Environmental Protection Agency. 1986. "Test Methods for Evaluating Solid Waste." In 'Laboratory Manual, Physical/Chemical Methods, SW-846, 3rd ed., Vols. 1A-1C. Washington, DC.

U.S. Environmental Protection Agency. 1987a. Data Quality Objectives for Remedial Response Activities, EPA/540/G-87/003. Washington, DC.

U.S. Environmental Protection Agency. 1987b. Test Methods for Evaluating Solid Waste Physical/Chemical Methods, 3rd ed., Proposed Update Package Instructions. Washington, DC.

U.S. Environmental Protection Agency. 1987c. Test Methods for Evaluation Solid Waste, 3rd ed., Parts 1-4, SW-846. Washington, DC.

U.S, Environmental Protection Agency.' 1988a. Contract Laboratory Program, Statement of Work for Organic Analysis, Multi-Media, Multi-Concentration, CLP SOW 2/88. Washington, DC.

U.S. Environmental Protection Agency. 1988b. Contract Laboratory Program, Laboratory Data : Validation Functional Guidelines for Evaluating Organic Analyses, CLP SOW. Washington, DC.

U.S. Environmental Protection Agency. 1989a. RCRA Facility Investigation (RFI) Guidance, EPA 530/SW-89-031, Interim Final. Wảshington, DC.

U.S. Environmental Protection Agency. 1989b. Soil Sampling Quality Assurance User's Guide (EPA/600/8-89/046). Washington, DC.

U.S. Environmental Protection Agency. 1991. User's Guide to the Contract Laboratory Program, CLP SOW. Washington, DC.

U.S. Environmental Protection Agency. 1994. Guidance for the Data Quality Objectives Process (EPA QA/G4). Washington, DC. 


\section{Distribution List}

(Page 1 of 2)

\section{Copies}

Mr. Kevin J. Cabble, TTR Project Manager

5 ( 2 uncontrolled)

DOE/Nevada Operations Office

Ms. Sabine T. Curtis,

Acting Industrial Sites Subproject Manager

DOE/Nevada Operations Office

Mr. David Shafer,

Acting Environmental Restoration Division Director DOE/Nevada Operations Office

Environmental Restoration Divișion Record Center DOE/Nevada Operations Office

Mr. Richard A. Dubiskas, Project Manager

IT Corporation

Las Vegas, Nevada

Mr. Ken Beach, Project Manager

IT Corporation

Las Vegas, Nevada

Ms, Cheryl Rodriquez

IT Corporation

Las Vegas, Nevada

Mr. Don Cox

IT Corporation

Las Vegas, Nevadá

Mr. Brad Schier

IT Corporation

Las Vegas, Nevada

Ms. Angelica Russel

IT Corporation

Las Vegas, Nevada 


\section{Distribution List}

(Page 2 of 2)

Ms. Stacey Sorg

IT Corporation

Las Vegas, Nevada

Ms. Jeanne Wightman

IT Corporation

Las Vegas, Nevada

Mr. Dave Madsen

Bechtel Nevada

Ms. Karen Patton

Bechtel Nevada

DOE/Nevada Operations Office

Technical Information Resource Center

Post Office Box 98518

Las Vegas, Nevada $89193-8518$

U.S. Department of Energy

2 (uncontrolled)

Office of Scientific and Technical Information 175 Oak Ridge Turnpike

Post Office Box 62

Oak Ridge, Tennëssee 37831 